\title{
REVIEW ON THE ROTATING DETONATION ENGINE AND ITS TYPICAL PROBLEMS
}

\author{
Qiaofeng Xie $^{\text {a }}$ (D) 0000-0001-6807-7731, \\ Zifei Ji ${ }^{a}$ (D) 0000-0002-8729-3111, \\ Haocheng Wen ${ }^{a}$ (iD 0000-0002-5460-9247, \\ Zhaoxin Ren ${ }^{\text {b }}$ (iD 0000-0002-6305-9515, \\ Piotr Wolanskic (DD 0000-0003-3963-7722, \\ Bing Wang a* (iD 0000-0003-3373-7351. \\ a School of Aerospace Engineering, Tsinghua University, Beijing 100084, China \\ b School of Power and Energy, Northwestern Polytechnical University, 1 Dongxiang Road, \\ Xi'an 710129, China \\ c Institute of Heat Engineering, Warsaw University of Technology, Nowowiejska 21/25, \\ 00-665 Warsaw, Poland \\ *wbing@tsinghua.edu.cn
}

\begin{abstract}
Detonation is a promising combustion mode to improve engine performance, increase combustion efficiency, reduce emissions, and enhance thermal cycle efficiency. Over the last decade, significant progress has been made towards the applications of detonation mode in engines, such as standing detonation engine (SDE), Pulse detonation engine (PDE) and rotating detonation engine (RDE), and the understanding of the fundamental chemistry and physics processes in detonation engines via experimental and numerical studies. This article is to provide a comprehensive overview of the progress in the knowledge of rotating detonation engine from the different countries. New observations of injection, ignition, and geometry of combustor, pressure feedback, and combustion modes of RDE have been reported. These findings and advances have provided new opportunities in the development of rotating detonation for practical applications. Finally, we point out the current gaps in knowledge to indicate which areas future research should be directed at.
\end{abstract}

Keywords: Detonation, propulsion system, rotating detonation.

\section{DETONATION THEORY}

\subsection{Deflagrations and detonations}

The combustion has become an important source for humankind to obtain energy since thousands of years ago. Nowadays, people recognize that the combustion waves have two basic types: deflagrations and detonations. The deflagration wave usually propagates within a low subsonic velocity (less than 150 $\mathrm{m} / \mathrm{s}$ ) and the entire process is approximately isobaric. The deflagration widely exists in the industrial and 
engineering applications. Most of the propulsion systems that people have developed are based on the deflagration, such as the turbojet engine, ramjet engine, rocket engines, etc. Distinguished from the deflagration, the detonation is a pressure-gained combustion process and the propagation velocity are high supersonic (Ma 4-5). Recently, its potential to enhance the thermal cycle efficiency attracts people's interest to apply it into traditional propulsion systems. Table 1 shows the comparison of some basic parameters of deflagration and detonation for gaseous mixtures.

Table 1. Comparison of the basic parameters of deflagration and detonation.

\begin{tabular}{ccc}
\hline Parameter & Deflagration & Detonation \\
\hline Wave Mach number Ma & $0.0001-0.03$ & $4-5$ \\
Pressure ratio $\mathrm{p}_{1} / \mathrm{p}_{0}$ & $0.98-0.976$ & $13-55$ \\
Temperature ratio $\mathrm{T}_{1} / \mathrm{T}_{0}$ & $4-16$ & $8-21$ \\
Density ratio $\rho_{1} / \rho_{0}$ & $0.06-0.25$ & $1.4-2.6$ \\
\hline
\end{tabular}

The recognition of detonation started from 1860s, when Able [1], Berthelot and Vieille [2] successfully measured the detonation velocity of several types of reactant. The famous Chapman-Jouguet (CJ) theory that first predicted the theoretical detonation velocity were published around $1900[3,4]$. The solutions of the steady conservation equations across the detonation wave can be represented in the Rayleigh-Hugoniot plot as shown in Fig. 1.1. The possible physical solutions exist in two zones, namely the detonation and deflagration zones. Generally, each Rayleigh line has two intersections with the Hugoniot curve and they correspond to strong or weak detonation/deflagration solutions. By assuming the minimum velocity or minimum entropy criterion, the $\mathrm{CJ}$ detonation can be

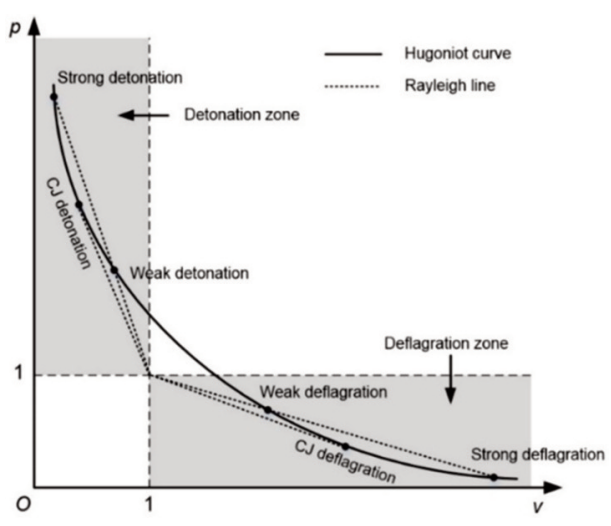

Fig. 1.1. The Rayleigh-Hugoniot plot. determined as the tangency solution of Rayleigh line and Hugoniot curve.

The CJ theory fails to analyze the detailed structure of detonation wave. Later in 1940s, the Zeldovich [5] -Neumann [6] -Doring [7] (ZND) model were put forward and analyzed the 1-D laminar structure of the detonation wave, which describes the detonation front as a leading shock front coupled with the induction and chemical reaction zones. However, today the studies have shown that all real detonation waves observed in the experiments are unsteady. The transverse shock on the detonation front was first observed for the spinning detonation [8] and later for the detonation away from the marginal state. By adopting the soot foil technique, the cell structure of detonation can be manifested (Fig. 1.2a) [9] Figure.1.2b shows a schematic of the cell structure [10]. For the detonation away from the marginal state, the cell size $\lambda$ depends on the properties of the mixture, such as the composition, equivalence ratio, pressure and temperature, etc. Many studies indicate that the ratio of geometry size (i.e., tube diameter or channel width) to cell size is a significant parameter for the propagation of detonation and a minimum ratio is required for the stable propagation. This criterion is verified for both the tube detonations [11,12] and rotating detonations [13-15]. 


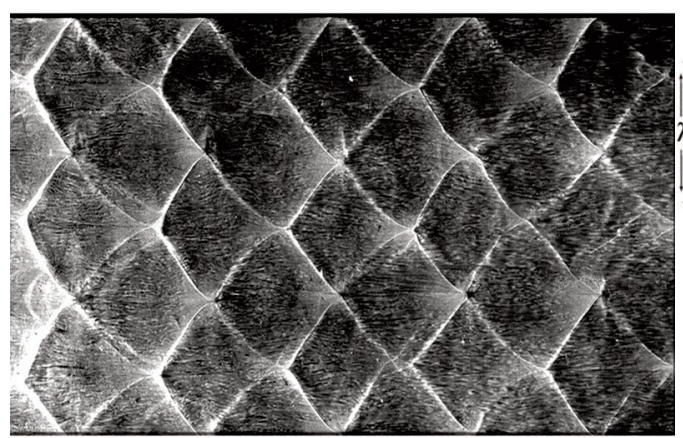

(a)

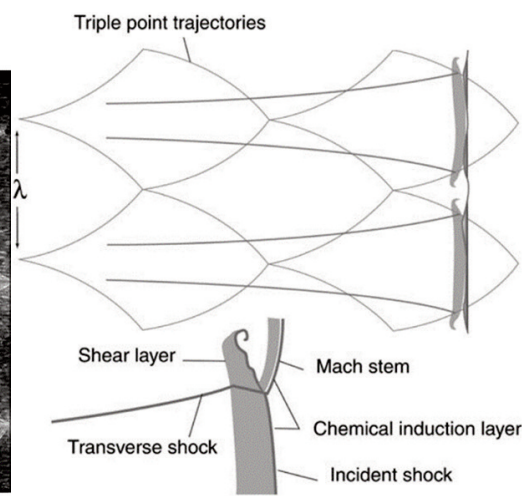

(b)

Fig.1.2. (a) Detonation cell structure shown by the soot foil [9]; (b) schematic of cell structure [10].

\subsection{Deflagration-to-detonation transition}

The direct initiation of detonation requires a minimum initiation energy, but in most situations the required condition is difficult to satisfy. Generally, the detonation can originate from the deflagrationto-detonation transition (DDT), which is triggered by a flame accelerating process after ignition. Within an appropriate constrained space, the combustion products can continuously push and accelerate the deflagration front to a high supersonic velocity (in the order of CJ deflagration velocity) and the transition to detonation will abruptly occur. Fig. 1.3a shows a typical streak photo of the DDT process [15]. The deflagration accelerating process from 2 to 5 and the abrupt transition at 6 are clearly illustrated in this figure.

The DDT process consists of two independent phases, namely the flame acceleration and the onset of detonation. These two phases are both random, and thus it is difficult to quantitatively predict the transition distance or transition time. Additionally, the mechanisms of the two phases are also diverse.

The flame acceleration is depend on the flame surface growth that are related to the Landau-Darrieus instability, Richtmyer-Meshkov instability, Kelvin-Helmholtz instability and thermal-diffusion effect, etc. $[17,18]$. For smooth tubes, Shchelkin suggested that the flame surface growth is governed by the turbulence in the unburned reactant ahead of the flame [19]. He also demonstrated that the wall roughness can influence the accelerating process and the flame acceleration distance can be significant reduced by using the spiral.

The different modes of detonation onset are well demonstrated in the experiments conducted by Urtiew and Oppenheim [20]. It is shown that the onset of the detonation can originate from the turbulence flame front (Fig. 1.3b), the leading shock front (Fig. 1.3c) or the contact surface of two leading shock waves. Despite the various details, the mechanism of detonation onset is generally the local explosion or the so-called "explosion in the explosion" that produces in the shock-flame interaction. Lee et al. [21] suggested that the detonation is always overdriven as it first forms from the local explosion and they proposed the SWACER mechanism to illustrate how the overdriven detonation develops from the relatively weak shock of a local explosion.

Usually the DDT is not a significant process in the rotating detonation combustor and it only exist at the very beginning of initiation [22]. However, in some cases, the deflagration can last for a long time or even the entire experimental run [23]. Therefore, it is also worthy to well understand the characteristics of DDT in the rotating detonation combustor. 


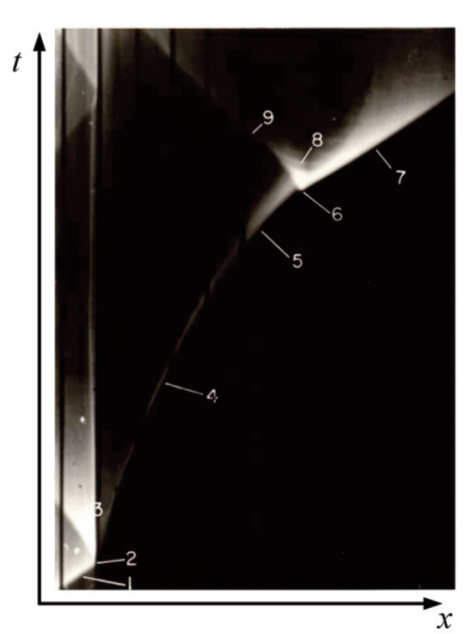

(a)

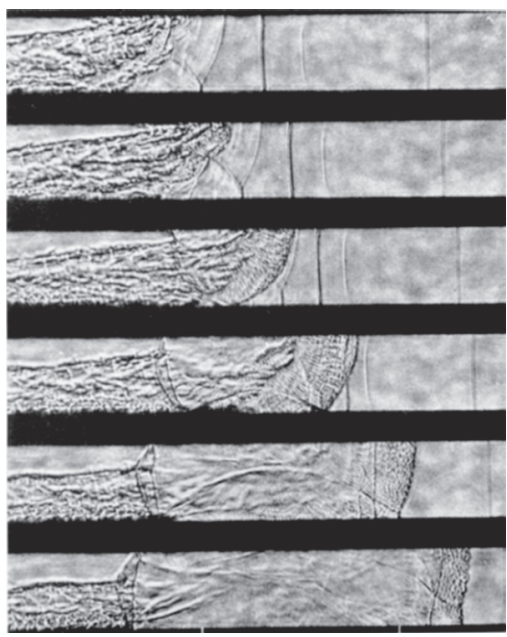

(b)

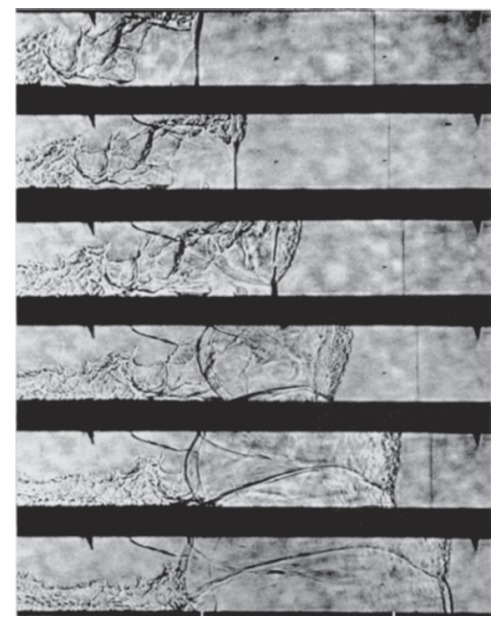

(c)

Fig.1.3. (a) Streak photo of the deflagration-to-detonation transition [16];

(b) Schlieren photos showing the onset of the detonation originating from the turbulence flame front [20];

(c) Schlieren photos showing the onset of the detonation originating from the leading shock front [20].

\section{DETONATION BASED PROPULSION: THEORY AND TECHNOLOGY}

\subsection{Standing detonation engine}

The development of air-breathing aircrafts with hypersonic speeds has attracted increasing attention in recent years. The energy conservation for the air-breathing hypersonic aircraft is usually achieved by supersonic combustion. Oblique detonation wave (ODW) is a kind of detonation formed as a reactive mixture flows onto a solid body at a supersonic speed usually exceeding its Chapman-Jouguet (C-J) value [24-28], and the standing detonation wave on the solid body has been studied extensively as a potential power source for conceptual hypersonic propulsion technologies such as standing detonation engine (SDE) or oblique detonation wave engine (ODWE). This kind of propulsion system inherits the advantages of the scramjet (supersonic combustion ramjet), and furthermore achieves the high thermal 
cycle efficiency through detonation. This type of engine, along with a diffusive scramjet configuration, is illustrated in Fig. 2.1.1 [29]. It mainly contains three parts, namely inlet, combustion chamber and nozzle. The attached oblique shock wave pre-compresses the supersonic ambient flow in the aircraft inlet. Then the fuel is injected into the main flow and mixes with air to form reactive mixtures. In the combustion chamber, the oblique shock wave induced by the solid wedge trigger exothermic chemical reactions and subsequently induce an oblique detonation wave downstream. The detonation has a high oxidization rate and the combustion products expand in the nozzle to produce thrust.

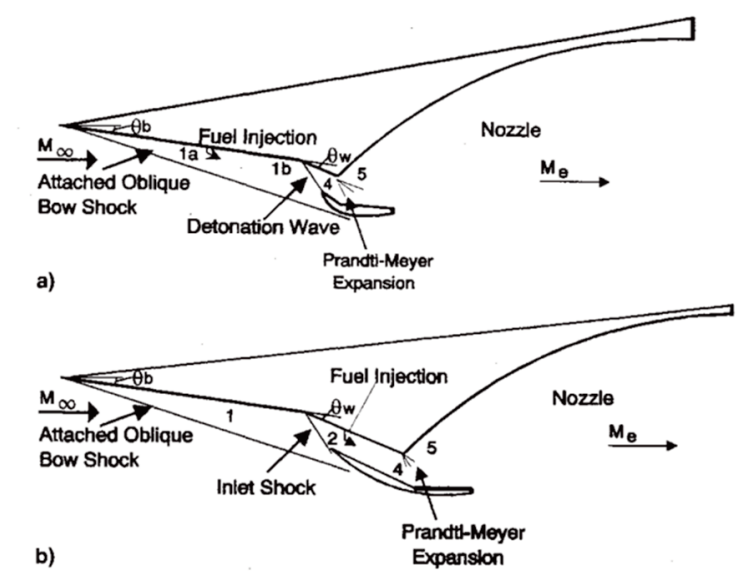

Fig. 2.1.1. The engine diagrams for (a) ODWE and (b) diffusive scramjet engine [29].

\subsubsection{Analysis of oblique detonation wave and thermodynamic cycle}

First a non-reactive oblique shock is analyzed. Fig. 2.1.2 depicts the supersonic flow of an ideal gas past a solid wedge with an inclination angle $\theta$ [30]. The wedge induced oblique shock wave is formed with an angle of $\beta$ from the initial direction of flow. When considering the chemical reaction within the shock wave, the kinematic and thermodynamic state of the gas is changed accordingly due to the heat release from the exothermic reaction. For the analysis, the heat release is contained in the oblique shock and the detonation wave is treated as a discontinuity.

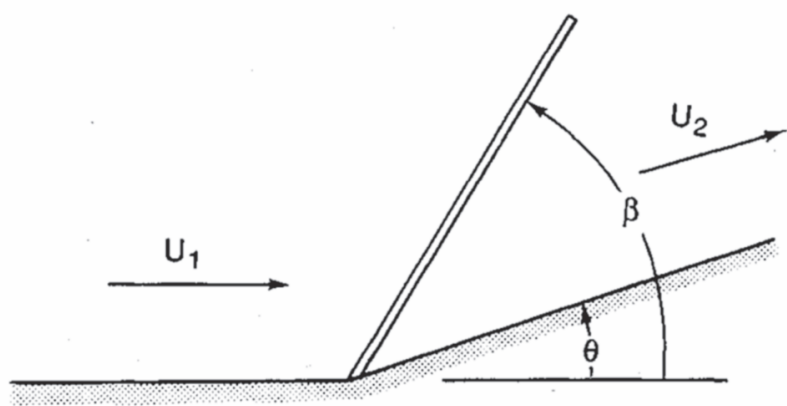

Fig. 2.1.2. The geometry of plane oblique shock [30].

Fig. 2.1.3 gives the variation of the oblique shock wave angle with turning angle for the oblique detonation wave. Here, $q$ is the specific heat addition from chemical reaction. The curve with $q=0$ is for the oblique shock wave. The free stream Mach number and temperature are constant. UD is the under 
driven regime, and OD is the overdriven regime. S means strong shock and W is for the weak shock. CJ is the Chapman-Jouguet state. The polar of the ODW is similar with that of the oblique shock wave. For any given fuel-air mixture and free stream temperature, there exists a unique specific heat release $\mathrm{q}$, and a corresponding C-J Mach number, which would result for a complete combustion.

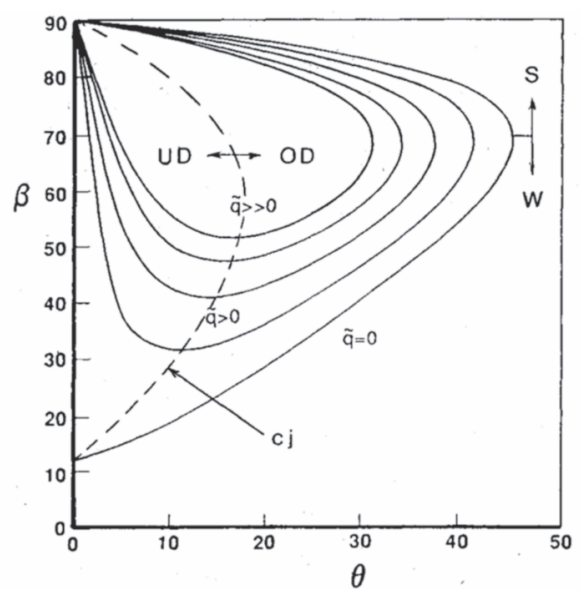

Fig. 2.1.3. Variation of oblique shock wave angle with turning angle [30].

Miao et al. [31] provided a thermodynamic cycle for the overdriven oblique detonation, compared with a CJ detonation. The atmospheric pressure and temperature at an altitude of $27 \mathrm{~km}$ are chosen as the initial conditions for the theoretical analysis. The wedge angle to initiate the oblique detonation is $\theta=22 \mathrm{deg}$, and the inflow velocity is $U=2400 \mathrm{~m} / \mathrm{s}$. The work during the two detonation cycles is obtained from the enclosed area in Fig. 2.1.4. The cycle efficiency of the CJ detonation is 39\%, whereas that of the ODW is $35 \%$, and the efficiency loss is observed in the thermodynamic cycle of the ODW. The initial compression, inflow condition, and wedge angle influence the cycle efficiency remarkably.

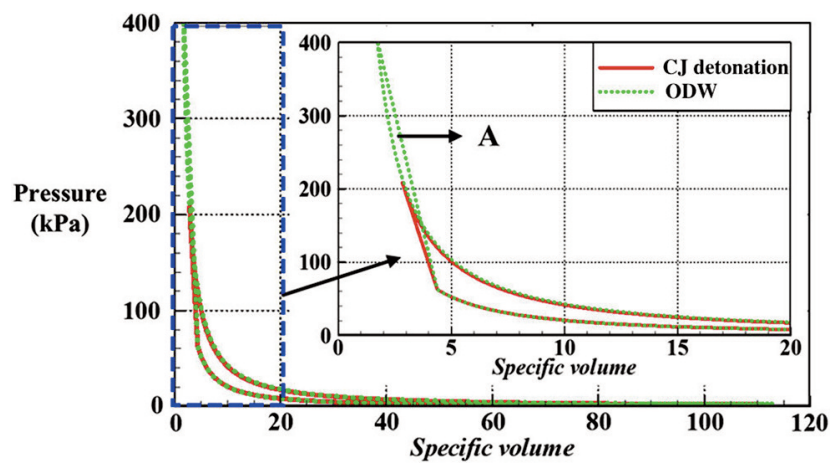

Fig. 2.1.4. The ideal thermodynamic cycles for a CJ detonation and an overdriven oblique detonation [31].

\subsubsection{System configuration and component matching}

The oblique detonation wave engine mainly contains three parts and they are air intake (inlet), ODW-based combustor and supersonic nozzle. A mixing device is usually used to mix the inflow air the injected fuel between inlet and combustor. 
For the range of flight Mach number of ODWE, the mixed external-internal supersonic compression (MSC) method is more effective than the internal supersonic compression (ISC) and external supersonic compression (ESC) [32]. The speed of the flow past the intake and ahead of ODW must be at supersonic condition. The process of MSC has two stages, as depicted in Fig. 2.1.5. First, the incoming supersonic flow is compressed by means of the oblique shock waves (external compression) induced by a series of ramps placed along the body surface of the air intake ahead of the cowl to $M_{1}$. Second, the flow with $M_{1}$ enters the duct enclosed by the cowl and the body surface, and the flow is compressed to reach $\mathrm{M}_{\mathrm{B}}$ by means of the internal oblique shock waves. To increase the efficiency of both the external and internal diffusion, the pressure jumps are redistributed among many oblique shocks to minimize the overall pressure losses.

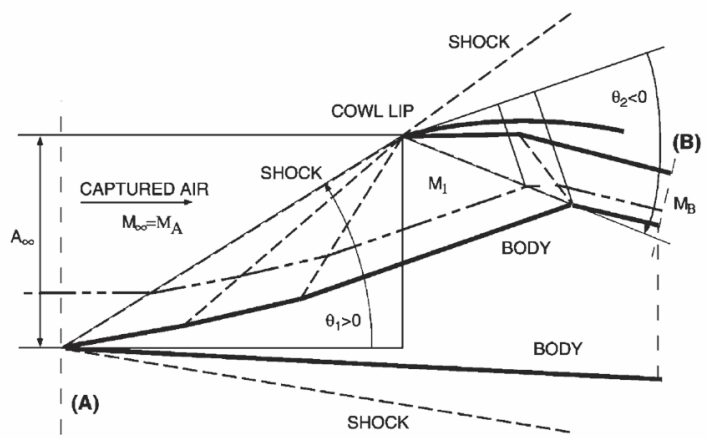

Fig. 2.1.5. Schematic of mixed external-internal supersonic compression (MSC) inlet [32].

Fuel might be heated before injection to reduce the losses since the fuel mass flow having a lower total enthalpy than that of the air flow. The fuel is injected with supersonic speed through a row of struts into the supersonic air stream to enhance the mixing, as shown in Fig. 2.1.6.

(B)

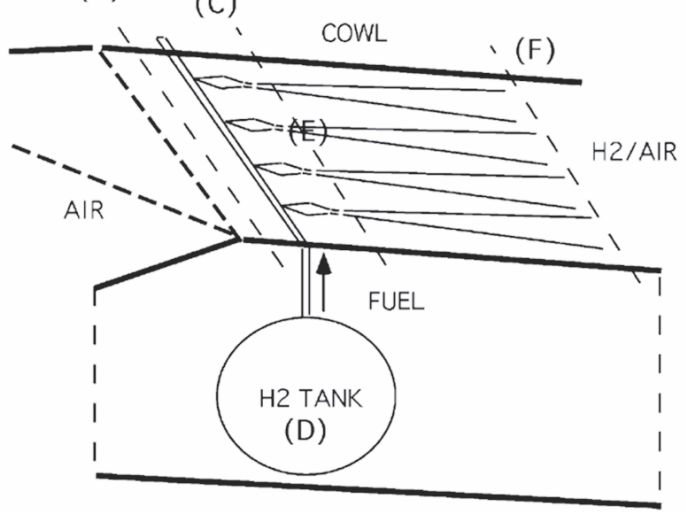

Fig. 2.1.6. Mixing between the fuel with the air stream [32].

The pre-mixed mixture of fuel and air is burned across an oblique detonation wave stabilized over a wedge placed at the combustion chamber. The oblique detonation wave might be the overdriven or CJ type according to the combination of the flow conditions ahead of the wedge and the wedge angle, and these can be controlled by the combustor wedge in real time during the flight. 
The burned production gases flowing supersonically out of the combustion chamber are expanded by means of a supersonic nozzle. The area ratio between the cross-section of the combustion chamber and the nozzle exit is chosen so as to adapt the nozzle to the atmospheric pressure.

\subsubsection{Evaluation model for overall performance}

Ashford and Emanuel [29] evaluated the performance of an oblique detonation wave engine (ODWE) and compared it with a diffusive scramjet engine. A major advantage for an ODWE is its smaller size in comparison to a scramjet, which produces less drag and less engine heat transfer. An ODWE does not require the ramp used in the scramjet engine and the shock it generates tends to cause pre-ignition.

The thrust of the ODWE operated with an adapted nozzle is defined as,

$$
T=\dot{m}_{\text {exit }} v_{\text {exit }}-\dot{m}_{\infty} v_{\infty}
$$

Here, $\dot{m}_{\text {exit }}, v_{\text {exit }}$ and $\dot{m}_{\infty}, v_{\infty}$ are the mass flow rates and flow velocities at the nozzle exit and at free stream, respectively.

The specific impulse is defined as,

$$
I_{\mathrm{sp}}=\frac{T}{g_{0} \dot{m}_{\mathrm{f}}}=\frac{T}{g_{0} \phi \dot{m}_{\infty}}
$$

where $\phi$ is the fuel-air equivalence ratio and $g_{0}$ is the reference gravity acceleration.

The net thrust $S$ is found by subtracting the drag $D$ from the uninstalled thrust $T$,

$$
S=T-D
$$

Valorani el al. provided the overall performance parameters of the ODWE [32]. Fig. 2.1.7 shows that the specific impulse decreases as the fuel-air equivalence ratio (higher fuel mass flow) and the free stream Mach number (higher pressure losses) are increased.

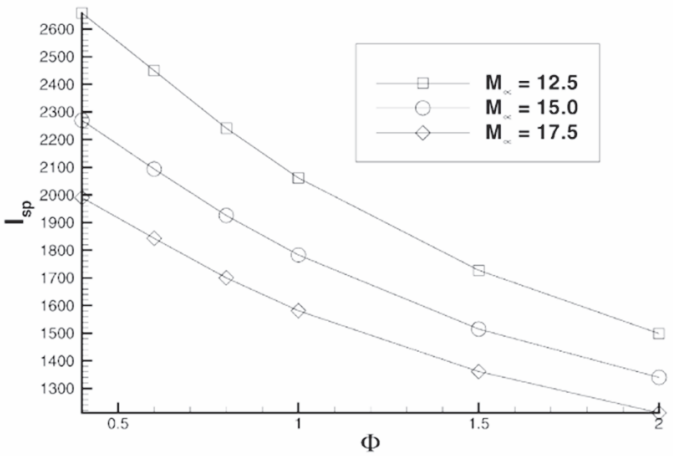

Fig. 2.1.7. The dependence of $I_{\mathrm{sp}}(\mathrm{s})$ on $\phi$ for different $\mathrm{M}_{\infty}$. Here, the fuel re-heat temperature is $1100 \mathrm{~K}$ and the free stream dynamic pressure $q_{\infty}$ is $90 \mathrm{kPa}$ [32].

Sislian et al. studied and compared the propulsive characteristics of the hypersonic detonation wave and shock-induced combustion ramjets. The same ramjet design methodology is used for both types of ramjets. They found that the thrust generation can be enhanced by more than $10 \%$ and the fuel specific impulses improved by more than one-third for a detonation wave ramjet. 


\subsection{Pulse detonation engine}

\subsubsection{Operating principle and thermodynamic cycle analysis}

$\mathrm{PDE}$ is a form of detonation-based propulsion system with the most attention and highest technical maturity. In the 1940s, the research about PDE has started in Germany, Hoffmann has finished the first report of PDE [34]. Then research projects of PDE have been implemented successively in many countries, and the related research achievements are endless [35-37]. In 2007, the flight test of the fourtube pulse detonation rocket engine Todoroki II has been conducted in Japan [38]. In 2008, the US Air Force Laboratory has conducted the flight experiment powered by a PDE successfully [39].

$\mathbf{t}_{1}$

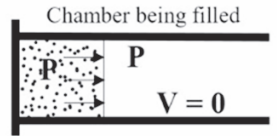

Detonation Initiation

t2

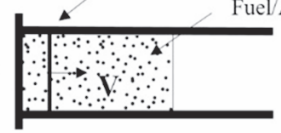

$P=0$

$\mathbf{V}=\mathbf{0}$

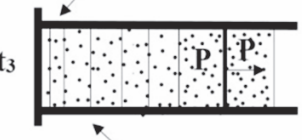

Rarefaction Waves
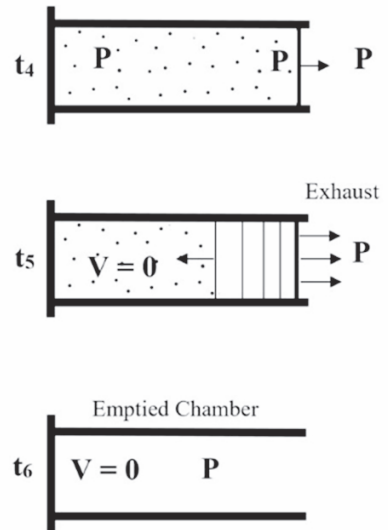

Fig. 2.2.1. Schematic diagram of operating principle of PDE [40].
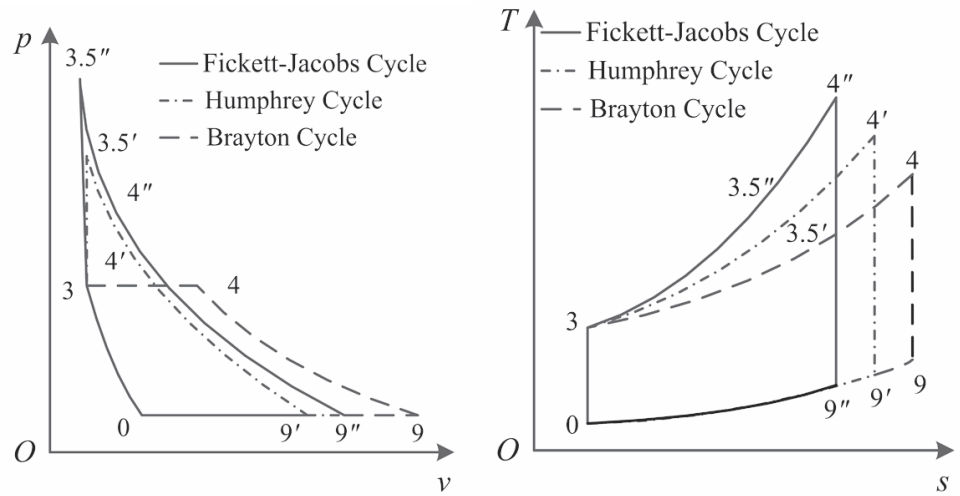

Fig. 2.2.2. Comparison of ideal thermodynamic cycle processes [249].

As depicted in Fig. 2.2.1, the operating principle of PDE can be simplified into six stages [40]: (1) the chamber being filled with isolation gas; (2) the chamber being filled with fresh mixture; (3) ignition; (4) the detonation waves is formed and propagated downstream; (5) the expansion wave is reflected into the detonation chamber; (6) the detonation products are expanded and accelerated and the thrust is generated. The ideal thermodynamic cycle of the PDE can be characterized by Fickett-Jacobs cycle [41]. Fig. 2.2.2 shows the comparison of the $\mathrm{p}^{-\mathrm{v}}$ diagrams of the Fickett-Jacobs cycle (based on detonation), 
Humphrey cycle (based on constant volume combustion), and the Brayton cycle (based on isobaric combustion). According to the thermodynamic analysis for ideal cycles, it can be calculated that FickettJacobs cycle offers the highest thermal efficiency, as is illustrated in Table 1 [37], which implies the remarkable advantage of PDE in fuel consumption.

Table 1. Comparison of calculated thermal efficiencies of different thermodynamic cycles with different fuels for initial compression ratio equal to 5 [37].

\begin{tabular}{cccc}
\hline Fuel & Brayton & Humphrey & Fickett-Jacobs \\
\hline Hydrogen & $36.9 \%$ & $54.3 \%$ & $59.3 \%$ \\
Methane & $31.4 \%$ & $50.5 \%$ & $53.2 \%$ \\
Acetylene & $36.9 \%$ & $54.1 \%$ & $61.4 \%$ \\
\hline
\end{tabular}

\subsubsection{System configuration and component matching}

Previous studies mainly focused on the application of pulse detonation technology in main combustors for pulse detonation engines. There are two forms of PDE: pulse detonation rocket engine and airbreathing pulse detonation engine, and the five-tube airbreathing pulse detonation engine ITR-2 which was developed for the supersonic missile by Pratt \& Whitney and Boeing [42], the fourtube pulse detonation rocket engine Todoroki II [38], and the pulse detonation turbine engine developed by Northwestern Polytechnical University [43] are the representative configurations of the PDEs. Based on these prototypes, the technical feasibility and performance superiority of various types of PDE have been preliminarily verified.

Multi-tube configuration is the inevitable choice of the PDE for engineering applications. Compared to single-tube configuration, the multi-tube one offers numerous advantages [44]. First, for the multitube PDE, the thrust as well as the operating frequency can be improved, and the thrust can be adjusted by adjusting the operating mode and operating frequency of the engine. Then, the multi-tube configuration reduces the proportion of the closing time of the combustion chamber valve, which is benefit to reduce the total pressure loss of the PDC. Finally, the tubes share the intake and nozzle in the multi-tube PDE, so the instability caused by intermittent operation of pulse detonation combustor can be weakened. In addition, the interaction between the reactant filling process and the product exhaust process is weakened in the multi-tube configuration, and the stable operating range is broadened. For the multi-tube configuration, a reasonable intake structure is quite important for the interaction among the tubes.

The thermodynamic process proceeding in the PDC is periodic unsteady process, and therefore, compatibility between the turbomachinery and PDC should be considered for the application of pulse detonation technology in propulsion. In order to decrease the intensity of back-propagation waves, various valve schemes including aero-valve and mechanical valve affecting on back-propagation were studied. Because of the complex configuration, high aerodynamic resistance, as well as the potential strength and fatigue problems of mechanical valves, the aero-valve is believed to be the most promising solution [45-48]. With the reasonable inner channel design of the aero-valve, the compatibility between the compression component and the periodic and strong back-propagation waves, and the self-adaptive reactant supply can be realized. In recent years, a series of aero-valve configurations, such as cone aerovalve, area-abrupt, and reserved-flow aero-valve, have been proposed, and their feasibility and effectiveness have also been confirmed in relevant studies [49-52].

According to the numerical simulation and experiment results, a strong shock wave will be reflected when the detonation wave passes through the two-dimensional turbine cascade, and a weak shock wave will propagate downstream through the turbine cascade channel [53]. Therefore, the operation and 
interaction between the turbine and PDC should also be considered for the pulse detonation turbine engine. Based on the numerical simulation and experiments, various studies have been conducted focus on the interaction between PDC and turbines. Various integrated experimental systems of single/multiple tube PDC and radial/axial flow turbine are developed. The throttling effect of turbine could affect the propagation of detonation waves, besides, the unsteady flow at the PDC outlet section can lead to pulsing inlet condition of the turbine. The relevant studies show that, the unsteady exhaust of the PDC could lead to local separation bubbles on the turbine blades, and further increase the boundary layer loss of the turbine [54]; the effects of unsteady flow from the PDC on the axial turbine efficiency is not significant if the PDC exhaust is mixed with the steady bypass flow [55]. The performance analysis of the axial flow turbine under high-amplitude, high-frequency pulsating flow conditions shows that the turbine efficiency is closely related to the corrected mass flow and mass flow averaged rotor blade intake angle [56-57].

\subsubsection{Evaluation model for overall performance}

Experiment and numerical simulation are both critical for the investigation of pulse detonation technology, and a series of important results have been generated based on them. However, due to the limitations in the measurement techniques, the flow and combustion mathematical model, and the computer performance, it is not possible to obtain the macroscopic characteristic and variation trends of the overall performance of the engine. Reduced-order method is effective for the evaluation and optimization of the overall performance of the pulse detonation engine. The low-order performance simulation model of the pulse detonation engine can be roughly classified into three categories: (1) the steady-state thermodynamic analysis model, based on this method, the upper bounds of the PDE overall performance can be obtained [41,58]; (2) the constant-volume combustion model, considering that the detonation wave moves so rapidly that the combustion product exhausts before it has time to expand in the combustor, the detonation process can be regarded as a constant-volume combustion process [59]; (3) pressure history model, the empirical and semi-empirical models can be developed based on the results of unsteady thermodynamic analysis and experiment $[43,60]$.

The results obtained by the reduced-order models show that, the comparison of the engine equipped with a pulse detonation combustor or a pulse detonation duct burner versus the similar engine embedded with conventional isobaric ones demonstrated the potential benefits of the pressure gain combustion $[43,61]$. The overall performance of the pulse detonation rocket engine is higher than that of the conventional rocket engine with the operation parameters. And the same performance metrics can be achieved for the PDRE with a lower filling pressure compared to conventional rocket engines [62]. The pulse detonation turbine engine exhibits competitive improvements in thermal efficiency and fuel consumption performance compared to the conventional gas turbines, and the improvements decrease with the increase of flight Mach number [63].

\subsection{Rotating detonation engine}

\subsubsection{Operating principle and thermodynamic cycle analysis}

Fig. 2.3.1 shows the typical configuration and flow field structure of the rotating detonation combustor [37]. The fuel and oxidant separately flow into the rotating detonation combustor and become the fresh mixture after mixing. After igniting, one or more detonation waves are formed and continuously propagate circumferentially, and high enthalpy combustion products are generated simultaneously. Then the products are expanded and accelerated in the RDC, and the thrust is generated. Unique in comparison to the PDE, the RDE needs to be initiated only once under the proper operating conditions to sustain continuous detonation, in view of its high detonation frequency (several thousand $\mathrm{Hz}$ ). Since the propagation direction and exhaust direction are independent of each other, the detonation waves are 
enclosed in the combustor, and the energy loss generating by the detonation wave being discharged from the RDC can be avoided. Compared to the SDE, the detonation waves can be formed over a wide range of operating condition. Therefore, the rotating detonation engine is regarded as one of the most promising aerospace propulsion system in the future.

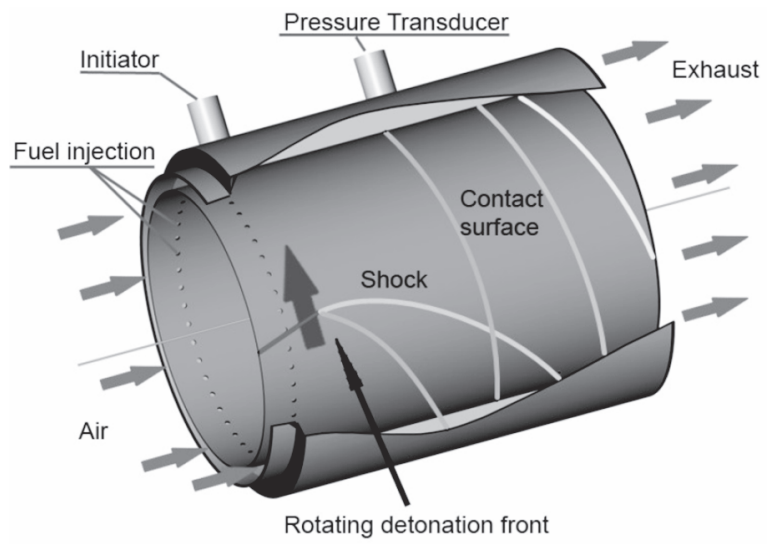

Fig. 2.3.1. Schematic diagram of a rotating detonation combustor [37].

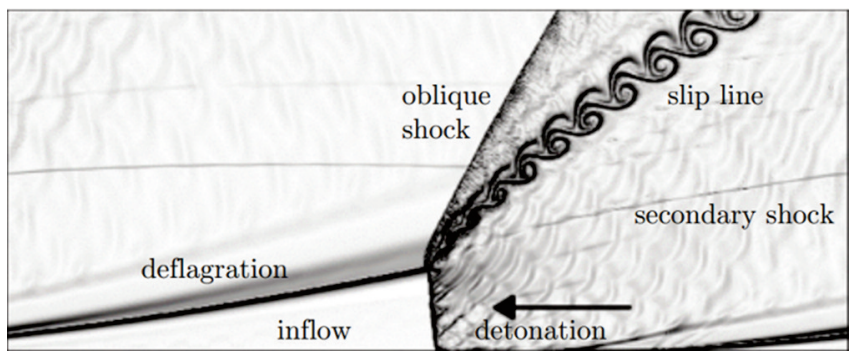

Fig. 2.3.2. Main flow features inside the rotating detonation combustor [64].

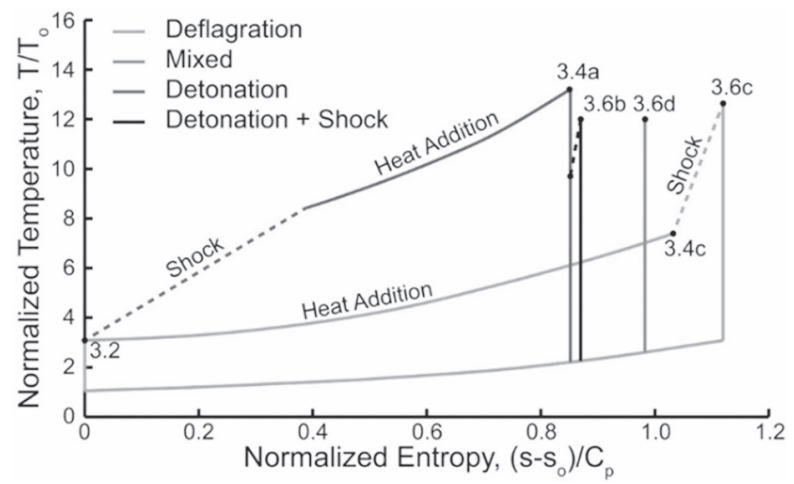

Fig. 2.3.3. Primary thermodynamic flow paths in a rotating detonation engine [65]. 
Since the radial size is much smaller than the azimuthal and axial dimensions, the flow in the RDC can be approximated as two-dimensional in space. Fig. 2.3.2 depicts the typical two-dimensional numerical solution of the flow field in the RDC [64]. It can be seen that, the primary thermodynamic flow paths of the flow particles in the different region of the RDE contains four forms [65]: deflagrated flow, detonated flow, a mixed flow comprising both detonated and deflagrated flows, and detonated flow plus secondary shock, as shown in Fig. 2.3.3. The thermal efficiency of the different flow paths are quite different, and the equivalent thermal efficiency of the RDE can be estimated by mass-flow average method.

\subsubsection{System configuration and component matching}

The operational stability of the RDC can only be achieved with a specific air mass flow rate. When the mass flow rate is high, the single-wave mode can be replaced by the multi-wave mode in the RDC [66-67]. However, the stable detonation wave cannot be formed when the mass flow rate is quite low [68-69]. In contrast to the single-wave mode, the total pressure improvement is reduced [70]. In addition, the flow capacity of the typical single-annular RDC, which is a narrow annular chamber, is limited, and the annulus width should be broadened for improving the flow capacity. However, as the annulus width increases, the curvature effect of the inner wall becomes more significant [71], and an oblique shock system establishes between the inner and outer walls [72]. Considering the abovementioned problems, the concept of multi-annular RDC is proposed [73-74]. As shown in Fig. 2.3.4, the single large annular chamber is replaced by several isometric small ones, and then the "staged combustion" can be achieved. The geometrical dimensions of single small-size chamber is defined by the lower boundary of the engine mass flow rate, and the chamber number is defined by the upper boundary of the engine mass flow rate. The number of annular chambers in the "on" mode varies with the engine operating condition. Compared with the conventional single-annular RDC, the multi-annular one shows the potential advantages of wider stable operation range and more uniform outlet parameter distribution [74-75].

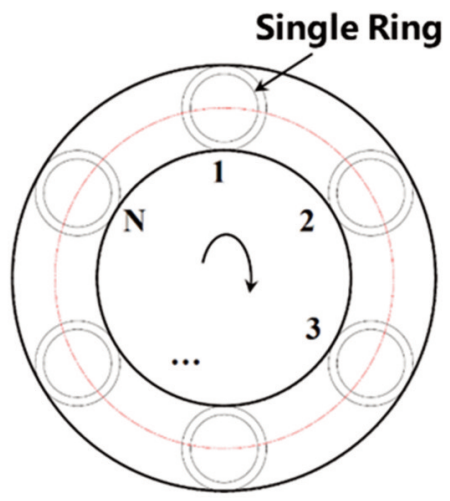

(a) Circular chamber

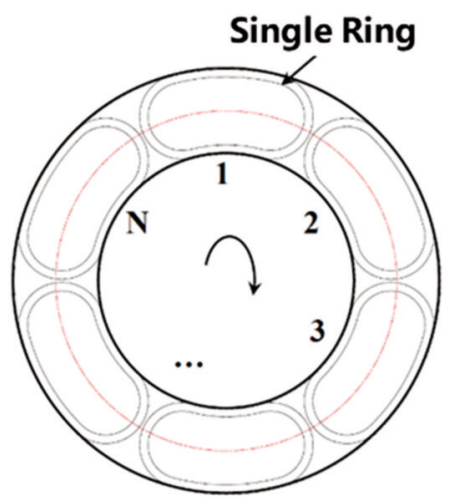

(b) Track shaped chamber

Fig. 2.3.4 Schematic of circumferential multi-annular RDC [74-75].

The feedback pressure perturbation of the RDC has been confirmed in previous studies [76-78], and it has certain unfavorable effects on turbomachinery operability and engine stability. Schwer et al. [77] attempted to weaken the pressure perturbation by different injectors, but the effect was not significant. Ji et al. [73-74] proposed a form of isolator configuration to reduce the effects of feedback pressure, as shown in Fig. 2.3.5, according to the propagation of feedback pressure perturbation. Based on numerical simulation, the feasibility and practicability of the isolator has been verified, and the results also show that, 
the geometric parameters of the obstacles play a critical role in reducing the feedback pressure of the RDC. Zhou et al. [79-80] verified the feasibility of the integrated system of the compressor and the RDC, and studied the impact of the turbine guide vane on the propagation characteristics of the detonation wave. Liu et al [81-82] studied the effects of supersonic high-frequency pulsating exhaust of the RDC on the operating characteristics of axial turbine based on three-dimensional numerical simulation, and revealed that the leading-edge shock waves play a critical role in the overall unsteady loss mechanism.

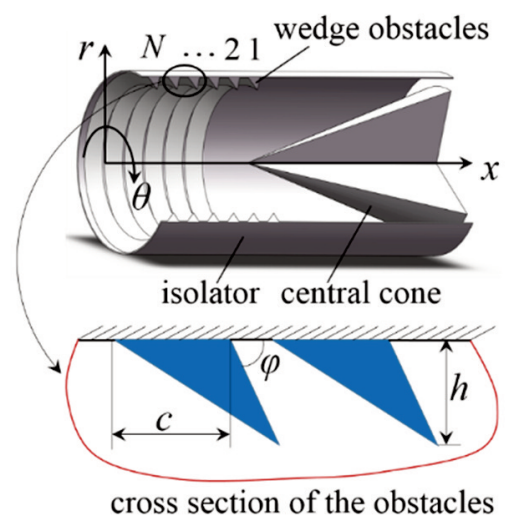

Fig. 2.3.5. Schematic structure of the isolator [73].

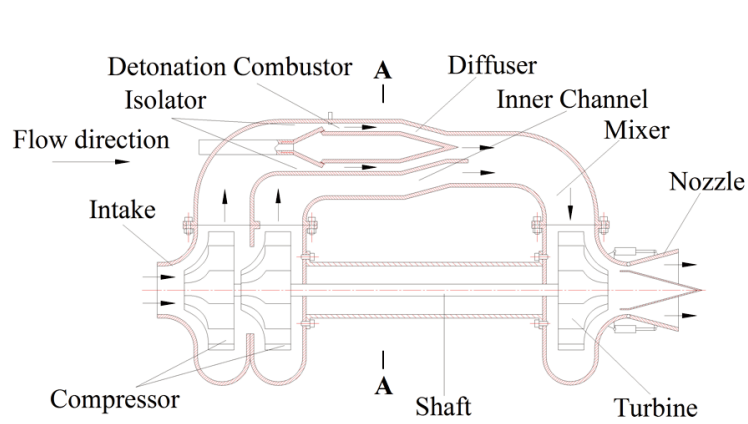

(a) Diagrammatic representation of the DRDATE

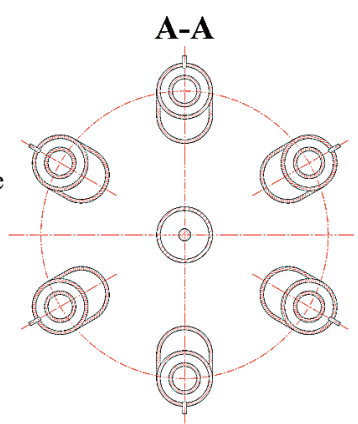

(b) Sectional view of the multi-annular RDC

Fig. 2.3.6. Schematic structure of DRDATE with the multi-annular RDC [73].

The studies regarding the compatibility between the turbomachinery and RDC have led a deeper understanding of the operating principle and matching mechanism of the rotating detonation turbine engine. For the potential configuration of the rotating detonation turbine engine, the previous solutions mainly focused on the main combustor being replaced by the RDC directly [79-80, 83-84], without considering the interaction between the turbomachinery and RDC. Sousa et al. [85] proposed to cure the turbine-RDC matching by replacing the conventional turbine with a supersonic one, however, the technical maturity is quite low. Ji et al. [73-74] presented a configuration of dual-duct rotating detonation aero-turbine engine (DRDATE), as shown in Fig. 2.3.6. With the isolator and mixer arranged upstream and downstream from the RDC, the turbomachinery-RDC matching was realized. With the DRDATE being used as the gas generator, the rotating detonation-based turboprop, turboshaft, turbofan, and industrial gas turbine can also be derived. Just thank to the shock trains formed in 
the isolator of the ramjet engine, the interactions between the combustor and intake are weakened [8687]. As the shock trains can also reduce the effects of feedback pressure, there is no need to introduce any new components for the configuration of rotating detonation ramjet engine. The rotating detonation ramjet engine exhibits competitive improvements in overall performance at low flight Mach numbers, compared to the conventional ramjet [74].

\subsubsection{Evaluation model for overall performance}

With the improvement of the technical maturity of rotating detonation technology, the application of rotating detonation in propulsion systems has attracted significant interest in both academia and industry. Reduced-order method is effective for the evaluation and optimization of the overall performance of the rotating detonation engine. However, the research related to the low-order model of the RDE is quite scarce. As the detonation wave propagation characteristics were partially ignored, some low-order models might overestimate the potential benefits of the RDC $[68,88]$. Some low-order models were developed based on the empirical and semi-empirical equations derived by numerical simulation or experimental results [65, 89-90]. With the method of characteristics method and shock-expansion theory combined with the C-J detonation solver, a quasi-2D analytical model of the RDC can be built, but this model requires spatial discretization [91-92]. Based on the matching relationship between the injection process and pressure decay after the detonation front, a low-order model of the RDC can be developed. This model avoids spatial discretization and solving differential equations, and shows satisfactory accuracy over a wide range of injection parameters [73-74].

Based on the reduced-order models, the technical feasibility and potential benefits of the RDE have been preliminarily verified. The method of characteristics method coupled with T-MATS software is developed to estimate the overall performance of the turboshaft engine with a rotating detonation combustor, and the results show that the thermal efficiency of the gas turbine with an RDC is 5\% higher than the similar engine with a deflagration combustor, but the performance improvement decreases with the increase of compressor pressure ratio [85]. Ji et al. [73-74, 88] demonstrated that, the rotating detonation turbine engine exhibits competitive improvements in overall performance at low compressor pressure ratios, compared to the conventional turbojet. With the increase of compressor pressure ratio, the performance improvements in thermal efficiency and specific fuel consumption tend to disappear. Furthermore, as the flow path of the bypass duct is ideal for the rotating detonation combustor, the concept of rotating detonation duct burner is proposed, and it is regarded as an alternative to the afterburner for mixed exhaust turbofan engine [74-75].

\section{RESEARCH PROGRESS OF CONTINUOUSLY ROTATING DETONATION ENGINE}

\subsection{Research progress of Russia}

In the 1950s, Voitsekhovskii at the Institute of Hydrodynamics of Siberian Branch of Soviet Academy of Sciences in the former Soviet Union discovered the phenomenon of rotating detonation combustion that occurs in liquid-propellant rocket engines. Subsequently, his research team successfully obtained the rotating detonation wave [93] through a disc-type experimental device (with acetylene/oxygen gas mixture added) for the first time. The experimental device has been shown in Fig. 3.1.1(a). The team has successfully captured the structure of the rotating detonation wave through photography of velocity compensation, as shown in Figure 3.1.1(b). This is the first detailed rotating detonation wave structure captured in the world. 


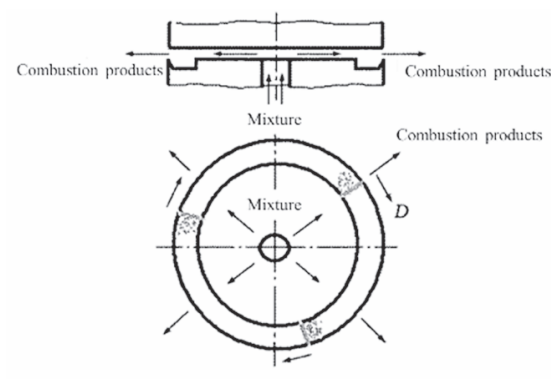

(a) Disk-type rotating detonation combustor

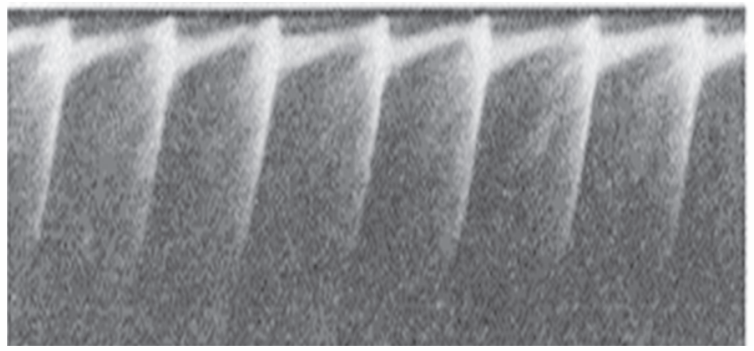

(b) Photograph of rotating detonation wave

Fig. 3.1.1. An experimental facility of rotating detonation engine at Voitsekhovskii's lab [93].

Bykovskii et al. [94] with the Lavrentyev Institute of Hydrodynamics conducted a large number of experiments using rotating detonation combustors of various geometric configurations, and successfully obtained rotating detonation wave propagating stably in these combustors. Figure 3.1.2 shows the geometry of the combustors used in their study, including circular ring type, circular ring type with cone, and flat disc type with products diffusing toward the edge, and flat disc type with products diffusing toward the center. In addition, it also carried out experimental researches on a variety of fuel / oxidant injection methods [95-97], and obtained rotating detonation wave of stable propagation. The injection can be classified as the dual cross-injection, tangential and fuel axial injection of oxidant, fuel and oxidant axial injection, coaxial injection of fuel and oxidant, and collision injection, as shown in Fig. 3.1.3. The experimental results show that ensuring perfect mixture of fuel and oxidant is the key to forming rotating detonation wave of stable propagation, no matter which form of injection is applied.

Bykovskii et al. [95-99] also conducted experiments on different combinations of fuel and oxidant, with the gaseous fuel including $\mathrm{H}_{2}, \mathrm{CH}_{4}, \mathrm{C}_{2} \mathrm{H}_{2}, \mathrm{C}_{3} \mathrm{H}_{8}, \mathrm{CO} / \mathrm{H}_{2}$, and binary mixture; and the liquid fuel including gasoline, kerosene and alcohol. The oxidant involved is mainly air and oxygen. What's more, they also studied the effect of various factors including the mass flow rate of different fuel/oxidant, as well as the back-pressure changes at the combustor outlet, on the stability and propagation modes of rotating detonation wave, and summarized the main parameters affecting the stable propagation of rotating detonation wave [100]. It can be concluded from the above-mentioned studies that ensuring the full mixture of fuel and oxidant, and the filling height along the axial direction is a prerequisite for the stable self-sustaining propagation of rotating detonation wave.

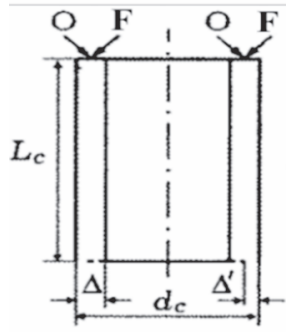

(a) Ring-type

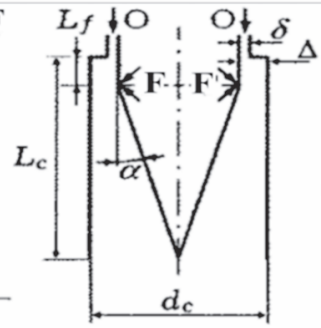

(b) Ring-type with cone

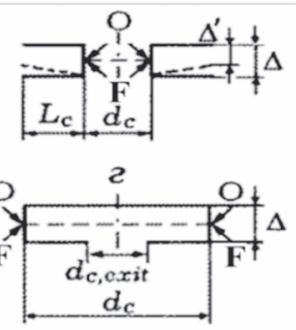

(c) Disk-type

Fig. 3.1.2. Schematic diagram of rotating detonation engine with different geometric configurations [94]. 

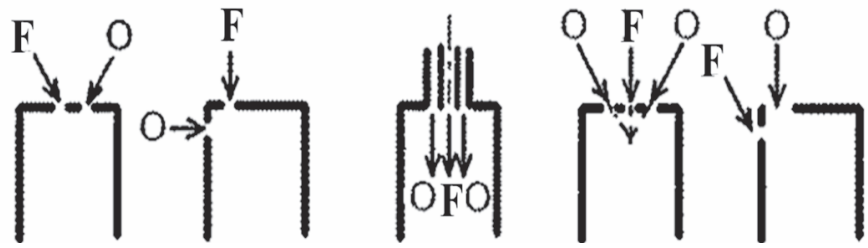

Fig. 3.1.3. Schematic diagram of different injection forms of rotating detonation combustor [95]

Frolov et al. [101] with the Moscow Research Center of Pulse Detonation Combustion in Russia tested the operating characteristics of rotating detonation engines with a diameter of $50 \mathrm{~mm}$ and $100 \mathrm{~mm}$, respectively, using hydrogen and air. By controlling the pressure of the gas source, they compared the thrust and specific impulse characteristics of the rotating detonation engine and the conventional isobaric combustion rocket engine under the same injection conditions. The results show that under the same air pressure conditions, the rotating detonation engine (Figures 3.1.4, 1, 2, 3, and 4 show the different air supply pressure respectively) can produce greater thrust compared with the conventional rocket engines with a smaller hydrogen pressure supply, and the specific impulse of the rotating detonation engines increases by about $6-7 \%$ compared with the conventional rocket engines.

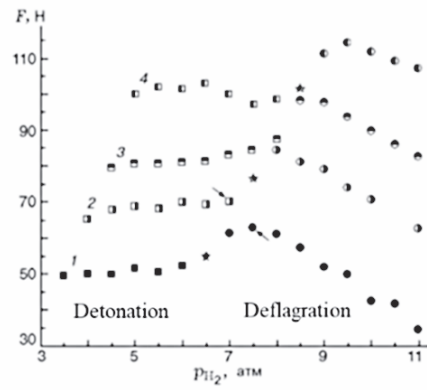

(a) Thrust Vs Hydrogen pressure

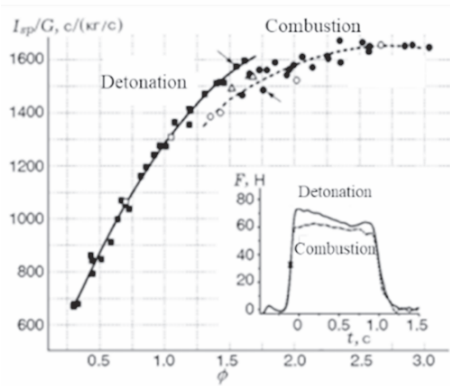

(b) Specific impulse Vs Equivalence ratio

Fig. 3.1.4. Comparison of specific impulse and thrust between rotating detonation engine and rocket engine [101]

To obtain the influential pattern of the nozzle on the thrust and specific impulse characteristics of the rotating detonation engines, Frolov et al. [102] installed a nozzle with a diameter of $50 \mathrm{~mm}$ and $100 \mathrm{~mm}$ to the end of the rotating detonation engines, and carried out experiments. The experimental results show that compared with the rotating detonation engines without an nozzle, the installation of convergent-divergent nozzles can significantly increase the thrust and specific impulse of the engines, and reduce the propagation velocity of the detonation wave.

Subsequently, Frolov et al. [103] successfully tested a large-scale rotating detonation engine with a diameter of $406 \mathrm{~mm}$, with hydrogen and air applied as fuel and oxidant. The experimental setup and results are shown in Fig. 3.1.5. In the experiment, they used a pressure sensor and an ion probe to observe the propagation of single, double, and multiple detonation waves in a rotating detonation combustor. The total mass flow rate of the engine involved reached $7.5 \mathrm{~kg} / \mathrm{s}$, with a maximum net thrust of $6 \mathrm{kN}$ and maximum specific impulse of 3000s for the engine. Besides, it has also been discovered that the contraction-expanding nozzle can increase the number and thrust of detonation wave in the rotating detonation combustor. 


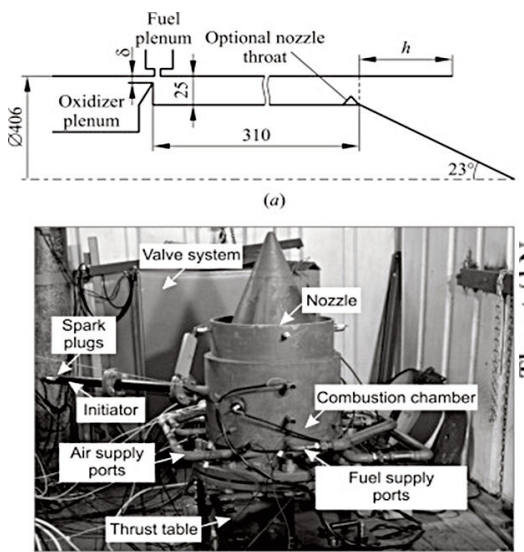

(a) Combustor $(\mathrm{D}=406 \mathrm{~mm})$

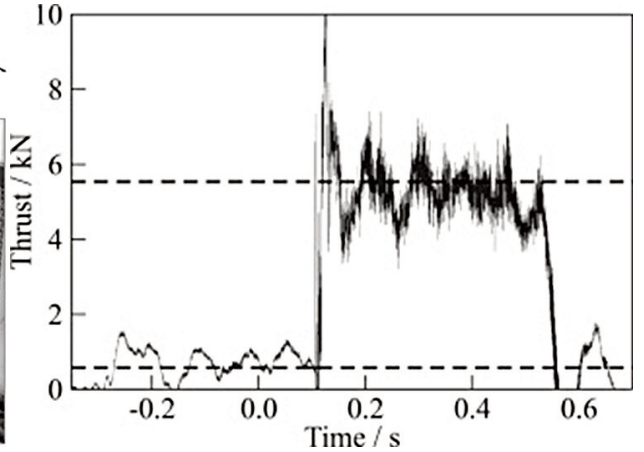

(b) result of thrust

Fig. 3.1.5. A test bed with a diameter of $406 \mathrm{~mm}$ for the rotating detonation combustor [103].
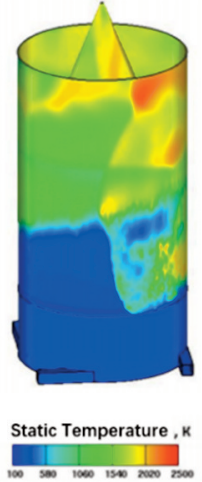

(a)

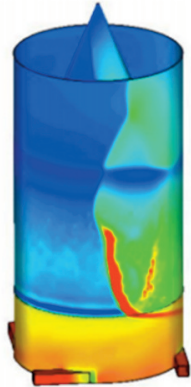

$t=7.65 \mathrm{Mc}$

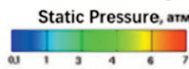

(б)

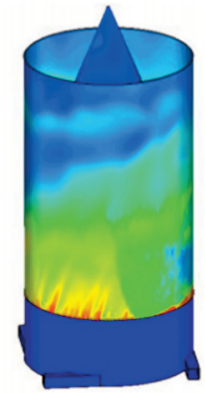

Mass Fraction of $\mathrm{H}_{2}$

(B)

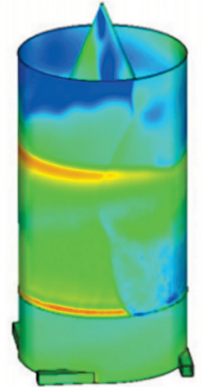

Mach Number

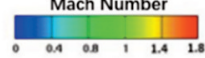

(r)

Fig. 3.1.6. Numerical results of the rotating detonation combustor [104].

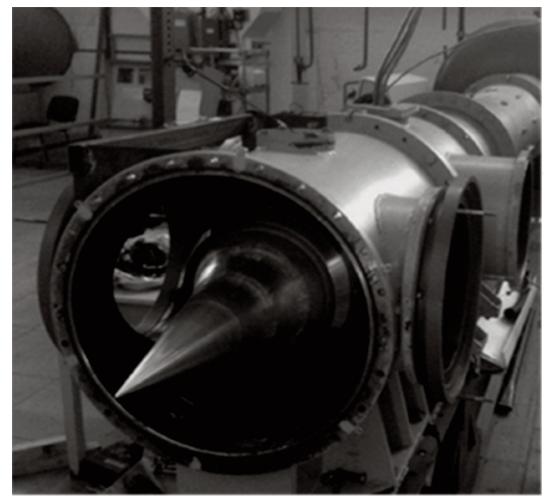

(a) Rotating detonation ramjet

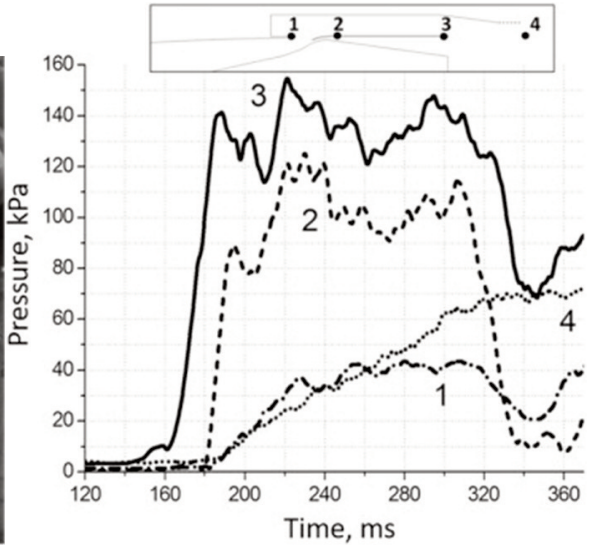

(b) Pressure changes with time

Fig. 3.1.7. Rotating detonation ramjet and pressure measurement results [105]. 
Frolov et al. [104] carried out a three-dimensional numerical simulation studies on the rotating detonation engines with a diameter of $406 \mathrm{~mm}$, and obtained a specific impulse of $3000 \mathrm{~s}$ for the engines. The numerical results are shown in Fig. 3.1.6.

Frolov et al. [105] using hydrogen as the fuel conducted an experiment on a ramjet-type rotating detonation engine in a wind tunnel with a Mach number of 4, as shown in Fig. 3.1.7 (a). The figure 3.1.7 (b) shows the pressure variation of the four different measuring points of the rotating detonation ramjet obtained from the experiment with time. In the experiment, they also observed the continuously detonation wave propagating in the circumferential direction and the pulse detonation wave propagating in the longitudinal direction.

In 2017, the Russian Alegamas Energy Company in aviation industry, the Lavrentyev Institute of Hydrodynamics and the Moscow Aviation Academic-founded the Liquid-Propellant Detonation Rocket Engine Laboratory. For the first time in the world, the lab successfully tested a full-scale continuous liquid oxygen/kerosene rotating detonation rocket engine and obtained rotating detonation wave of stable propagation with a frequency of about $20 \mathrm{kHz}$. The experimental setup is shown in Fig. 3.1.8. In order to ensure the normal operation of the rotating detonation rocket engine, the Russian Keldysh Thermal Barrier Coating Research Center specially developed the thermal barrier coating material for its engine, enabling the rotating detonation engine to function under ultra-high temperature conditions over and over again. It is found that the thrust and the specific impulse of a rotating detonation rocket engine increased by $10 \%$ and $10-15 \%$ respectively, compared with the conventional rocket engine of the same thrust level. The results fully demonstrate the performance advantages of detonation combustion in applying to rocket engines [106].

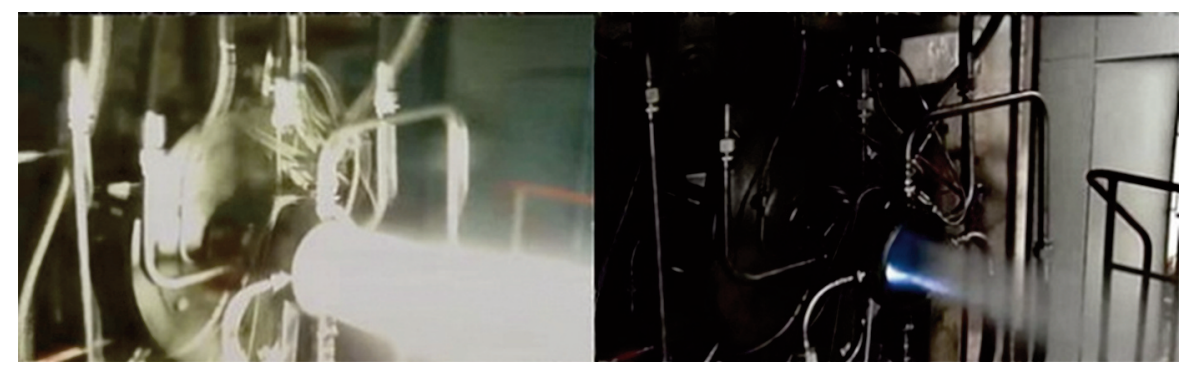

Fig. 3.1.8. A test bed for the liquid-propellant detonation rocket engine [106]

\subsection{Research progress of America}

In the 1960s, Nicholls et al. [107] with the University of Michigan made a detailed demonstration of the feasibility of the rotating detonation engine as a potential propulsion device in the future. They obtained continuously rotating detonation wave in an annular combustor. The experimental setup at that time is shown in Fig. 3.2.1. However, it is quite unfortunates that the detonation wave generated in the experiment failed to achieve sustained and stable propagation.

At the beginning of the 21 st century, Pratt $\&$ Whitney conducted an experimental study on the rotating detonation engines. The researchers studied the fuel/oxidant single injection and premixed gas injection in experiments, using acetylene / oxygen as fuel / oxidant respectively. However, due

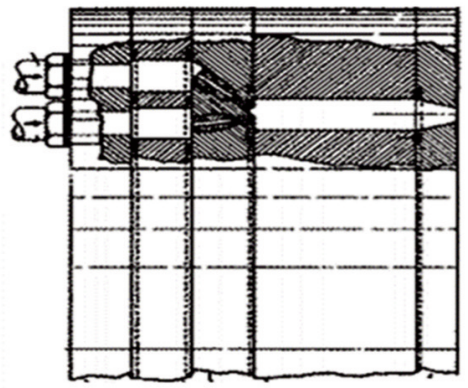

Fig. 3.2.1. The setup diagram of the rotating detonation engine of the University of Michigan [107]. 
to the tempering accident that occurred in the premixed gas injection, the entire test bench got burned, resulting in the termination of the study. Research institutions including the Air Force Institute of Technology, Air Force Research Laboratory, Naval Research Laboratory, Aerojet Rocketdyne Company, National Energy Technology Laboratory, University of Texas at Arlington (UT Arlington), and the University of Cincinnati have begun the theoretical, numerical, and experimental researches on rotating detonation engines since then.

Russo et al. [108-109] with the Air Force Institute of Technology studied the impact of parameters such as mass flow rate and equivalence ratio on rotating detonation wave with hydrogen/air and fuel/oxidant. The study was based on the experimental platform with a diameter of 3 inch provided by Pratt \& Whitney for the research on rotating detonation engines, as shown in Fig. 3.2.2 (a). Shank et al. [110-111] designed a 6-inch rotating detonation engine, and its experimental setup is shown in Fig. 3.2.2 (b). They successfully observed three propagation modes of detonation wave, namely the forward propagation, back propagation and collision of double detonation wave, and verified the three propagation modes by means of high-speed photography. Thomas et al. [112] conducted a large number of experimental studies on the operating characteristics of rotating detonation engines under different mass flow rates and equivalence ratios using the Pratt \& Whitney's rotating detonation engine program, and found that detonation can be achieved for a large part under fuel-rich conditions.

Due to the self-pressurization of detonation combustion, a combination of the detonation combustor with the turbine is potential to gain advantages in performance. Therefore, Tellefsen et al. [113-114] attempted to simulate the effect of the turbine on the propagation characteristics of rotating detonation wave by adding a converging nozzle at the end of the rotating detonation engine. The experimental setup is shown in Fig. 3.2.3 (a). The experimental results show that the nozzle tends to slow down the propagation of the rotating detonation wave, and lead to obvious oscillation of pressure in the combustor. Furthermore, in order to verify the effect of the rotating detonation exhausting on the turbine, they also installed turbines at the outlets of the rotating detonation engine with a diameter of 3 and 6 inches, respectively, as shown in Fig. 3.2.3 (b). The experimental results show that the hightemperature detonation product is very likely to cause damage to turbine blades, and the static pressure at the outlet guide vane (OGV) of the combustor also reduces by about 26.3 Psi $(33.5 \%)$.

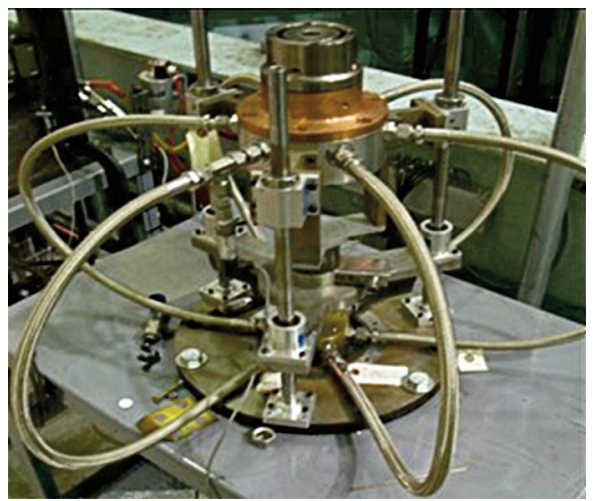

(a) A rotating detonation combustor with a diameter of 3 inches

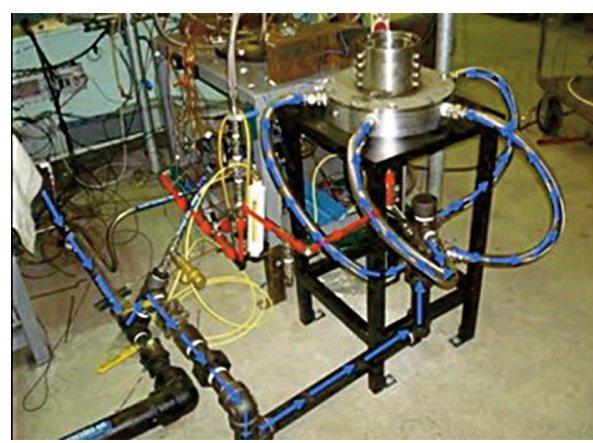

(b) A rotating detonation combustor with a diameter of 6 inches

Fig. 3.2.2. The experimental set-up of the rotating detonation engine of the Air Force Institute of Technology [113]. 


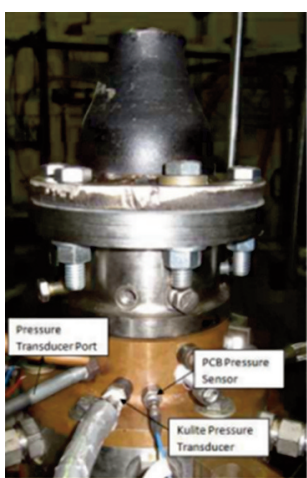

(a) Combustor with nozzle

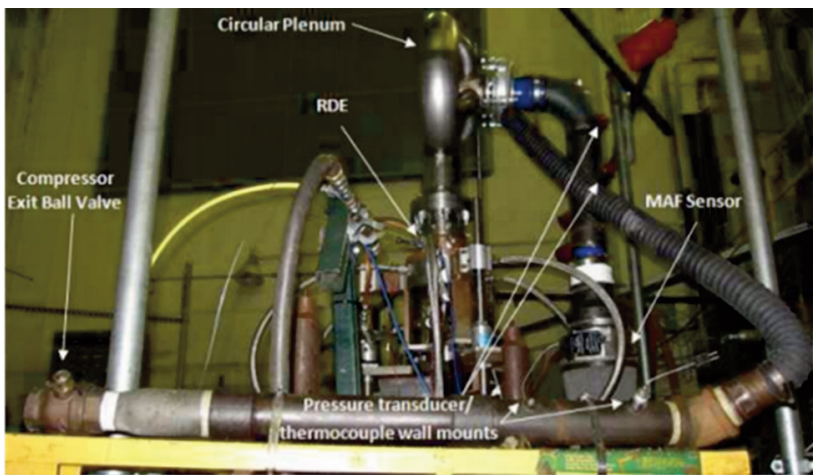

(b) rotating detonation turbine engine

Fig. 3.2.3. The experimental set-up of the rotating detonation turbine engine of the Air Force Institute of Technology [114].

Matt Fotia et al. [115-116] independently designed a small test bench for the rotating detonation engine, as shown in Fig. 3.2.4, with which they studied the effect of the combustor length, the nozzle type on the air and injection pressure in the combustor. It has been found that the shorter the length of the combustor, the higher the efficiency of injection in the combustor. While the length of combustors and the various nozzles cannot affect the specific thrust of the engine. Matt Fotia et al. [116-117] also successfully initiated the rotating detonation wave and made them propagate stably using various fuel/oxidant mixture, including a mixture of hydrogen/air, ethylene/air, and kerosene/oxygen; besides, they also analyzed the effect of mass flow rate, equivalence ratio and oxygen content on the thrust and specific impulse characteristics of the rotating detonation engine [118]. The experimental results show that the thrust of the engine increases with increase in mass flow rate, while the specific impulse decreases with the increase of the equivalence ratio; and the increase of oxygen content in the air can significantly improve the thrust and specific impulse of the engine.
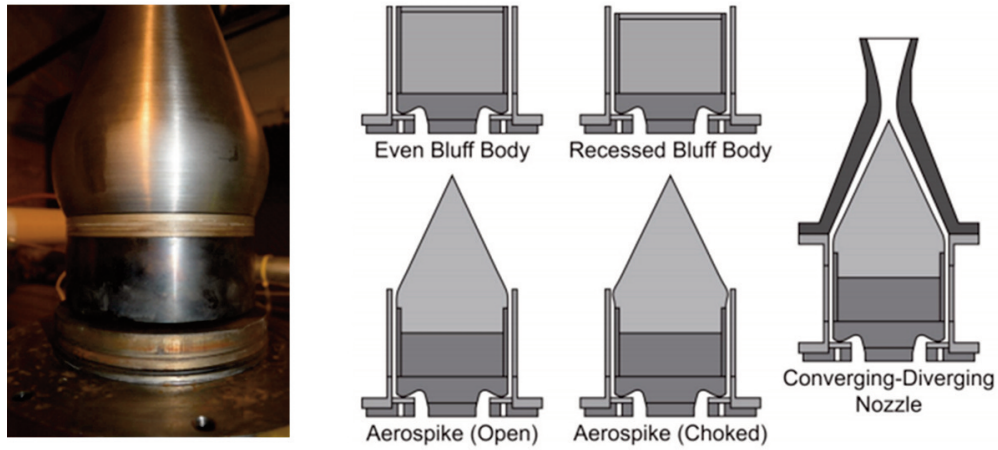

Fig. 3.2.4. The experimental set-up of the rotating detonation engine, and the diagram showing the nozzles of various types [115].

Matt Fotia et al. [116] using hydrogen and air as fuel and oxidant studied the effect of the annular combustor width on the specific thrust of a rotating detonation engine. The experimental results show that under the same mass flow rate, the narrower the annular combustor, the larger the specific thrust will be. Theuerkauf et al. [119-121] designed a visualized outer wall surface of the rotating detonation engine 
with a diameter of 6 inches, to carry out the study of the wall surface thermal equilibrium with hydrogen and air as fuel and oxidant, respectively. The experimental set-up is shown in Fig. 3.2.5. A high-frequency temperature sensor was used to measure the wall surface heat flow, discovering that the combustor heat increases with the increase of air mass flow rate and equivalence ratio. The maximum heat flux density of the engine wall surface measured reached $9 \mathrm{MW} \cdot \mathrm{m}^{2}$, while the minimum heat flux density is less than $1 \mathrm{MW} \cdot \mathrm{m}^{2}$. In addition, Braunt al. [122] used a simplified model to evaluate the flow and heat transfer characteristics of the wall surface. Meyer et al. [123] studied the variation of heat flow in the combustor experimentally, and found that the heat flow increases with the increase of air mass flow rate, equivalence ratio and detonation wave velocity.
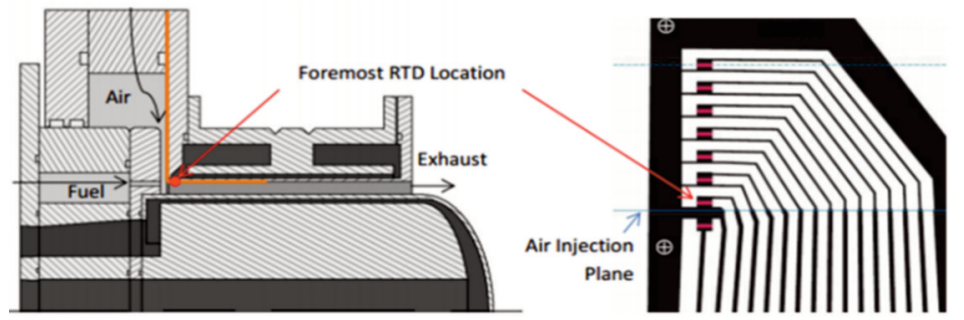

Fig. 3.2.5. The schematic diagram showing the 6-inch rotating detonation engine and the thermal sensor of the Air Force Institute of Technology [123].

Rankin et al. [124] replaced the outer wall of the rotating detonation engine with a visualized quartz glass. The experimental setup is shown in Fig. 3.2.6 (a). They studied the flow field characteristics of the rotating detonation engine, such as flow field structure, detonation wave height, detonation wave angle, oblique shock wave angle, shear layer angle and contact surface angle, by $\mathrm{OH}$-based chemiluminescence experiments. Subsequently, Rankin et al. [125] also carried out research on non-premixed rotating detonation engines by means of $\mathrm{OH}$-based chemiluminescence imaging technology, and obtained the effect of air mass flow rate, equivalence ratio, air injection area and fuel injection scheme on the rotating detonation wave. The experimental results show that a transition from single wave to double waves occurs in the combustor at a larger mass flow rate. At the same time, they found that the distribution of $\mathrm{OH}$-based groups in the combustor tends to become more extensive under lean-burn conditions, but the $\mathrm{OH}$-based groups are more likely to concentrate in the narrower areas near the front of the detonation wave under rich-burn conditions. They also clearly observed the area of higher intensity of pressure in front of the detonation wave, and the cell structure of detonation wave, as shown in Fig. 3.2.6 (b).

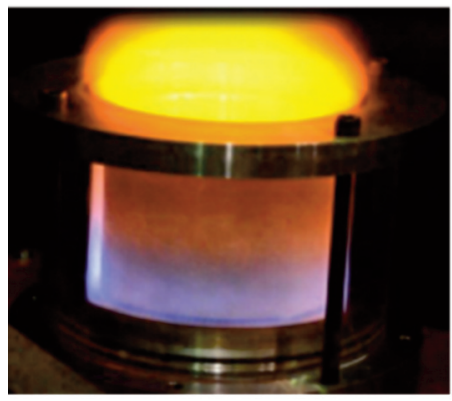

(a) Visualized rotating detonation combustor

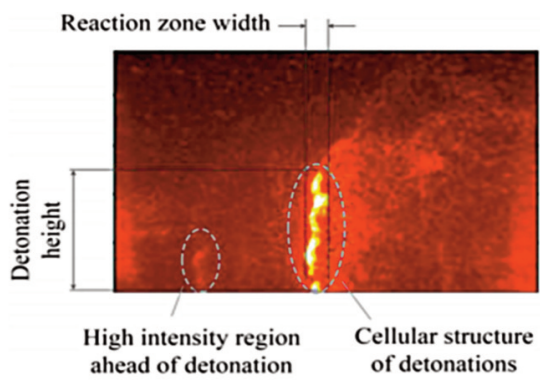

(b) $\mathrm{OH}$-based chemiluminescence

Fig. 3.2.6. Visualized rotating detonation combustor and $\mathrm{OH}$-based chemiluminescence experiment [125]. 
Matt Fotia et al. [116] with the Air Force Laboratory independently designed a 10-inch rotating detonation engine, and the experimental setup is shown in Fig. 3.2.7. The effect of high-temperature air at the combustor inlet on the performance of the rotating detonation engine was studied experimentally. The experimental results show that although the high-temperature air can improve the specific impulse and specific thrust of the rotating detonation engine, the effect is not significant. Subsequently, Matt Fotia et al. [116] also conducted a comparative study on the 6-inch and 10-inch rotating detonation combustors, which also indicated that the effect of the diameter variation of combustor is not significant on the specific thrust.

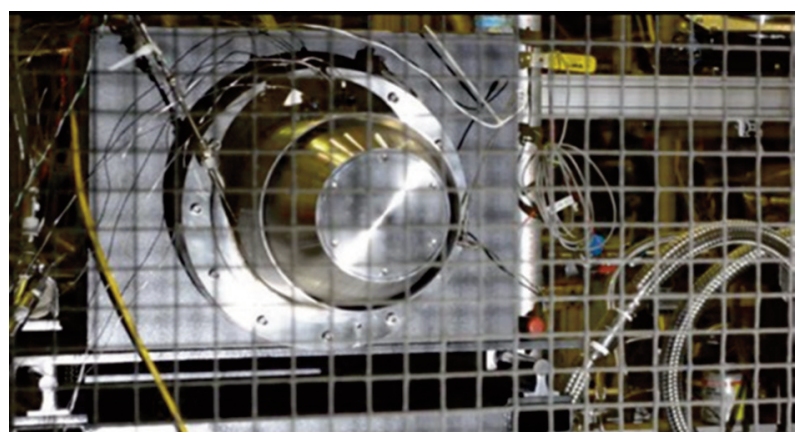

Fig. 3.2.7. The experimental set-up for the 10-in rotating detonation engine of the USAir Force Research Laboratory [116].

Kailasanath et al. [126-129] with the Naval Research Laboratory conducted large number of numerical simulation studies on rotating detonation engines, obtaining a detailed flow structure of rotating detonation wave using hydrogen/ethylene as fuel/oxidant, as well as the effect of combustor geometry (length, width and diameter), total flow pressure, combustor outlet backpressure and injection area on the thrust characteristics of engines. The numerical results show that the length of the annular combustor has a greater influence on the thrust characteristics of the engine at a lower pressure ratio (backpressure/injection pressure). However, at higher pressure ratios, the effect of length of the combustor on the thrust is not significant. In addition, it's also indicated that the mass flow rate of the engine is in positive and linear correlation with the total pressure of the incoming flow.

Schwer et al. [130-131] also studied the effects of nozzle geometry, nozzle area ratio, and injection pressure on the flow field characteristics of rotating detonation wave and the engine performance, and carried out simulations on the disturbing effect of rotating detonation wave on the plenum. The numerical results show that the detonation wave pressure propagating back to the plenum causes significant pressure oscillations in the chamber.

For the discharge of the detonation combustion products from a rotating detonation engine, Schwer et al. [132] analyzed the distribution pattern of NOx in the head of a rotating detonation combustor by numerical simulations. They found that most of the NOx existed in detonation wave of higher temperature and the expanded gas flow hereby, while no NOx was observed in the deflagration reaction zone of relatively low temperature. They compared the NOx emission indexes of two different combustion modes of rotating detonation and pulse detonation under the same conditions in numerical simulations, and found that the NOx emission index of rotating detonation is significantly lower than that of pulse detonation.

Since 2010, Edward et al. [133] with the Aerojet Rocketdyne have conducted more than 600 hot runs for the rotating detonation engine. The research plan included the verification of concepts, successfully achieving detonation initiation and stable detonation using gas fuel $\left(\mathrm{H}_{2}, \mathrm{CH}_{4}, \mathrm{C}_{2} \mathrm{H}_{6}\right.$, natural gas), achieving efficiency improvement by means of plasma technology, successfully achieving detonation 
initiation and stable detonation using liquid fuel (JP-8, JP-10). These have been summarized in Table 2. In addition, the analysis of the emissions of rotating detonation engines was carried out by probing combustion products; and further experiments on the combination of rotating detonation and turbine was carried out, together with series of theoretical, numerical researches on the modeling of rotating detonation gas turbines.

Table 2. Researches on the rotating detonation engines of the US Aerojet Rocketdyne co., Ltd [133].

\begin{tabular}{|c|c|c|c|}
\hline Year & Project & Num of Test & Photo \\
\hline 2010 & Proof of principle & 28 & \\
\hline 2010 & $\begin{array}{l}\text { Experimental study on } \\
\text { detonation engine }\end{array}$ & 163 & \\
\hline 2011 & Plasma ignition & 21 & \\
\hline 2012 & $\begin{array}{l}\text { Determination of design } \\
\text { parameters }\end{array}$ & 198 & \\
\hline 2013 & $\begin{array}{l}\text { Experimental study on liquid } \\
\text { fuel }\end{array}$ & 79 & \\
\hline 2013 & Exhaust emission measurement & 35 & \\
\hline 2014 & $\begin{array}{l}\text { Experimental study on } \\
\text { detonation turbojet engine }\end{array}$ & 13 & \\
\hline 2015 & $\begin{array}{l}\text { Detonation turbojet engine } \\
\text { modeling }\end{array}$ & 0 & \\
\hline
\end{tabular}

Since 2015, Ferguson et al. [134] with the National Energy Technology Laboratory have used the design concept of the rotating detonation combustor of the Air Force Research Laboratory to build a rotating detonation engine. The experimental setup is shown in Fig. 3.2.8 with hydrogen and air used as fuel and oxidant respectively. The effects of equivalence ratio and intake air temperature on the pressure and velocity of rotating detonation wave were studied experimentally, and the results show that when the equivalence ratio is increased from 0.6 to 1.0, the pressure of the combustor increases first, and then decreases. At the same time, the propagating speed of the detonation wave also increase slightly. They also found that increasing the air temperature can enhance the number of detonation wave in the combustor. In addition, they also explored the interactive law between the injection port and the detonation wave by means of the Schlieren technique, and found that the detonation wave is prone to cause uneven equivalence ratio at the injection port. 


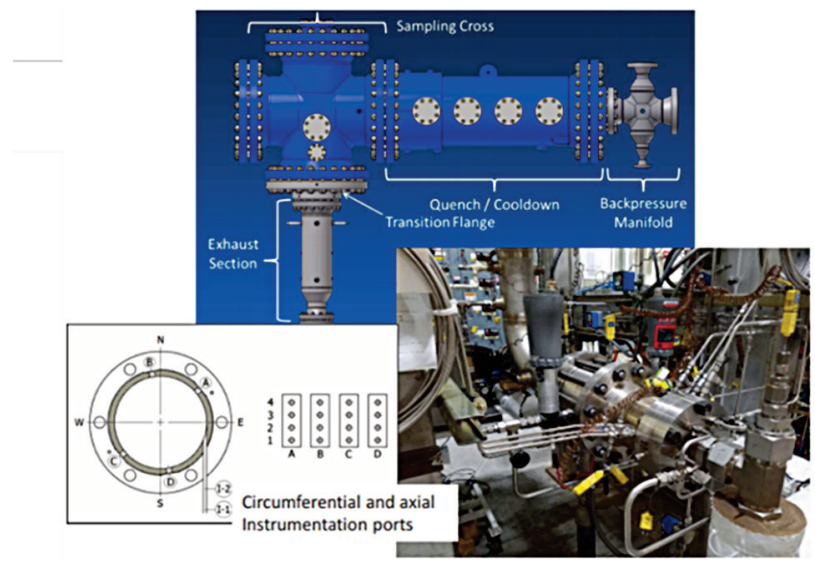

Fig. 3.2.8. The experimental facility of the rotating detonation engine of the National Energy Technology Laboratory [134].

Anand et al. [135] with the University of Cincinnati conducted a large number of research work on the two types of rotating detonation engines with or without a central column. The experimental setup is shown in Fig. 3.2.9. They conducted experimental studies on a variety of rotating detonation combustors of different geometric injection configurations under different air and fuel mass flow rates (air mass flow rate of $300 \mathrm{~g} / \mathrm{s}$ to $500 \mathrm{~g} / \mathrm{s}$, equivalent ratio of 0.5 to 1.9). In the experiment, they observed four kinds of unstable phenomena: chaotic instability, wax and wane, modal transformation and axial pulse detonation. In addition, experimental studies were also conducted on the operating range and performances of the rotating detonation engines, including the detonation wave propagation velocity, together with the study on the three different fuel injections and two air injection schemes [136]. The experimental results show that the three injection schemes have similar operating characteristics, and unstable detonation in the rotating detonation combustor was observed in the fuel injection scheme with the maximum length-diameter ratio (L/D). They also conducted experimental studies on the behavioral characteristics of the air inlet and fuel plenum of a rotating detonation combustor [137], and it was observed that a strong back-propagation of pressure from rotating detonation wave occurred at the air injection port. They also carried out numerical simulations for the mixture performance and cold injection characteristics of the fuel/oxidant in a rotating detonation engine [139], and the results show that the reactants were mainly mixed by the reversely rotating vortex pair formed in cross flow.

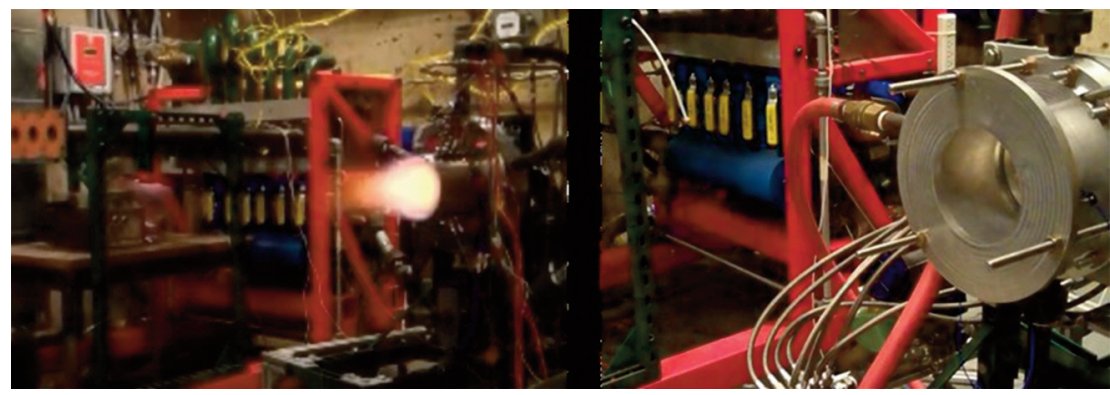

(a) With central column

(b) Without central column

Fig. 3.2.9. The experimental bench of the rotating detonation engine of the University of Cincinnati [135]. 
Suchocki [139] with the Ohio State University experimentally studied the inter relationship between the number of detonation wave and mass flow rate in a rotating detonation engine with hydrogen and air applied as fuel and oxidant. They found three modes of propagation for a rotating detonation engine: single detonation wave, single and double detonation wave mixing, and double detonation wave. They also used the normal air and oxygen-enriched air as oxidants to test the thrust performance of the rotating detonation engine; and over 200 pounds of thrust was achieved.

Figure 3.2.10 shows two sets of rotating detonation engines independently designed by Braun [140] with the University of Texas at Arlington. For the first set shown in Fig. 3.2.10 (a), the detonation process of deflagration-to-detonation transition was achieved with hydrogen/oxygen and propane/oxygen applied, but unfortunately the detonation wave got extinguished after several cycles of propagation. For the second set shown in Fig. 3.2.10 (b), hydrogen/oxygen was used as the fuel/oxidant respectively, and the rotating detonation wave was achieved. However, the self-sustained propagating detonation wave was never obtained. Braun [141] also carried out an experimental study on the pressure oscillation in the plenum caused by the detonation wave passing through the injection holes, and found the dimensionless relationship between the pressure oscillation recovery time and the detonation wave pressure in the plenum of fuel.

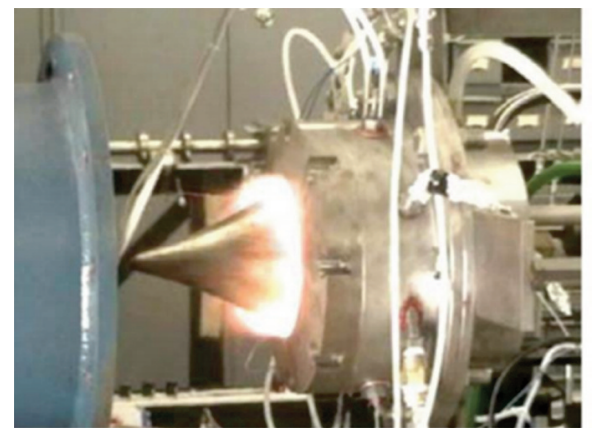

(a) The first experimental device

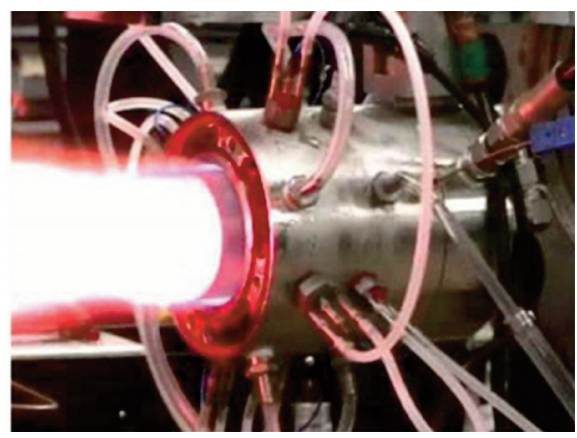

(b) The second experimental device

Fig. 3.2.10. The experimental bench of the rotating detonation engine of the University of Texas at Arlington [140-141].
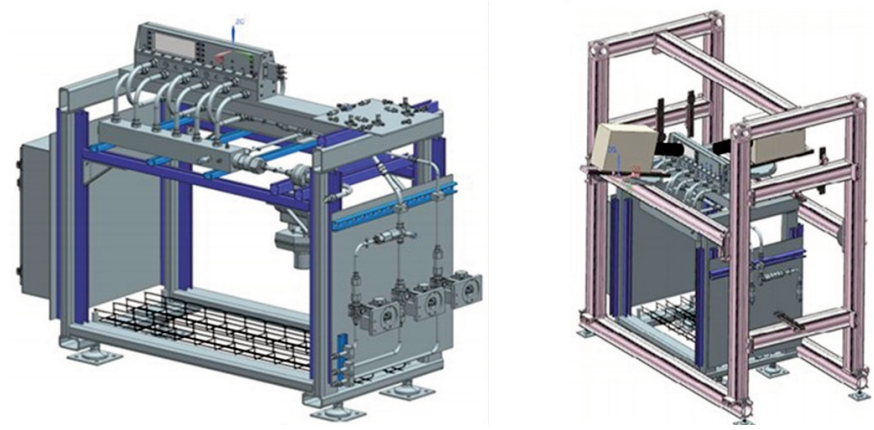

Fig. 3.2.11. The 2-D test bench for the rotating detonation combustor at the Purdue University [142].

Heister et al. [142] with the Purdue University started experiments and numerical simulations targeting critical aspects, including injection kinetics, small-scale combustor design, pressure gain evaluation, inlet and outlet parameter measurement, exhaust emission measurement, and mathematical 
modeling. Presently, they have established a experimental device, as shown in Figure 3.2.11. In addition, they independently designed a large-scale test bench for the rotating detonation engines, and carried out experimental tests with methane/air used as fuel/oxidant respectively, with the assistance of the Aerojet Rocketdyne. The test bench is shown in Fig. 3.2.11.
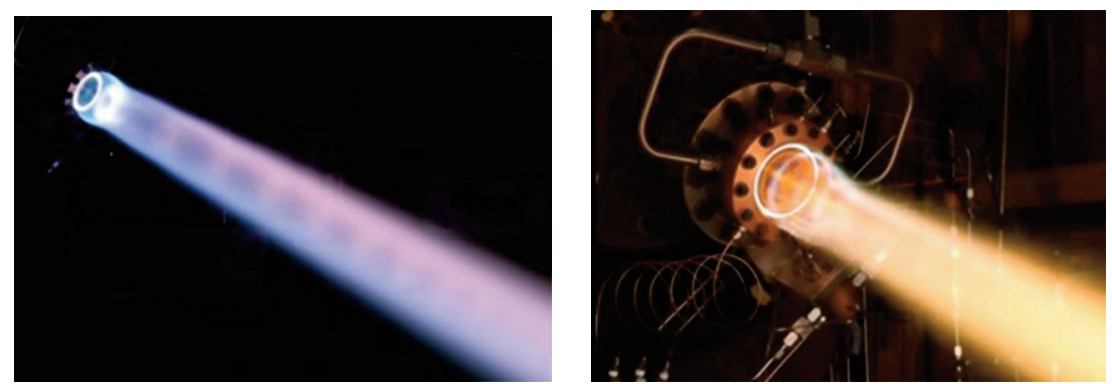

Fig. 3.2.12. The experimental bench for the rotating detonation engine at the Purdue University [142].

\subsection{Research progress of Europe}

Falempin et al. [143-147] with French MBD A collaborated with the LIH Institute of Russian Academy of Sciences to conduct research on rotating detonation engines. They applied a variety of fuel/oxidant mixture, including hydrogen/liquid oxygen, kerosene/air, and kerosene/oxygen, to achieve the initiation and stable propagation of rotating detonation wave in a rotating detonation engine with a length of $100 \mathrm{~mm}$ and an inner diameter of $50 \mathrm{~mm}$. Figure 3.3 .1 shows the testing picture and a threedimensional model of the engine. They achieved a thrust of $2.750 \mathrm{~N}$ on a rotating detonation engine with a kerosene/oxygen mixture. At the same time, they found that the thermal load was most serious on the combustor head, and measured a heat flow of up to $12-17 \mathrm{MW} \cdot \mathrm{m}-2$ on the outer wall surface of the engine combustor with a hydrogen/oxygen mixture. In order to ensure that the engine can work for a long time, MBDA has used $\mathrm{C} / \mathrm{SiC}$ composite material to manufacture the rotating detonation engines and conducted experimental tests for up to 5 seconds. In addition, the thrust vector adjustment for the engine was achieved by means of partitioning the injection chamber.

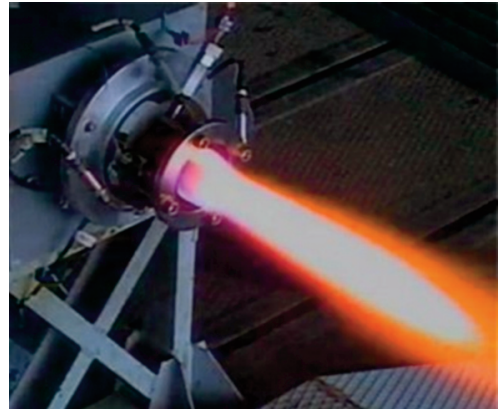

(a) Test of rotating detonation engine

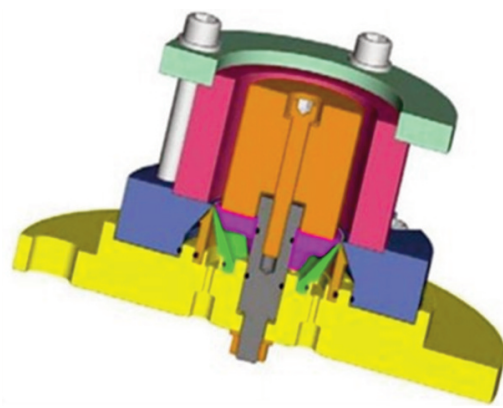

(b) 3-D model of rotating detonation engine

Fig. 3.3.1 An experimental facility for the rotating detonation engine at the French MBDA [145].

Eude et al. [148-149] of the French Institute of Combustion/Aerodynamics and Reaction Environment explored the problems of reflection, bending and velocity loss of rotating detonation wave in the annular combustor through two-dimensional numerical simulations. And the flow field structure differences were comparatively studied for the rotating detonation wave with two- and three-dimensional 
numerical simulations. The numerical results show that under the same injection conditions, the flow field structures of the two- and three-dimensional rotating detonation engines are basically the same. They also theoretically analyzed the thermodynamic cycle efficiency and specific impulse characteristics of rocket engine and rotating detonation engine based on a mixture of hydrogen/oxygen under different equivalence ratios and injection pressures. The results show that the rotating detonation engine is apparently superior to the rocket engine in terms of thermodynamic cycle efficiency and specific impulse.

Kindracki et al. [13,150-152] with Warsaw University of Technology in Poland conducted a large number of experiments on the rotating detonation engines with a diameter of $46 \mathrm{~mm}$ and $150 \mathrm{~mm}$ respectively, using a variety of fuel/oxidant mixture, including methane/oxygen, ethane/oxygen, and propane/oxygen. The study has obtained rotating detonation wave with self-sustaining propagation. They analyzed the stability of detonation and propagation of rotating detonation wave under different initial pressures. Subsequently, they tested the thrust and specific impulse performance of the rotating detonation engine. The test bench is shown in Fig. 3.3.2. A small-sized rotating detonation engine with an outer diameter of $46 \mathrm{~mm}$ can reach a thrust of about $43 \mathrm{~N}$ at an initial pressure of 0.1 bar, while a large-scale rotating detonation engine with an outer diameter of $150 \mathrm{~mm}$ can obtain a thrust of 250 to $300 \mathrm{~N}$ and a specific impulse of 120-146 s.

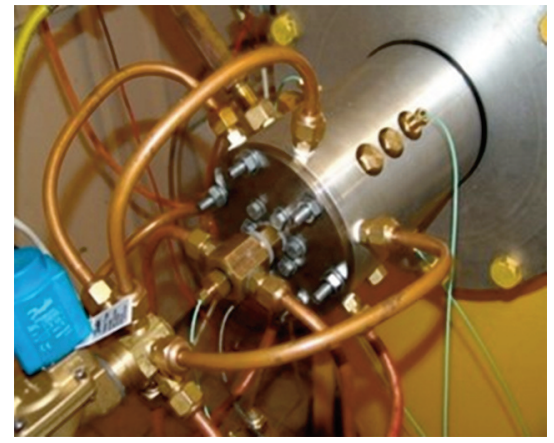

(a) Rotating detonation chamber $(46 \mathrm{~mm})$

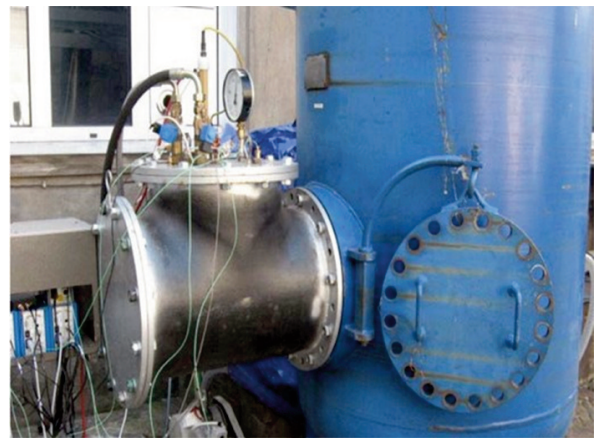

(b) Rotating detonation chamber $(150 \mathrm{~mm})$

Fig. 3.3.2. An experimental facility of the rotating detonation engine at the Warsaw University of Technology [150].

Kindracki et al. [153] studied the initiation and propagation of rotating detonation wave with kerosene/air used as fuel/oxidant respectively. They found that the addition of kerosene/air as fuel/oxidant could not achieve the self-sustained propagation of rotating detonation wave under the condition of normal temperature, and only the addition of hydrogen could promote the initiation and self-sustaining propagation of the rotating detonation wave, as shown in Fig. 3.3.3 (a).

They also collaborated with Japanese researchers to propose the concept of a rotating detonation turbine engine, and applied for a patent in the US [154]. Then, they replaced the conventional combustor in the GTD350 turbojet-propelled engine with a rotating detonation combustor, and conducted a large number of experimental tests with the experimental setup shown in Fig. 3.3.3 (b). The stable rotating detonation wave was achieved by adding a small amount of hydrogen to the kerosene in the experiments. The experimental results also fully verify the feasibility of applying the rotating detonation turbo engine to engineering applications [155]. 


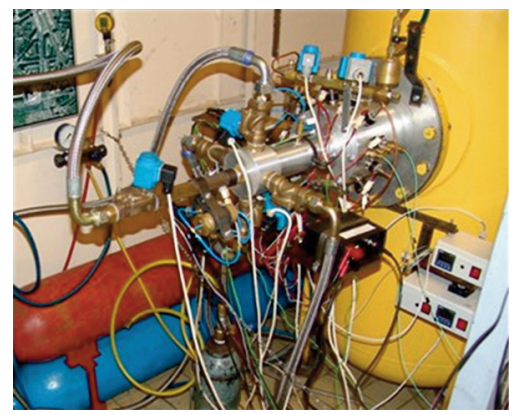

(a) Liquid rotating detonation engine

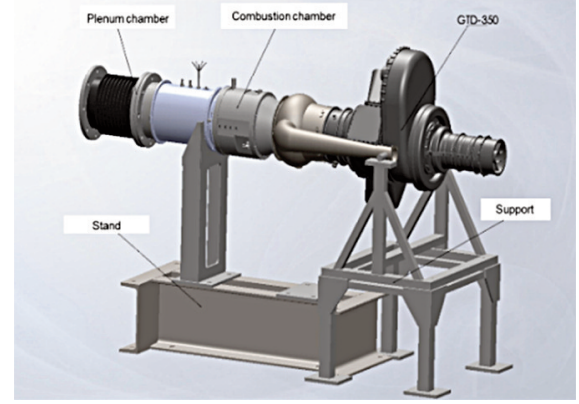

(b) Rotating detonation turbine engine

Fig. 3.3.3. A experimental facility of the rotating detonation engines at the Warsaw University of Technology (a) and the Institute of Aviation in Warsaw(b) [156].

Kawalec et al. [156] of the Polish Institute of Aviation independently designed the injection structure of surface mount for the rotating detonation engine, which effectively improved the convenience of the engine injection structure replacement. The experimental setup is shown in Fig. 3.3.4. They studied the effect of the equivalence ratio on the average pressure of the rotating detonation combustor by means of a rotating detonation engine equipped with the injection structure of surface mount. The results show that the average pressure of the combustor decreases with the increase of the equivalence ratio. In addition, they also studied the effect of the equivalence ratio on the specific impulse properties of a rotating detonation engine. In conclusion, the specific impulse of the rotating detonation engine decreases with the increase of the equivalence ratio.

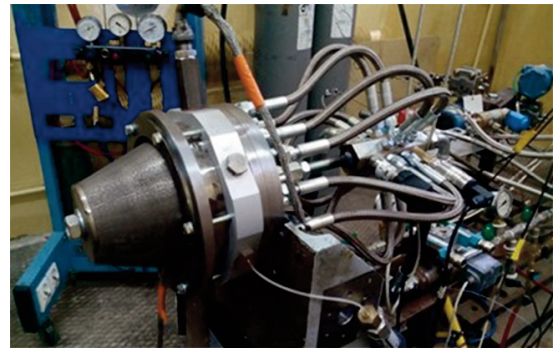

(a) New design engine

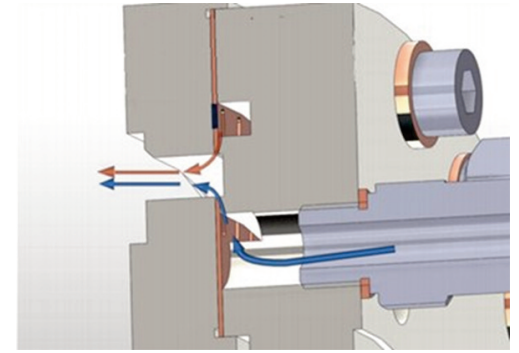

(b) New design of injection

Fig. 3.3.4. An experimental facility of the rotating detonation engine with surface mount added to its injection structure at the Polish Institute of Aviation [156].

Kawalec et al. [157] studied the effect of gaseous fuel mixture parameters on the engine performance based on a large rotating detonation rocket engine, with a diameter of $200 \mathrm{~mm}$ using a fuel/oxidant mixture of methane/oxygen. In the experiment, they controlled the throttle ratio by adding a self-designed slit-shaped nozzle. The specific impulse characteristics of different mass flow rates $(0.12 \mathrm{~kg} / \mathrm{s}, 0.17 \mathrm{~kg} / \mathrm{s}$, $0.22 \mathrm{~kg} / \mathrm{s}$ and $0.32 \mathrm{~kg} / \mathrm{s}$ ) were tested under an equivalent ratio of 0.85 . The experimental results show that the engine specific impulse increases gradually with the increase in mass flow rate. They also studied the effects of combustor pressure on engine specific impulse characteristics under a throttling ratio of $80 \%$ and $60 \%$. The experimental results show that the engine with a throttling ratio of $60 \%$ can obtain a larger specific impulse under a lower combustor pressure. In addition, the effect of annular combustors of various height (a height of $4 \mathrm{~mm}, 6 \mathrm{~mm}$ and $8 \mathrm{~mm}$ ) on the specific impulse properties of the engine was studied under the same throttling ratio and different mass flow rates of $0.12 \mathrm{~kg} / \mathrm{s}, 0.17 \mathrm{~kg} / \mathrm{s}, 0,22 \mathrm{~kg} / \mathrm{s}$ 
and $0.32 \mathrm{~kg} / \mathrm{s}$. The experimental results show that the engine specific impulse of the annular combustors with a width of $6 \mathrm{~mm}$ and $8 \mathrm{~mm}$ is significantly higher than that of the $4 \mathrm{~mm}$-high combustor, but the specific impulse of the $6 \mathrm{~mm}$-wide annular combustor is almost the same with that of the $8 \mathrm{~mm}$-wide one.

Wolanski et al. [158] obtained the stable rotating detonation wave with fuel/oxidant mixture of kerosene/air and gasoline/air added in the experiments, based on a large rotating detonation rocket engine with a diameter of $225 \mathrm{~mm}$. The experimental results fully verify the feasibility of applying the twophase rotating detonation engine of kerosene/air to engineering applications, as shown in Fig. 3.3.5.
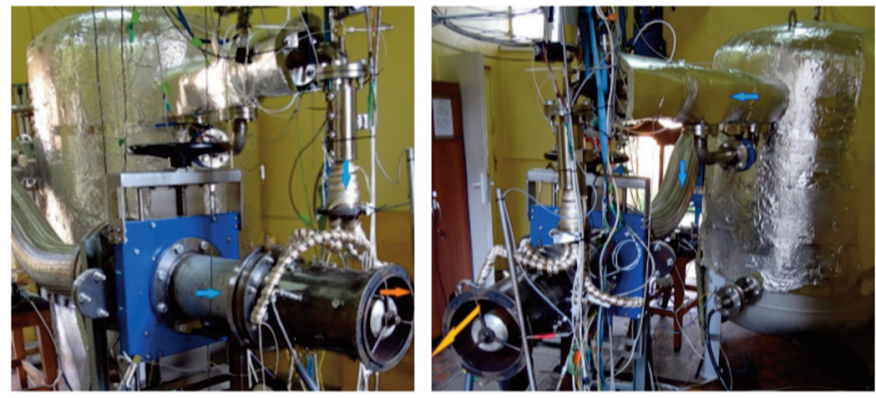

Fig. 3.3.5. An experimental facility of the kerosene/air rotating detonation chamber at the Polish Institute of Aviation [158].

Folusiak [159-163] and Swiderski [164-165] with the Polish Institute of Aviation also made threedimensional numerical simulations for the rotating detonation engine models involved, including the premixed Euler model, the non-premixed Euler model, and the non-premixed viscous model.

\subsection{Research progress of Japan, Korea and Singapore}

Hishida [166] with Nagoya University in Japan studied the flow field dynamics of a rotating detonation engine by numerical calculation based on a two-step hydrogen/air reaction mechanism, as shown in Fig. 3.4.1. The detailed flow field characteristics of the rotating detonation wave were obtained therein. They also studied the triple-point structure of the standing waves detonation, the detonation wave, and the detonation cell size.

Hayashi et al. [167] in Japan conducted two- and three-dimensional numerical simulations of rotating detonation engines based on the hydrogen/oxygen mixture and the detailed chemical reaction mechanism, and compared the flow field structures of the two engines under the same injection conditions. The numerical results show that the flow field structures are almost the same under the same injection conditions, and the propagation velocity of detonation wave is close to $96 \%$ of

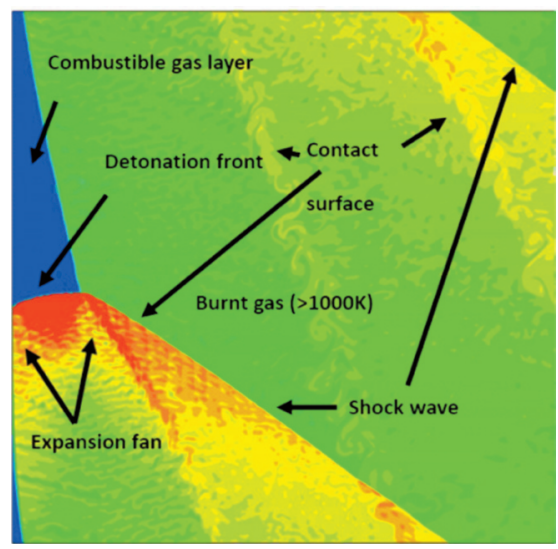

Fig. 3.4.1. Numerical simulations of the temperature field characteristics of the rotating detonation $n$ engine [166]. the theoretical CJ velocity. Hayashi et al. [167] carried out two- and three-dimensional numerical simulation of the two-phase rotating detonation engine based on the JP10/air and two-step chemical reaction mechanism. The numerical results reveal the oscillation mechanism between the front and the boundary of the detonation wave. 
Tsuboi et al. [168-170] with the Reactor Fluid Dynamics Laboratory of Kyushu Institute of Technology in Japan studied the effects of different converging-diverging nozzles and hydrocarbon fuels (including methane and ethylene) on the outlet pressure oscillation of the rotating detonation engine, by means of two- and three-dimensional numerical simulation techniques. The numerical calculation results are shown in Fig. 3.4.2, indicating that the converging-diverging nozzle functions to properly suppress the pressure oscillation caused by the emission at the outlet of the rotating detonation combustor.
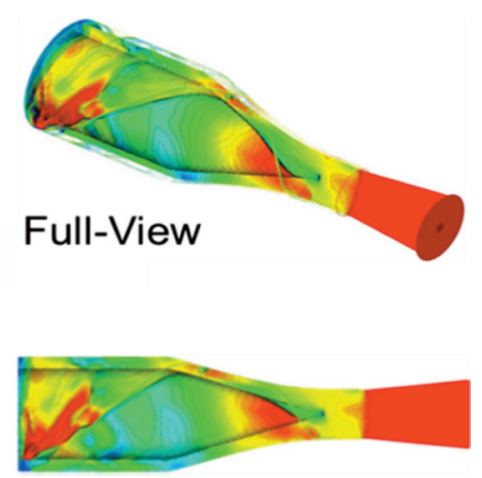

\section{Side-View}

Fig. 3.4.2. The distribution of Mach numbers of converging-diverging nozzle in a rotating detonation engine [170].

Kasahara et al. [171] with Nagoya University in Japan independently developed a sliding rail system powered by the rotating detonation rocket, and conducted an experimental study on the sliding rail system using an ethylene/oxygen mixture. The experimental setup is shown in Fig. 3.4.3. The railcar of the rotating detonation rocket successfully ran for 2 seconds on the 70-meter-long slide rail, with the average thrust and specific impulse reaching $201 \mathrm{~N}$ and $144 \mathrm{~s}$ respectively. In addition, they also studied the effects of different nozzle configurations and the injection pattern of the engine on the thrust performance. The experimental results show that the installation of a converging nozzle can increase the thrust by about $10 \%$.

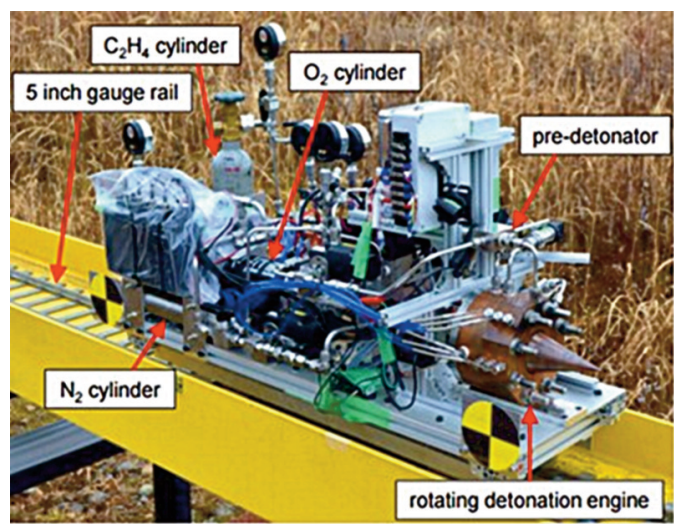

Fig. 3.4.3. The testing system of the rotating detonation rocket railcar [171]. 
Kasahara [171] conducted an experimental study on the rotating detonation rocket engine of the S520 sounding rocket, as shown in Fig. 3.4.4. The specific impulse of the rotating detonation rocket engine involved is over $90 \%$ of the ideal one.

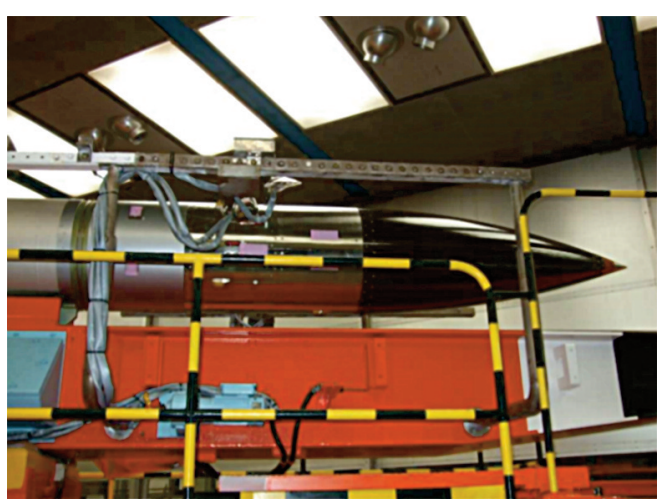

Fig. 3.4.4. The S520 sounding rocket of Japan [171].

Tae-Hyeong et al. in Singapore collaborated with Wolanski of the Warsaw University of Technology in Poland, [172-174] and studied the effects of different parameters in design (total pressure, total temperature, injection area ratio, axial length of the combustor and number of detonation wave) on the propulsion performance of the rotating detonation engine by means of numerical simulations. The calculation results show that the performance of the rotating detonation engine is highly dependent on the injection conditions of the engine, but hardly on the combustor length and number of detonation wave. In addition, they also made a comparative study on the performances of the rotating detonation engine and the single-tube pulse detonation engine, with the results indicating that the total impulse of the rotating detonation engine is significantly higher than that of the pulse detonation engine under the same initial conditions.

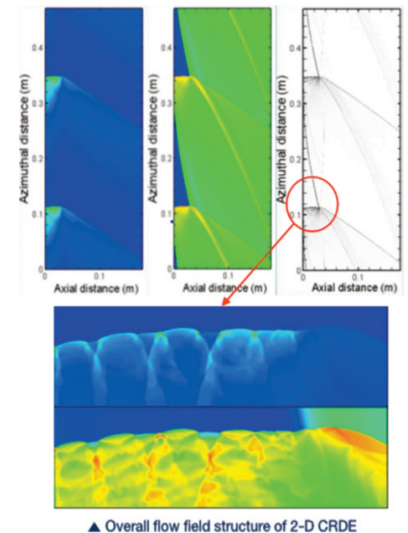

(a) 2-D temperature field

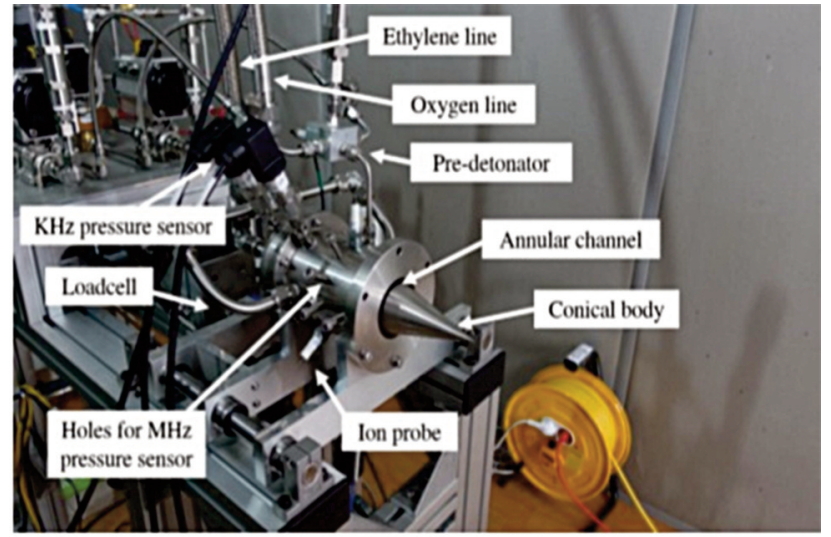

(b) Rotating detonation engine

Fig. 3.4.5. Numerical simulation results and experimental design of the Busan National University in South Korea [175].

Choi et al. [175] with Busan National University in South Korea studied the rotating detonation wave through two-dimensional numerical simulations, and obtained the detailed flow field structure of 
the rotating detonation wave, as shown in Fig. 3.4.5 (a). In addition, they also independently designed the rotating detonation engine, with the experimental setup shown in Fig. 3.4.5 (b). They compared the effects of the cone and bluff body nozzles on the performance of the rotating detonation engine. The results show that the cone nozzle can achieve an increase of the thrust and specific impulse by about 10-30\% compared with the blunt body nozzle.

\subsection{Research progress of China}

The National University of Defense Technology independently designed a variety of rotating detonation engines with its experimental setup shown in Fig. 3.5.1 [176-184]. Based on the proportional relationship between combustor pressure and backpressure, the stability of rotating detonation wave was analyzed in depth. The effects of geometrical parameters such as annular combustor width, total flow temperature and outlet converging-diverging ratio on the flow field structure, propagation process and thrust performance of the rotating detonation wave were studied using hydrogen/air as fuel/oxidant respectively. The experimental results show that the peak pressure of the rotating detonation wave gradually increases with the decrease of the annular combustor width. In addition, higher total temperature of the incoming flow is beneficial to the mixture of fuel and oxidant, thereby increasing the heat release and propagation velocity of detonation wave in the post-detonation reaction zone. The thrust performance of the engine with a diverging or converging-diverging nozzle added will be increased by $20 \%$ or $50 \%$ respectively.

Researchers at the National University of Defense Technology also used methane/oxygen, hydrogen/air as fuel/oxidant to conduct an experimental research on the rotating detonation combustor without central column, and the detailed structure and propagation mode of the rotating detonation wave were obtained. The thrust of the engine was measured under single/double wave modes. In addition, it was found that the effective thrust of the engine is $183.7 \mathrm{~N}$ and $808.5 \mathrm{~N}$ under single and double wave modes respectively. Therefore, an increase in the number of detonation wave in the combustor helps to provide greater thrust to the engine.
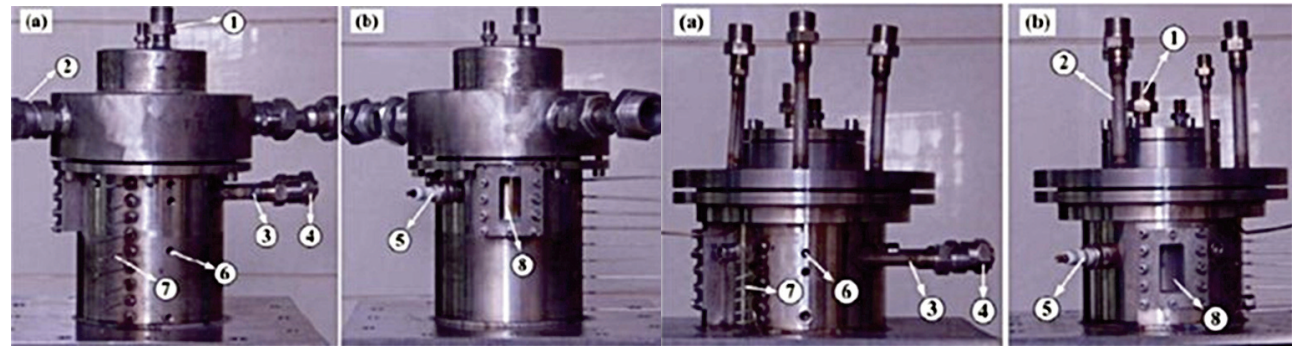

Fig. 3.5.1 An experimental facility of the rotating detonation engines at the National University of Defense Technology [176].

Liu et al. [185] with the National University of Defense Technology, based on large number of experiments and numerical simulations of the rotating detonation engines independently designed an air breathing rotating detonation ramjet engine. The experimental setup is shown in Fig. 3.5.2 (a). They also carried out experimental studies on free jet in the supersonic air tunnel, and tested the propagation of the rotating detonation wave, and thrust properties of rotating detonation engine. The experimental setup is shown in Fig. 3.5.2 (b). The experiments have achieved the stability of rotating detonation, with the propagating frequency of the detonation wave reaching $8.35 \mathrm{kHz}$, and the propagation velocity equivalent to $90 \%$ of the theoretical value of CJ velocity. 


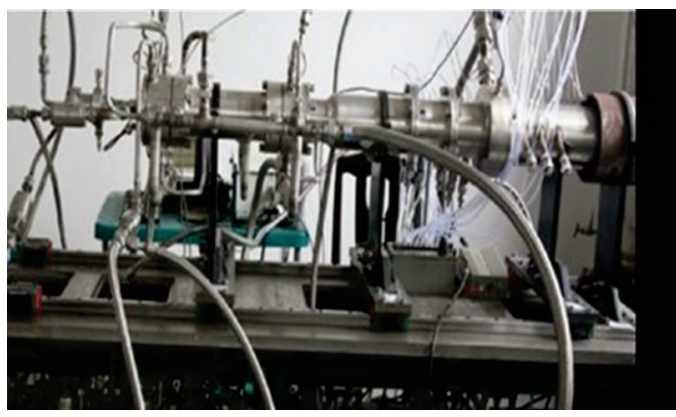

(a) Air breathing rotating detonation engine

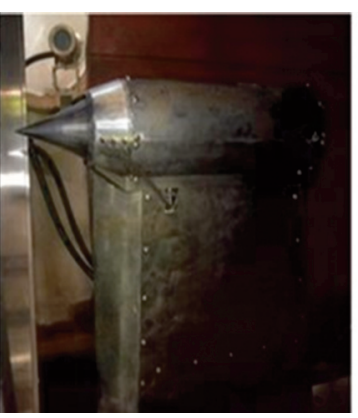

(b) Free jet experiment

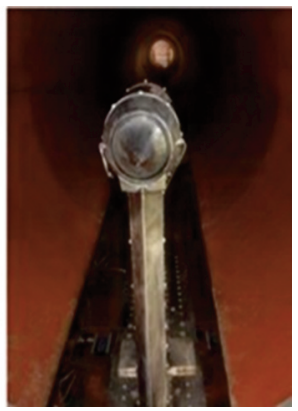

Fig. 3.5.2. An experimental facility of the air-breathing rotating detonation engine and free jet test bench [185].

Liu et al. $[176,185]$ carried out two- and three-dimensional numerical simulations of the internal flow of a rotating detonation engine using hydrogen/air premixed gas, to study the detonation initiation of the rotating detonation engine in detail, and analyze the flow field structure of the rotating detonation wave. They compared the effects of the height of the combustible gas mixture filled in front of the detonation wave on the structure and propagation process of the detonation wave. Numerical calculations show that the detonation waves are susceptible to lateral rarefaction waves when they are narrower in width, resulting to the decoupling of leading shock waves of the detonation wave and the reaction zone. Lin et al. [182] studied the effects of factor including the incident position, incident width and incident dip angle of pre-detonation tube on the initiation of the detonation wave in the engine through two-dimensional numerical calculations. The numerical results show that the higher the speed of the thermojet, the more favorable the initiation of detonation wave, and when the incident position of the pre-detonation tube is towards the side wall of the combustor, the coupling of the wall reflection shock wave and the reaction zone becomes easier to cause detonation and facilitate detonation by improving the incident area of the pre-detonation tube .

Ma et al. [186-193] with Nanjing University of Science and Technology have conducted a large number of studies on rotating detonation engines using gaseous and liquid fuels. The effects of inlet total pressure, external backpressure and axial length on the engine performance were explored experimentally. The experimental results show that the pressure, temperature of the detonation wave are under the influence of the total inlet pressure; meanwhile, the total inlet pressure and the external backpressure have great influence on the mixture of oxidant and fuel, which will in turn affect the stable propagation of detonation wave. They also found that the maximum specific impulse is obtained with an axial length of the engine of $200 \mathrm{~mm}$.

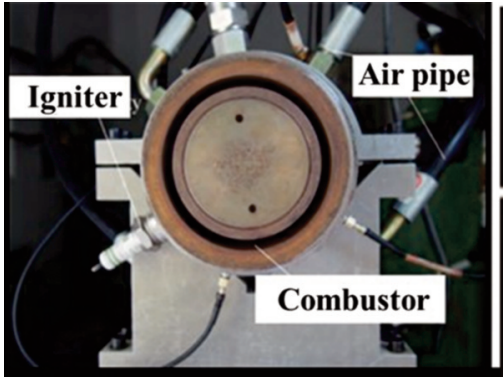

(a) Rotating detonation engine
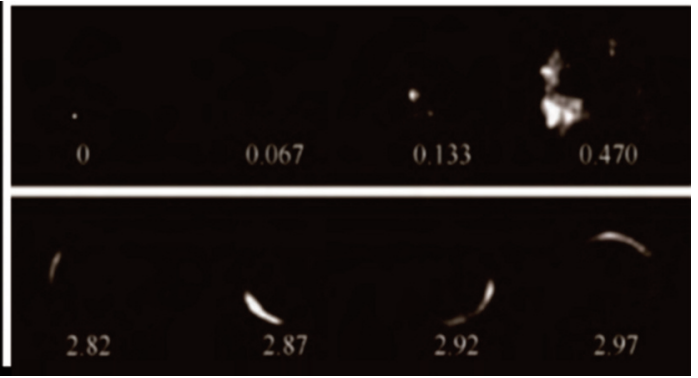

(b) High speed photography

Fig. 3.5.3. An experimental facility of the rotating detonation engine at the Nanjing University of Science and Technology [186]. 
Peng et al. [194] used the ordinary spark plug initiation to ignite the combustor, to study the initiation and detonation wave propagation process of rotating detonation engine. The experimental device is shown in Fig. 3.5.3. It's found that the rotating detonation engine has a successful ignition rate of $94 \%$ under normal spark plug initiation conditions. Weng and Zheng et al. [195-198] successfully obtained the rotating detonation wave by adding oxygen to the air, and using liquid gasoline as a fuel. The experimental results show that the loss of the detonation wave propagation velocity is affected by the atomization and mixture of liquid fuels. In addition, within a certain range of equivalence ratios, the propagation velocity of the detonation wave increases as the oxygen content of the oxidant increases.

The research group of Peking University lead by Wang [199-211] carried out numerical simulations and experimental researches on the three-dimensional structure of rotating detonation wave, described the propagating properties of detonation wave under different injection conditions and analyzed the initiation and extinction mechanisms of detonation wave. In addition, they also analyzed the thermodynamic processes of a rotating detonation engine. Subsequently, the effects of convergence and divergence, equal section, as well as diverging and converging-diverging nozzles on the performance of the rotating detonation engine were discussed in depth. It was found that the thrust reaches the top when the diverging nozzle was added, and the specific impulse comes to the top when the convergingdiverging nozzle was added. They also tested the rotating detonation combustor without a central column, with its experimental setup shown in Fig. 3.5.4. The feasibility of this combustor was verified numerically and experimentally, and the effects of inner wall surface structure of the engine without a center cone on the creation, development and stable propagation of the continuous detonation wave were explored.

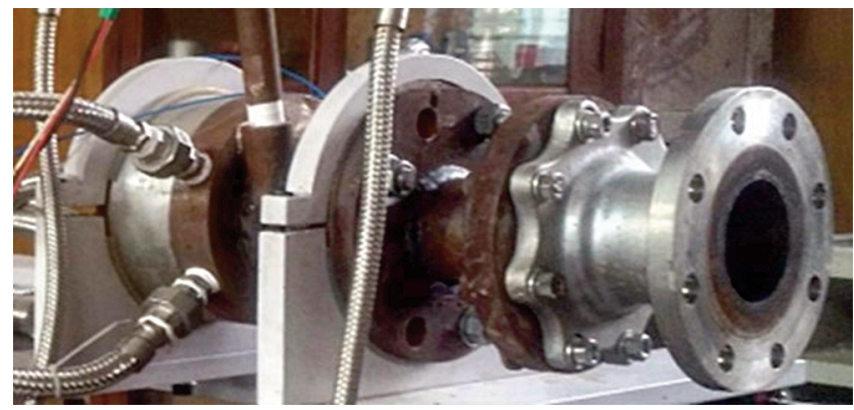

Fig. 3.5.4. An experimental facility of the rotating detonation combustor at the Peking University in China [207].

The research group of Tsinghua University lead by Wang [212-217] carried out large number of theoretical analyses and experimental researches on the theoretical calculation of the combined cycle engine of rotating detonation. They calculated the outlet parameters of the rotating detonation rocket engine at given initial parameters based on the rotating detonation rocket model established by Bykovskii, and thus realized the performance calculation of the combined cycle engine ejector mode based on rotating detonation rocket, with the outlet parameters as the inlet parameters of the ramjet model. In addition, a comparative study on the performances of the combined cycle engine of the rotating detonation and the rocket-based combined cycle engine of the same thrust level was made. The results show that the ejecting and specific impulse properties of the combined cycle engine based on the rotating detonation rocket are obviously superior to those of the rocket-based combined cycle engine.

They independently designed the experimental platform for the rotating detonation engine, as shown in Fig. 3.5.5 (a). Experimental research on small rotating detonation engines was carried out using hydrogen as fuel [218-220]. The combustion characteristics under fuel-lean, fuel-rich, and wide mass flow rate conditions were thereby achieved. The operating map under the conditions of wide-equivalence and 
wide-flow of the rotating detonation combustor was established, with five main areas divided based on combustion characteristics, namely unstable fast deflagration, stable fast deflagration, unstable detonation, quasi-stable detonation and stable detonation. There are three kinds of combustion in the fast deflagration area: unstable longitudinal fast deflagration, stable longitudinal fast deflagration and fast rotating deflagration, as shown in Fig. 3.5.5 (b) [219]. In addition, they also studied the propagation properties of rotating detonation wave by means of oxygen addition to air, when oxygen-enriched air of varying oxygen concentrations was used as oxidant. The effects of different mass flow rates and equivalence ratios on the velocity and pressure variation of combustion waves or rotating detonation wave, as shown in Fig. 3.5.5 (c), as well as the fuel-lean/rich boundary of the rotating detonation wave of stable propagation in the combustor were analyzed [220].

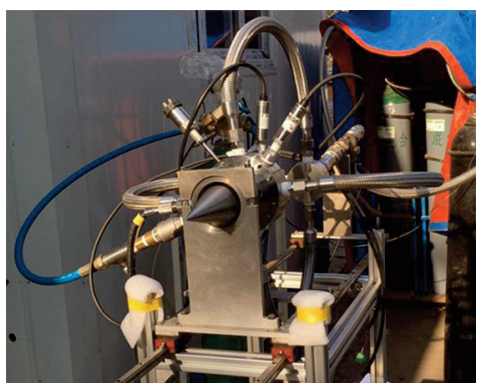

(a) Experimental facility

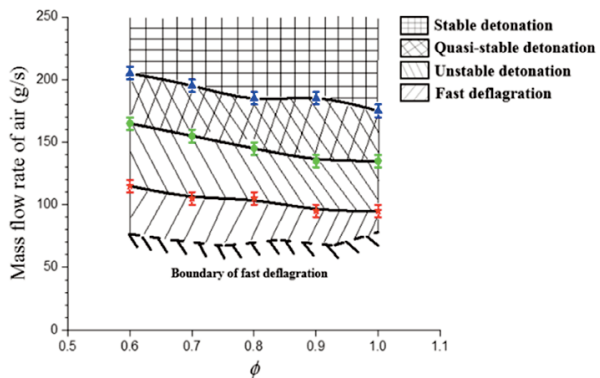

(b) Operation diagram of the RDC under the lean fuel condition

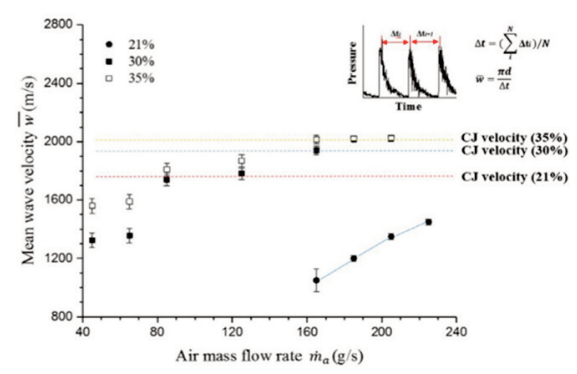

(c) Effects of oxygen volume fractions on

the propagation velocity of stable rotating detonation

Fig. 3.5.5. An experimental facility of the rotating detonation combustor at the Tsinghua University in China $[219,220]$.

\section{TYPICAL SCIENTIFIC PROBLEMS}

In the annular combustor of a rotating detonation engine, the detonation waves are confined within a radically enclosed space, and maintained by propagating with high speed circumferential rotation. The rotating detonation combustion involves complex physical and chemical processes, which interact with each other.

Fig. 4.1 shows the multiple physical factors involved in the rotating detonation combustion process and the interaction among them. First, the oxidant and fuel enter the combustor (arrow 1) through the injection port of the combustor, and the injection into the combustor affects the fuel/oxidant mixture (arrow 2). Efficient mixture is the key to ensuring stable detonation combustion, while the combustion process has also an effect on mixture (arrow 3). On the other hand, due to the self-pressurization property 
of detonation combustion, the detonation wave propagates upstream through the injection port (arrow 4 ), which tend to trigger pressure oscillation in the upstream plenum. Consequently, the pressure oscillations tend to cause instability of the fuel/oxidant injection, thereby affecting the effect of mixture (arrow 5). In addition, the initiation mode determines the energy generated for initiation (arrow 6), which is used to determine whether the combustible mixture formed in the combustor can be successfully detonated (arrow 7) and develop into a self-sustaining detonation combustion process (arrow 8). In the case of the determination of injection and initiation mode, changes in mass flow rates and equivalent ratio can also result in changes in the detonation combustion mode in the combustor (arrow 9). Shock wave reflections occur when there is a throat in the detonation combustor, which can also in turn affect the rotating detonation combustion process (arrow 10), causing an interconversion between combustion modes.

Therefore, injection, mixture, initiation, combustor structure, pressure back propagation and detonation combustion mode interrelate and interact with each other. Next, the research progress of injection, mixing, initiation, combustor structure, pressure back propagation and detonation combustion mode in the rotating detonation combustor is to be expounded.

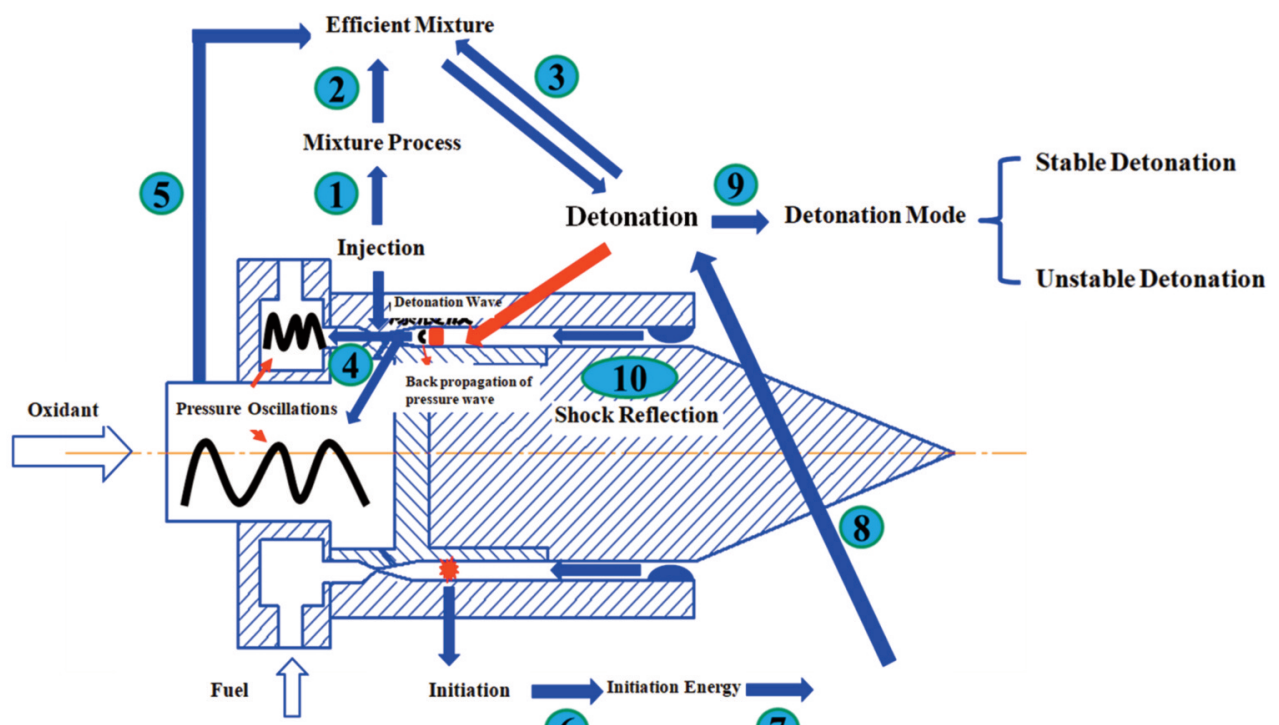

Fig. 4.1. Factors affecting the rotating detonation combustion and their interaction.

\subsection{Injection and mixing}

Different injection conditions tend to lead to different mixture behaviors of fuel and oxidant in the combustor, thus affecting the mixture effect of fuel and oxidant, and further the detonation combustion process. Therefore, the research on the effects of injection on the detonation wave in the rotating detonation combustor has drawn wide attention.

Bykovskii et al. [95] pioneered an experimental study on the effects of various injection modes on rotating detonation wave. Frolov et al. [221] using independent injection of fuel and oxidant, carried out numerical simulations of the flow field of three-dimensional rotating detonation wave in a rotating detonation combustor. The numerical results show that there can be multiple rotating detonation wave of different intensity in the combustor. Rankin et al. [124] studied the effects of air injection area and 
fuel injection scheme on the structure of rotating detonation wave by means of OH-based chemiluminescence imaging. The experimental results show that as the air injection gap enlarges, the rotating detonation wave front gets more concave with respect to the filling area, and the angle between the detonation front and the fuel injection surface (ahead of the detonation front) gets steeper. However, reducing the number of fuel injection ports also affects the structural properties of the rotating detonation wave, such as a conversion of the single-wave mode to double-wave mode. At the same time, they also believed that the non-ideal mixture of fuel and oxidant is the main cause of two backpropagating detonation wave generated in the combustor.

Anand et al. [136] conducted an experimental study on the stable operating range of the rotating detonation combustor and the propagation velocity properties of the detonation wave for the three different fuel injection schemes and two air injection schemes for the same rotating detonation combustor. The results show that the length-diameter ratio of the fuel injection port and the air injection mode serve to determine whether the rotating detonation combustor can operate stably. They also found that the length-diameter ratio of the fuel injection port varies from 12.8 to 17 , and the mass flow rate from $0.2 \mathrm{~kg}$ to $0.5 \mathrm{~kg}$, resulting in the operating mode variation of the rotating detonation. Schwer et al. [222, 223] studied the effects of the length-diameter ratio of various injection ports on the performance of rotating detonation engines by numerical simulations. The results show that the thrust of the rotating detonation combustor gets unstable with the increase of the length-diameter ratio of injection ports. Lin et al. [224] conducted experimental studies on rotating detonation engines with air injection ports of two sizes $(0.4 \mathrm{~mm}$ and $0.2 \mathrm{~mm}$ respectively). They observed three typical propagation modes of detonation wave therein: single-wave, alternating single- and double-wave mode and double-wave mode. Following the analysis of the time domain and frequency domain, they found that when the air injection port is $0.4 \mathrm{~mm}$ in size, and the air mass flow rate gets continuously increased, only single-wave can be observed in the rotating detonation combustor; but the other two propagation modes may also occur sometimes. Wang [212] observed in the experiment that the mass flow fluctuation caused by unstable injection can trigger fluctuation in equivalence ratio, which will in turn gives rise to fluctuation of the propagation velocity and frequency of the detonation wave. The results show that only when the upstream air of the injection port and the flow field in the fuel plenum are stable, can the stability of fuel and oxidant added to the combustor be ensured. Wu et al. [225] studied the influence of total injection pressure on the stability of rotating detonation wave through three-dimensional numerical simulations. The results show that the propagation of rotating detonation wave in the detonation combustor tend to become unstable with the increase of the total pressure of the reactant injection. When the total injection pressure is high enough, the rotating detonation wave in the combustor exhibits periodic oscillation in terms of intensity, appearing to be strong and weak alternatively. At the same time, it's found that under the operating mode of single detonation wave, the total pressure of higher injection could easily lead to the oscillation of rotating detonation wave modes.

The above studies indicate that changes in injection port size and injection conditions tend to affect the combustion properties of rotating detonation in the combustor. In fact, this is dependent on the process and effect of mixture of the fuel and oxidant added to the combustor.

Driscoll et al. [138] performed three-dimensional numerical simulations of the fuel/oxidant mixture in the combustor. The results show that the reactants are mainly mixed by the reverse vortex pair formed in the cross flow, where the injected air surrounds the injection flow of hydrogen, driving the hydrogen into the vortex structure so as to mix with air by shearing. In addition, they also studied the injection parameters, including the reaction flow rate, the injection area, and the distribution of fuel injection ports, the changing of which is used to evaluate their influence on mixture properties. The results show that reducing the injection area of air and hydrogen can effectively increase the amount of hydrogen incorporated into the air flow, thereby enhancing the hydrogen/air mixture effect in the annular combustor structure; besides, as the number of fuel injection holes decreases, the vortex mixture 
mechanism becomes more efficient. Conversely, as the number of fuel injection holes continues to increase, the fuel jet may create a fuel wall that prevents air from surrounding the fuel. The blocking effect in turn causes the fuel to shift toward the inner wall of the annular combustor, thereby reducing the overall mixture efficiency of fuel and oxidant.

It has been found that the uneven mixture of fuel/oxidant from injection can generate a certain concentration gradient of the fuel/oxidant mixture in the combustor, thereby affecting the propagation of the detonation wave. Thomas et al. [226] experimentally studied the effect of reactant concentration gradient on the detonation wave, and found that when the detonation wave propagates to the region where the fuel concentration gradient changes, the propagation velocity and frontal structure of the detonation wave will change significantly. The uneven gradient will also in turn promote the phenomenon, but the uneven gradient may cause the separation of leading shock waves from the reaction zone, thereby causing the detonation wave to collapse. Ishii et al. [227] experimentally studied the propagation properties of detonation wave in reactants with various concentration gradients, and observed by Schlieren technique that the tilt angle of the front surface of the detonation wave increase with an increase in the concentration gradient. Boeck et al. [228] experimentally studied the propagation pattern of detonation wave under a lateral concentration gradient of hydrogen/air mixture, and a lower hydrogen concentration gradient would result in single-head detonation wave. However, a higher hydrogen concentration gradient will result in the generation of multi-head detonation wave. Boulal et al. [229] experimentally studied the dynamics of detonation wave in a heterogeneous mixture (propane/oxygen). The experiment relies on high-frequency pressure sensor, smoke screen, Schlieren and visualized $\mathrm{OH}$-based chemiluminescence technology, to point out that the longitudinal propagation velocity, cell size, detonation front structure, propagation mode and detonation wave collapse of detonation wave are decided by the distribution of the mixture concentration and local equivalence ratio. When the equivalence ratio decreases, the detonation wave will collapse all of a sudden under large concentration gradient conditions.

In short, injection and mixture are two important steps in facilitating combustion. The mixture of fuel and oxidant and the mixture speed serve to determine the formation and maintenance mechanism of detonation wave. Therefore, injection and mixture are always integral to the design and research on the rotating detonation combustor.

\subsection{Ignition}

In general, the main ways of igniting detonation wave can be divided into two types: direct detonation and indirect detonation. Direct detonation demands large detonation energy; indirect detonation requires less detonation energy, but it takes a period of transformation from deflagration to detonation (DDT), and from initiation to detonation generation. The way of rotating detonation mainly involves the spark plug, high-energy igniter, pre-detonation tube and hot-jet tube.

Early studies have found that the ignition in the annular combustor of a rotating detonation engine is prone to form two counter-propagating detonation waves, which are likely to cause detonation wave collapse after collision, thereby decreasing the success rate of ignition [107]. Therefore, Cullen et al. [230] attempted to use a barrier film to improve the initiation success rate and control the propagation direction of detonation wave. Although a large number of experiments and tests were conducted, the results were not satisfactory. Braunt al. [231] designed a method of swirling injection detonation, which mainly relies on sequential control to control the propagation direction of detonation wave, but it is hard to put it into practice. Bykovskii et al. [232] designed a radial vortex chamber to achieve the ignition of the rotating detonation wave. The shock waves generated in the radial vortex chamber and the low-power pulse predetonation tube served as the source of ignition to realize detonation by detonation wave, but the design could not effectively control the propagation direction of the detonation wave. 
Researchers have also carried out researches on the mode of detonation. The pre-detonation tube is filled with premixed gas of oxidizing / fuel, and the detonation wave is generated by DDT process in the pre- detonation tube with small energy ignition. The detonation wave enters into the annular combustion chamber along the tangentially to realize the initiation of the detonation wave in the combustion chamber and the control of the propagation direction of the detonation wave. Lu et al. [233] adopted the way of pre- detonation tube detonation, and believed that a tangential connection between the pre- detonation tube and the detonation combustor is the most direct and effective way of detonation. Kindracki et al. [151] compared the reliability of ordinary spark plug and pre- detonation tube. The experimental statistics show that the success rate reaches up to $90 \%$ by means of pre- detonation tube, significantly higher than that by ordinary spark plug. Other researchers $[217,218]$ have used tangential pre- detonators for detonation. Although the pre- detonation tube is highly effective to start detonation, it needs to be filled with premixed gas to achieve the detonation of rotating detonation wave, bringing great difficulties to engineering applications.

Braunt al. [231], Dyer et al. [236] and Peng et al. [194] achieved successful detonation by rotating detonation wave using an ordinary spark plug. Yang et al. [235] compared the effects of detonation by the ordinary spark plug, high-energy igniter and pre- detonation tube on the velocity stability of detonation wave propagation, after initiation based on a rotating detonation combustor filled with hydrogen/air. The results show that the propagating velocityof the detonation wave is almost the same under the three modes of detonation. Peng et al. [194] achieved successful detonation by rotating detonation wave with hydrogen/air using an ordinary spark plug. The study indicates that there exists a complex DDT transition from the spark plug ignition and the formation of detonation wave, and the period of DDT transition is not fixed. Yang et al. [235] also showed through experiments that the pre- detonation tube can effectively shorten the time from the ignition to the formation of detonation wave.

For most gaseous fuels, high-energy spark plug is a reliable, efficient, reusable, and simple ignition device. However, the effects of the energy generated in ignition on the mixture, which will in turn develop into detonation wave propagating stably, is an important research content. In addition, another research focus should be a study on the effective control of the propagating direction of the detonation wave by selecting the mode of ignition.

\subsection{Architecture and geometry of the rotating detonation combustor}

In the early stage, the rotating detonation combustor was mainly composed of a flat disc type combustor without converging nozzle. However, the combustor of the disc type structure is large in radial dimension, which is disadvantageous as a propulsion plant. Nowadays, the rotating detonation combustor is generally dominated by a cylindrical annular combustor, from which similar structures have been developed, including an outer ring embedded in a solid cylinder, and an outer ring embedded in a cone. Studies have shown that the geometry of the combustor has a significant impact on the generation and stable propagation of detonation wave.

Bykovskii et al. [94-99] conducted a large number of experimental and theoretical studies earlier on the geometry of different rotating detonation combustors using different fuel (gaseous and liquid) and oxidant (air and oxygen) mixture. They pointed out that only when the width of an annular combustor channel $\mathrm{W}_{\mathrm{ch}}$ and the cell size of detonation wave $\lambda$ are of the same order of magnitude, can detonation wave propagating stably be generated in the annular combustor. In addition, the experimental results also show that the critical width of the annular combustor is $0.5 \lambda$ for the stable detonation. Further researches indicated that when the width of the annular combustor channel $\mathrm{W}_{\mathrm{ch}}$ is smaller than the critical dimension, unstable detonation combustion similar to pulse detonation appears in the combustor, characterized by irregular pulsation of pressure and velocity [99]. 
Frolov et al. [103] expanded the size of the air inlet of the rotating detonation engine's annular combustor from $2 \mathrm{~mm}$ to $15 \mathrm{~mm}$, and found that the number of detonation wave present in the combustor is reduced from four to one. Experimental studies have shown that enlarging the annular gap of a rotating detonation engine, on the one hand, can adversely affect the detonation wave, reducing the mass flow rate for the stability of detonation wave, equivalent operating range and stability of detonation wave (due to a decrease in the restriction to the detonation wave). On the other hand, in the case of maintaining stable propagation of the detonation wave, it can function to increase the total pressure gain and reduce the pressure loss if the gap is large enough. Driscoll [237] pointed out through experimental researches that the annular width of the combustor can affect the formation of the detonation wave, and is related to whether the detonation wave can keep stable and self-sustaining propagation. At the same time, they also found that the height of the filling reactants in the rotating detonation combustor and the number of the axial cells in the detonation wave, are under the influence of the transverse wave interaction.

At present, the mainstream rotating detonation combustor is a ring-shaped cavity. And there is still no consistent answer to the effects of the diameter and length of the central column on the stable rotating detonation wave. Therefore, the exploration of combustor of other structures may also be beneficial.

\subsection{Pressure feedback of the rotating detonation combustor}

The compression wave induced by the detonation wave in the combustor is back propagated to the plenum, causing pressure oscillation in the chamber, thus affecting the injection process, thereby affecting the generation and stable propagation of the rotating detonation wave.

Anand et al. [137] when experimenting with the rotating detonation combustor, observed a lowfrequency periodic unstable detonation wave. They pointed out that this phenomenon may be caused by the low-frequency oscillation occurring in the plenum, or due to the generation of Helmholtz resonance in the plenum induced by the rotating detonation wave. Furthermore, an experimental study was carried out on the behavioral characteristics of the air and fuel plenum of the rotating detonation combustor, and it was observed that a strong pressure back-propagation from the rotating detonation wave occurs in the air plenum, expressed in the form of a sinusoidal oscillation to a certain frequency range (similar to the pressure oscillation in the wax and wane instability observed in the combustor); but the pressure back-propagation of the fuel plenum is relatively weak. They also found that the pressure oscillation in the air plenum ranges from about $45 \%$ to $75 \%$, and the pressure oscillation in the fuel plenum varies relatively slightly, about $20 \%$. After further testing as to whether pressure back-propagation can be caused by a wider range of air mass flow rate and equivalence ratio, they found that low-frequency pressure oscillation can still be detected in the plenum at a basically constant frequency, $235( \pm 2.5) \mathrm{Hz}$. Therefore, it may be concluded that the pressure oscillation in the plenum is only correlated with the Helmholtz resonance generated in the chamber. Naples et al. [238] experimentally studied the dynamic characteristics (instantaneous velocity and pressure of fuel injection) of the fuel plenum in a rotating detonation combustor, and found in the experiments that the dominant frequency of the detonation combustor, as well as the pressure and the flow rate of the plenum are interrelated with each other.

Schweret al. [239] simulated the effects of pressure back-propagation of the rotating detonation wave on the plenum in the reaction zone under three different injection conditions. The results show that when the area ratio of the throat area of the injection port to the injection port is 0.2 , the possibility of the pressure back-propagation occurring at the injection port of the rotating detonation combustor is relatively small. When the area ratio reaches 0.4 , a serious pressure back-propagation occurs at the injection port of the rotating detonation combustor. Schwer et al. [240] also numerically simulated the suppression effects of injection ports of various geometry (cylinder, oblique, etc.) on the pressure back-propagation of the detonation waves. The results show that the oblique injection tends to exacerbate 
the pressure back-propagation of the detonation waves. Fotia et al. [241] unfolded an annular detonation combustor to construct a visualized two-dimensional rotating detonation test bed. Therein, they studied the effect of the detonation wave in the rotating detonation combustor on the fuel plenum by means of the high-speed Schlieren technique, and found that the pressure back-propagation of the detonation wave will trigger disturbance in the reactant plenum, thus affecting fuel refilling.

In short, the fact that the pressure of the detonation wave generated during the operating of the rotating detonation combustor is back propagated to the plenum, will severely impaction the fuel and oxidant supply process, and in some cases even make the fuel and oxidant supply process get coupled with the acoustic properties of the combustion system, thus causing instability. Furthermore, the instability will lead to the instability of the form or the propagation process of the detonation wave.

\subsection{Operating mode of the rotating detonation combustor}

Through experiments and numerical simulations, it has been found multiple times that under certain specific mass flow rate or equivalent conditions, single-wave, double-wave, multi-wave modes, and their interconversion will occur in the combustor, together with various complex combustion modes including detonation wave steering.

Frolov et al. [103] increased the size of the air injection port of the annular rotating detonation engine from $2 \mathrm{~mm}$ to $15 \mathrm{~mm}$, and found that the number of simultaneous detonation wave in the combustor was reduced from 4 to 1 , while the installation of the throat at the outlet of the detonation combustor serves to increase the number in the combustor. And the numerical calculation results of Frolov et al. indicate that there may be multiple detonation waves with different intensity in the combustor. In studying the independently-designed rotating detonation combustor, Anand et al. [135] observed four unstable detonation combustion phenomena, including the chaotic instability characterized by random pressure fluctuation with time; the wax and wane instability characterized by low frequency, and a fluctuation of cyclical detonation wave intensity; at the same time, combustion mode transition and pulse detonation mode were also detected in their experiments. As for the pulse detonation mode, the researchers believed that the air injection velocity is lower than that of sound, which is also related to the pressure wave reflection at the outlet of the combustor. Anand et al. [242] further studied the wax and wane instability featuring low-frequency periodic oscillation, displayed the variation of the amount of the detonation wave in multiple periods of wax and wane instability, and used the standard deviation of the detonation wave pressure fluctuation to characterize the low-frequency oscillation pattern. Pan et al. [243] studied the relationship between the rotating detonation wave and the tangential instability of the combustor, and realized the rotating detonation with hydrogen/air in a combustor almost hollow by gradually reducing the cylinder length in the rotating detonation combustor. Anand et al. [244] observed the effects of "pop-out" unstable combustion in the experimental study of different injection schemes. They found that multiple detonation waves will occur in the rotating detonation combustor when the air mass flow rate increases constantly.

Yao [245] numerically verified the feasibility of generating multiple detonation waves in a rotating detonation chamber through the three-dimensional Euler equation with reaction source terms, and studied the stable propagation of the multiple detonation waves. Suchocki et al. [139] experimentally found that the single wave in the rotating detonation combustor can be split into two under conditions of large air mass flow rate. Lin et al. [224] experimentally studied four typical propagation modes of the detonation wave in the rotating detonation combustor under conditions of different mass flow rates and equivalence ratios. They found that only a single detonation wave can be detected in the rotating detonation combustor, but in a few cases, there are also two other modes of propagation: alternating single and double waves and double waves. As the flow rate of hydrogen injection decreases gradually, double-wave collisions will occur in the detonation combustor. Lin et al. [246] further explored 
the propulsion performance of the rotating detonation engine of double- and single-wave modes. The results show that the double-wave mode can make the pressure in the combustor more uniform compared with the single-wave mode. The oscillation amplitude of the high-frequency thrust curve will also be smaller, and it is favorable for maintaining the thrust stability to obtain more numbers of the detonation wave.

Liu et al. [247,248] also studied the characteristics of the typical waveform, time domain and frequency domain of the rotating detonation wave in single- and double-wave modes of stable selfsustained propagation. Liu et al. [181] conducted an experimental study on the hydrogen/air rotating detonation combustor. The stable single-wave mode was observed under fuel-rich condition with an air mass flow rate of $280 \mathrm{~g} / \mathrm{s}$ and an equivalent ratio of 1.227. The mixed single- and double-mode was observed under lean burn conditions with an air mass flow rate of $370.5 \mathrm{~g} / \mathrm{s}$ and an equivalent ratio of 0.962. The double-wave mode was observed under lean burn conditions with an airmass flow rate of $413.3 \mathrm{~g} / \mathrm{s}$ and an equivalent ratio of 0.912 . The results show that the propagation mode and frequency of the detonation wave are mainly affected by the total mass flow rate and the equivalence ratio of the combustor. Rankin et al. [124] conducted an experimental study on a non-premixed rotating detonation engine with a visualized quartz casing by means of $\mathrm{OH}$-based chemiluminescence imaging. It is observed that in most cases, two detonation waves of homodromous propagating are generated in the rotating detonation engine; but in a few cases, two detonation waves of back propagation may occur.

The combustion mode and stability are interrelated with each other. Experimental studies have found the patterns of detonation waves different in number and propagation direction. The splitting, collision and merging mechanisms of the detonation wave determine the occurrence of complex combustion modes. This is also correlated with the combustor acoustics and detonation wave stability, as well as the combustion flow field. It is therefore the most complicated and difficult subject in studying the rotating detonation technology.

\section{FUTURE CHALLENGES}

Extensive researches have been made in the world on the geometry of the combustor, the injection conditions for propellant, the mixing characteristics of fuel and oxidant, and the initiation pattern through theoretical analysis, experimental testing and numerical simulation, in an attempt to reveal the mechanism of stable propagation of detonation waves. However, due to the multiple factors controlling the propagation of rotating detonation waves, there are still many scientific and key technological problems to be solved. In terms of scientific problems: 1. Injection and mixing are two important steps in combustion. The effect and speed of fuel and oxidant mixing serve to determine the formation and maintenance mechanism of the detonation wave. Therefore, the problems related to injection and mixing are always critical in the study on rotating detonation combustion. 2. The studies on the detonation wave formation and the effect of self-sustaining structure are necessary for the organization of continuous detonation, combustor configuration design and actual operation. It is also a scientific difficulty in current researches. 3. The combustion mode and stability are interrelated. Experimental studies have found the patterns of detonation waves different in number and propagation direction. The splitting, collision and merging mechanism of detonation wave tend to produce complex combustion modes, which is related to combustor acoustics, stability of detonation wave and combustion flow field; so, this is the most complicated and difficult topic in rotating detonation technology. In terms of key technologies: 1. Due to factors including the existence of stable rotating detonation waves and propagation areas under the effect of fuel/oxidant type, initiation mode and injection conditions, the in-depth, systematic research on the technique controlling the stability of rotating detonation and controlling effectiveness, is still in need. 2. The propagation direction of the detonation wave from the rotating detonation combustor is largely at random. How to develop effective technology controlling the propagation direction of the wave 
is also crucial. 3. During the rotating detonation in the combustor, the pressure of the detonation wave is under back propagation to the plenum. This will have a strong influence on the fuel/oxidant supply. Thus, the study on the suppression technology of pressure back propagation is also a focus for future research.

\section{CONCLUSION}

Multiple countries including Russia, the United States, Poland, France, Japan and China, have carried out researches and numerical simulation on the rocket-based rotating detonation engine and air-breathing detonation engine, along with the engine technology for the rotating detonation turbine engine. The effect of different fuels, combustor configuration, injection mode and operating mode on the propagation of the rotating detonation wave and engine performance was obtained thereafter.

Although many conclusions beneficial have been achieved through the above exploratory studies, the flow and physicochemical processes involved in rotating detonation technology are quite complicated, and the mechanism of rotating detonation combustion still needs studying further, such as the formation and self-sustaining mechanism of the rotating detonation wave, the generation mechanism of the instable detonation wave, and the mechanism controlling instability with high efficiency. With the breakthrough in the study on multiple key technologies for and the advancement of engineering research on rotating detonation, we are sure to make great progress in engine development based on rotating detonation technology, and in turn the engine development is bound to become a new growth point of new aerospace power technology.

\section{ACKNOWLEDGEMENT}

The authors thank the support from the National Natural Science Foundation of China (No. 51676111), the China Postdoctoral Science Foundation (No. 2018M640140) and the China Postdoctoral Science Special Foundation (No. 2019T120100).

\section{REFERENCES}

[1] Abel, F.A., 1869, XIV. Contributions to the history of explosive agents. Philos. Trans. R. Soc. London, 159, pp. 489-516.

[2] Berthelot, M. and Vieille, P., 1883, L’onde explosive, Ann. Chim. Phys. Ser 5, 28, pp. 289-332.

[3] Chapman, D. L., 1899, VI. On the rate of explosion in gases. The London, Edinburgh, and Dublin Philosophical Magazine and Journal of Science, 47(284), pp. 90-104.

[4] Jouguet, E., 1913, Sur l'onde explosive. CR Acad. Sci., Paris, 156, pp. 872-875.

[5] Zeldovich, Y. B., 1940, Zh. Exp. Teor. Fiz. 10(5), pp. 542-568. English translation, NACA TN No. 1261 (1950).

[6] von Neumann, J., 1942, Theory of detonation waves, OSRD Rep.

[7] Doring, W., 1943, Detonation waves. Ann. Phys. 5e Folge, 43, pp. 421-436.

[8] Campbell, C. and Woodhead, D.W., 1926, CCCCI.-The ignition of gases by an explosionwave. Part I. Carbon monoxide and hydrogen mixtures. J. Chem. Soc. (Resumed), 129, pp. 3010-3021. 10.1039/JR9262903010.

[9] Vasil'ev, A.A., 2006, "Cell Size as the Main Geometric Parameter of Multifront Detonation Wave," J. Propul. Power, 22(6), pp.1245-1260.

[10] Lee, J.H.S. and Radulescu, M.I., 2005, On the hydrodynamic thickness of cell detonations. Combust Explos Shock Waves, 41(6), pp. 745-765. 10.1007/s10573-005-0084-1. 
[11] Vasil'ev, A.A., 1982, Geometric limits of gas detonation propagation, Combust Explos Shock Waves, 18(2), pp. 245-249. 10.1007/BF00789626.

[12] Vasil'ev A.A., Mitrofanov, V.V. and Topchiyan, M.E., 1987, Detonation waves in gases. Combust Explos Shock Waves, 23(5), pp. 605-623. 10.1007/BF00756541.

[13] Kindracki, J., Kobiera, A., Wolanski, P., Gut, Z., Folusiak, M. and Swiderski, K., 2011, Experimental and numerical study of the rotating detonation engine in hydrogen-air mixtures, EUCASS Proceedings Series, 2, pp. 555-582. 10.1051/eucass/201102555.

[14] George, A.S., Driscoll, R., Anand, V., et al., 2017, On the existence and multiplicity of rotating detonations. Proc. Combust. Inst, 36(2), pp. 2691-2698. 10.1016/j.proci.2016.06.132.

[15] Wen, H., Xie, Q. and Wang, B., 2019, Propagation behaviors of rotating detonation in an obround combustor. Combust. Flame, 210, pp. 389-398.

10.1016/j.combustflame.2019.09.008.

[16] Lee, B.H.K., Lee, J.H., Knystautas, R., 1966, Transmission of detonation waves through orifices. AIAA J, 4(2), pp. 365-367.

[17] Ciccarelli, G. and Dorofeev, S., 2008, Flame acceleration and transition to detonation in ducts. Prog. Energy Combust. Sci, 34(4), pp. 499-550. 10.1016/j.pecs.2007.11.002.

[18] Lee, J.H.S., 2008, The detonation phenomenon. Cambridge, from http://mx.itam.nsc.ru/users/libr/eLib/4/2008/Lee-DetonPhenomenon.pdf.

[19] Shchelkin, K.I., 1940, Influence of tube roughness on the formation and detonation propagation in gas. J. Exp. Theor. Phys., 10, pp. 823-827.

[20] Urtiew, P.A. and Oppenheim, A.K., 1966, Experimental observation of the transition to detonation in an explosive gas. Proc. R. Soc. London. Series A. Mathematical and Physical Sciences, 295(1440), pp. 13-28.

[21] Lee, J.H., Knystautas, R. and Yoshikawa, N., 1980, Photochemical initiation of gaseous detonations//Gas dynamics of Explosions and Reactive Systems. Pergamon, pp. 971-982.

[22] Zhang, H., Liu, W. and Liu, S., 2016, Effects of inner cylinder length on H2/air rotating detonation. Int. J. Hydrogen Energy, 41(30), pp. 13281-13293. 10.1016/j.ijhydene.2016.06.083.

[23] Fotia, M.L., Hoke, J. and Schauer, F., 2018, Study of the ignition process in a laboratory scale rotating detonation engine. Exp. Therm. Fluid Sci, 94, pp. 345-354. 10.1016/j.expthermflusci.2017.11.002.

[24] Dunlap, R., 1958, A preliminary study of the application of steady-state detonative combustion to a reaction engine. Jof Jet Pro, 28(7), pp. 451-456.

[25] Gross, R.A., 1963, Oblique detonation waves. AIAA J, 1(5), pp. 1225-1227.

[26] Ostrander, M., Hyde, J., Young, M., et al.,1987, "Standing oblique detonation wave engine performance.” 23rd Joint Propulsion Conference. 1987-2002. 10.2514/6.1987-2002.

[27] Ren, Z., Wang, B., Xiang, G., et al., 2018, Effect of the multiphase composition in a premixed fuel-air stream on wedge-induced oblique detonation stabilization. J. Fluid Mech, 846, pp. 411-427. 10.1017/jfm.2018.289.

[28] Ren, Z., Wang, B., Xiang, G., et al., 2019, Numerical analysis of wedge-induced oblique detonations in two-phase kerosene-air mixtures. Proc. Combust. Inst, 37(3), pp. 3627-3635. 10.1016/j.proci.2018.08.038.

[29] Ashford, S.A. and Emanuel, G., 1996, Oblique detonation wave engine performance prediction. J. Propul. Power, 12(2), pp. 322-327. 10.2514/3.24031.

[30] Pratt, D.T., Humphrey, J.W. and Glenn, D.E., 1991, Morphology of standing oblique detonation waves. J. Propul. Power, 7(5), pp. 837-845. 10.2514/3.23399. 
[31] Miao, S., Zhou, J., Lin, Z., et al., 2018, Numerical Study on Thermodynamic Efficiency and Stability of Oblique Detonation Waves. AIAA J, 56(8), pp. 3112-3122. 10.2514/1.J056887

[32] Valorani, M., Giacinto, M. and Buongiorno, C., 2001, Performance prediction for oblique detonation wave engines (ODWE). Acta Astronaut, 48(4), pp. 211-228.

10.1016/S0094-5765(00)00161-2

[33] Sislian, J.P., Schirmer, H., Dudebout, R., et al., 2001, Propulsive performance of hypersonic oblique detonation wave and shock-induced combustion ramjets. J. Propul. Power, 17(3), pp. 599-604. 10.2514/2.5783.

[34] Hoffmann, N., 1940, Reaction Propulsion by Intermittent Detonative Combustion. Ministry of Supply, Volkenrode Ranslation.

[35] Kailasanath, K., 2000, Review of propulsion application of detonation waves, AIAA J., 38(9), pp. 1698-1708. 10.2514/2.1156.

[36] Kailasanath, K., 2003, Recent developments in the research on pulse detonation engines, AIAA J., 41(2), pp. 145-159. 10.2514/6.2002-470.

[37] Kindracki, J. Experimental research and numerical calculation of the rotating detonation, Ph. D. thesis (in Polish).

[38] Shunsuke, T., Morozumi, T., Matsuoka, K., Kasahara, J., et. al., 2014, Study on pulse detonation rocket engine using flight test demonstrator "Todoroki II", AIAA 2014-4033. 10.2514/6.2014-4033.

[39] Kailasanath, K., 2009, Research on pulse detonation combustion system-a status report, AIAA 2009-631. 10.2514/6.2009-631.

[40] Bussing, T. and Pappas, G., 1994, Introduction to pulse detonation engines, AIAA Paper 940263.

[41] Wintenberger, E. and Shepherd, J. E., 2006, Thermodynamic cycle analysis for propagating detonations, J. Propul. Power, 22(3), pp. 694-698. 10.2514/1.12775.

[42] Anderson, S.D., Tonouchi, J.H., Lidstone, G.L., et al., 2004, Performance trends for a product scale pulse detonation engine, AIAA 2004-3402. 10.2514/6.2004-3402.

[43] Lu, J., Zheng, L., Qiu, H., et al., 2016, Performance investigation of a pulse detonation turbine engine, Proc. IME G J. Aero. Eng., 230(2), pp. 350-359. 10.1177/0954410015591834.

[44] Yan, C. and Fan, W., 2005, "Theory and key technology of pulse detonation engine." Northwestern Polytechnical University Press. Xi an, China.

[45] Hinkey, J.B., Williams, J.T., Henderson, S.E., et al., 1997, Rotary-valved, multiple-cycle, pulse detonation engine experimental demonstration, AIAA 1997-2746. 10.2514/6.1997-2746.

[46] Gustavsson, J., Nori, V. and Segal, C., 2003, Inlet/engine interactions in an axisymmetric pulse detonation engine system, J. Propul. Power, 19(2), pp. 282-286. 10.2514/2.6109.

[47] Rasheed, A., Glaser, A., Dunton, R.A., et al., 2008, Experimental and numerical investigation of a valved multi-tube PDE, AIAA 2008-110. 10.2514/6.2008-110.

[48] Matsuoka, K, Esumi, M., Kasahara, J., et al., 2010, Study on valve systems for pulse detonation engines, AIAA 2010-6672. 10.2514/6.2010-6672.

[49] Shimo, M. and Heister, S.D., 2008, Multicyclic-detonation-initiation studies in valveless pulsed detonation combustors, J. Propul. Power, 24(2), pp. 336-344. 10.2514/1.29546.

[50] Peng, C., Fan, W., Zheng, L., et al., 2012, Experimental investigation on valves air-breathing dual-tube pulse detonation engines, Appl. Therm. Eng., 51(1-2), pp. 1116-1123.

10.1016/j.applthermaleng.2012.10.026.

[51] Lu, J., Zheng, L., Wang, Z., et al., 2015, Operating characteristics and propagation of backpressure waves in a multi-tube two-phase valveless air-breathing pulse detonation combustor, Exp. Therm. Fluid Sci., 61, pp. 12-23. 10.1016/j.expthermflusci.2014.10.010. 
[52] Lu, J., "Investigations on key technologies of the pulse detonation turbine engine." Northwestern Polytechnical University.

[53] Rasheed, A., Tangirala, V.E., Vandervort, C.L., et al., 2004, Interactions of a pulsed detonation engine with a 2D blade cascade, AIAA 2004-1207. 10.2514/6.2004-1207.

[54] Carlos, X., Olivier, P., Tomas, G., et al., 2018, The efficiency of a pulsed detonation combustoraxial turbine integration, Aero. Sci. Technol., 82-83, pp. 80-91. 10.1016/j.ast.2018.08.038.

[55] Glaser, A., Caldwell, N. and Gutmark, E., 2007, Performance of an axial flow turbine driven by multiple pulse detonation combustors, AIAA Paper 2007-1244. 10.2514/6.2007-1244.

[56] Fernelius, M., Gorrell, S., Hoke, J., et al., 2013, Effect of periodic pressure pulses on axial turbine performance, AIAA Paper 2013-3687. 10.2514/6.2013-3687.

[57] George, St A., Driscoll, R., Gutmark, E., et al., 2014, Experimental comparison of axial turbine performance under steady and pulsating flows, ASME J. Turbomach., 136(11), pp. 111005. $10.1115 / 1.4028115$.

[58] Roux, J.A., 2015, Parametric cycle analysis of an ideal pulse detonation engine, J. Thermophys. Heat Transf., 29(4), pp. 671-677. 10.2514/1.T4515.

[59] Hutchins, T.E. and Metghalchi, M., 2003, Energy and exergy analysis of the pulse detonation engine, ASME J. Eng. Gas Turbines Power, 125(4), pp. 1075-1080. 10.1115/1.1610015.

[60] Endo, T., Kasahara, J., Matsuo, A., et al., 2004, Pressure history at the thrust wall of a simplified pulse detonation engine, AIAA J., 42(9), pp. 1921-1930. 10.2514/1.976.

[61] Chen, W., Fan, W., Qiu, H., et al., 2012, Thermodynamic performance analysis of turbofan engine with a pulse detonation duct heater, Aero. Sci. Technol., 23(1), pp. 206-212. 10.1016/j.ast.2011.07.002.

[62] Li, J., Fan, W., Wang, Y., et al., 2010, Performance analysis of the pulse detonation rocket engine based on constant volume cycle model, Appl. Therm. Eng., 30(11-12), pp. 1496-1504. 10.1016/j.applthermaleng.2010.03.017.

[63] Ma, F., Choi, J.Y. and Yang, V., 2006, Propulsive performance of airbreathing pulse detonation engines, J. Propul. Power, 22(6), pp. 1188-1203. 10.2514/1.21755.

[64] Schwer, D.A. and Kailasanath, K., 2011, Numerical study of the effects of engine size on rotating detonation engines, AIAA 2011-581. 10.2514/6.2011-581.

[65] Kaemming, T.A., Fotia, M.L., Hoke, J., et al., 2017, Thermodynamic modeling of a rotating detonation engine through a reduced-order approach, J. Propul. Power, 33(5), pp. 1170-1178. 10.2514/1.B36237.

[66] Bykovskii, F.A., Zhdan, S.A. and Vedernikov, E.F., 2006, Continuous spin detonations, J. Propul. Power, 22(6), pp. 1204-1216. 10.2514/1.17656.

[67] Suchocki, J., Yu, S., Hoke, J., et al., 2012, Rotating detonation engine operation, AIAA Paper 2012-0119. 10.2514/6.2012-119.

[68] Liu, S., Liu, W., Lin, Z., et al., 2015, Experimental research on the propagation characteristics of continuous rotating detonation wave near the operating boundary, Combust. Sci. Technol., 187, pp. 1790-1804. 10.1080/00102202.2015.1019620.

[69] Xie, Q., Wen, H., Li, W., et al., 2018, Analysis of operating diagram for H2/air rotating detonation combustors under lean fuel condition, Energy, 151, pp. 408-419. 10.1016/j.energy.2018.03.062.

[70] Saracoglu, B.H. and Ozden, A., 2018, The effects of multiple detonation waves in the RDE flow field, Transp. Res. Proc., 29, pp. 390-400. 10.1016/j.trpro.2018.02.035.

[71] Tsuboi, N., Eto, S., Hayashi, A.K., et al., 2017, Front cellular structure and thrust performance on hydrogen-oxygen rotating detonation engine, J. Propul. Power, 33(1) pp. 100-111. $10.2514 / 1 . B 36095$. 
[72] Katta, V.R., Cho, K.Y., Hoke, J.L., et al., 2019, Effect of increasing channel width on the structure of rotating detonation wave, Proc. Combust. Inst., 37(3), pp. 3575-3583. 10.1016/j.proci.2018.05.072.

[73] Ji, Z., Zhang, H. and Wang, B., 2019, Performance analysis of dual-duct rotating detonation aero-turbine engine, Aerosp. Sci. Technol., 92, pp. 806-819. 10.1016/j.ast.2019.07.011.

[74] Ji, Z., 2019, Comprehensive performance analysis of the continuous rotating detonation based airbreathing propulsion systems, PhD Dissertation, Tsinghua University.

[75] Ji, Z., Zhang, H., Wang, B., and He, W. (January 10, 2020). Comprehensive Performance Analysis of the Turbofan With a Multi-Annular Rotating Detonation Duct Burner. ASME. J. Eng. Gas Turbines Power, 142(2), p. 021007. 10.1115/1.4045518.

[76] Schwer, D.A. and Kailasanath, K., 2012, Feedback into mixture plenums in rotating detonation engines, AIAA Paper, 2012-0617. 10.2514/6.2012-617.

[77] Schwer, D.A. and Kailasanath, K., 2013, On reducing feedback pressure in rotating detonation engines, AIAA Paper, 2013-1178. 10.2514/6.2013-1178.

[78] Anand, V., George, St A., Driscoll, R., et al., 2016, Analysis of air inlet and fuel plenum behavior in a rotating detonation combustor, Exp. Therm. Fluid Sci., 70, pp. 408-416. 10.1016/j.expthermflusci.2015.10.007.

[79] Zhou, S., Ma, H., Li, S., et al., 2017, Effects of a turbine guide vane on hydrogen-air rotating detonation wave propagation characteristics, Int. J. Hydrog. Energy, 42, pp. 20297-20305. 10.1016/j.ijhydene.2017.06.115.

[80] Zhou, S., Ma, H., Liu, D., et al., 2017, Experimental study of a hydrogen-air rotating detonation combustor, Int. J. Hydrog. Energy, 42, pp. 14741-14749.

10.1016/j.ijhydene.2017.04.214

[81] Liu, Z., Braun, J., and Paniagua, G., 2018, Three dimensional optimization for subsonic axial turbines operating at high unsteady inlet Mach number, AIAA Paper 2018-4480.

10.2514/6.2018-4480.

[82] Liu, Z., Braun, J., and Paniagua, G., 2019, Characterization of a supersonic turbine downstream of a rotating detonation combustor, ASME J. Eng. Gas Turbines Power, 141(3), pp. 031501. 10.1115/1.4040815.

[83] Wolański, P., 2015, Application of the continuous rotating detonation to gas turbine, Appl. Mech. Mater. 782, pp. 3-12. 10.4028/www.scientific.net/AMM.782.3.

[84] Naples, A., Hoke, J., Battelle, R., Wagner, M. and Schauer, F., 2017, Rotating detonation engine implementation into an open-loop T63 gas turbine engine, AIAA Paper 2017-1747. 10.2514/6.2017-1747.

[85] Sousa, J., Paniagua, G. and Morata, E.C., 2017, Thermodynamic analysis of a gas turbine engine with a rotating detonation combustor, Appl. Energy, 195, pp. 247-256.

10.1016/j.apenergy.2017.03.045.

[86] Ji, Z., Zhang, H. and Wang, B., 2019, Thrust control strategy based on the minimum combustor inlet Mach number to enhance the overall performance of a scramjet engine, Proc. IME G J. Aero. Eng., 233(13), pp. 4810-4824. 10.1177/0954410019830816.

[87] Segal, C., 2009, The scramjet engine: processes and characteristics. 1st ed. New York: Cambridge University Press.

[88] Ji, Z., Zhang, H., Xie, Q., et al., 2018, Thermodynamic process and performance analysis of the continuous rotating detonation turbine engine, J. Tsinghua Univ. (Sci. Technol.), 58(10), pp. 899-905. 10.16511/j.cnki.qhdxxb.2018.26.040.

[89] Braun, E.M., Lu, F.K., Wilson, D.R., et al., 2013, Airbreathing rotating detonation wave engine cycle analysis, Aerosp. Sci. Technol., 27(1), pp. 201-208. 10.1016/j.ast.2012.08.010. 
[90] Mizener, A.R. and Lu, F.K., 2017, Low-order parametric analysis of a rotating detonation engine in rocket mode, J. Propul. Power, 33, pp. 1543-1554. 10.2514/1.B36432

[91] Fievisohn, R.T. and Yu, K.H., 2017, Steady-state analysis of rotating detonation engine flowfields with the method of characteristics, J. Propul. Power, 33(1), pp. 89-99. 10.2514/1.B36103

[92] Sousa, J., Braun, J. and Paniagua, G., 2017, Development of a fast evaluation tool for rotating detonation combustors, Appl. Math. Model, 52, pp. 42-52. 10.1016/j.apm.2017.07.019

[93] Voitsekhovskii, B.V., 1959, Statsionarnaya dyetonatsiya. Doklady Akademii Nauk SSSR, 129(6), pp. 1254-1256.

[94] Bykovskii, F.A. Zhdan, S.A., 2013, Continuously detonation engine. Doklady Akademii Nauk.

[95] Bykovskii, F.A. Mitrofanov, V.V. Vedernikov, E.F., 1997, Continuous detonation combustion of fuel-air mixtures. Combust. Explos. Shock Waves, 33(3), pp. 344-353. $10.1007 /$ BF02671875.

[96] Bykovskii, F.A. and Mitrofanov, V.V., 2000, "A continuous spin detonation in liquid fuel sprays." Control of Detonation Processes, edited by G.D. Roy, S.M. Frolov, D.W. Netzer, and A.A. Borisov, Elex-KM Publishers, Moscow, pp. 209-211.

[97] Bykovskii, F.A. and Vedernikov, E.F., 2003, Continuous detonation of a subsonic flow of a propellant. Combust. Explos. Shock Waves, 39(3), pp. 323-334. 10.1023/A:1023800521344.

[98] Bykovskii, F.A. Zhdan, S.A., Vedernikov, E.F., 2005, Continuous spin detonation in annular combustors. Combust., Explos. Shock Waves, 41(4), pp. 449-459. 10.1007/s10573-005-0055-6.

[99] Bykovskii, F.A., Zhdan, S.A., Vedernikov, E.F., 2006, Continuous spin detonation of fuel-air mixtures.Combust., Explos. Shock Waves, 2006, 42(4), pp. 463-471. 10.1007/s10573-006-0076-9.

[100] Bykovskii, F.A., Zhdan, S.A., Vedernikov, E.F., 2006, Continuous spin detonations. J. Propul. Power, 22(6), pp. 1204-1216. 10.2514/1.17656.

[101] Frolov, S.M., Aksenov, V.S., Ivanov, V.S., 2015, Experimental proof of Zel'dovich cycle efficiency gain over cycle with constant pressure combustion for hydrogen-oxygen fuel mixture. Int. J. Hydrogen Energy, 40(21), pp. 6970-6975. 10.1016/j.ijhydene.2015.03.128.

[102] Frolov, S.M., Aksenov, V.S., Gusev, P.A., Ivanov, V.S., Medvedev, S.N., et al., 2015, Experimental studies of small samples bench engine with a continuously-detonation combustors. Gorenie Vzryv, 8(1), pp. 151-163.

[103] Frolov, S.M., Aksenov, V.S., Ivanov, V.S., et al., 2015, Large-scale hydrogen-air continuous detonation combustor. Int. J. Hydrogen Energy, 40(3), pp. 1616-1623.

10.1016/j.ijhydene.2014.11.112.

[104] Frolov, S.M., Aksenov, V.S., Dubrovskii, A.V., et al., 2015, Energy efficiency of a continuousdetonation combustion chamber. Combust. Explos. Shock Waves, 51(2), pp. 232-245. 10.1134/S0010508215020070.

[105] Frolov, S.M., Zvegintsev, V.I., Ivanov, V.S., et al., 2017, Demonstrator of continuousdetonation air-breathing ramjet: Wind tunnel data. Doklady Physical Chemistry, 474(1), pp. 75-79. 10.1134/S0012501617050013.

[106] The first successful test launch of a new generation of green propellant liquid fuel rocket engine in Russia, 2016, from http://fpi.gov.ru/press/news/20160826.

[107] Nicholls, J.A., 1962, "The feasibility of a rotating detonation wave rocket motor. Feasibility of A Rotating Detonation Wave Rocket Motor.” The University of Michigan.

[108] Russo, R., King, P., Schauer, F. and Lewis, T., 2013, Characterization of Pressure Rise Across a Continuous Detonation Engine. 47th AIAA/ASME/SAE/ASEE Joint Propulsion Conference \& Exhibit. 10.2514/6.2011-6046. 
[109] Russo, Rachel M., 2011, "Operational Characteristics of a Rotating Detonation Engine Using Hydrogen and Air." Theses and Dissertations. 1352. Air Force Institute of Technology, WrightPatterson Air Force Base, Ohio.

[110] Shank, J., King, P., Karnesky, J., et al., 2012, "Development and testing of a modular rotating detonation engine." 50th AIAA aerospace sciences meeting including the new horizons forum and aerospace exposition, AIAA 2012-0120. 10.2514/6.2012-120.

[111] Shank, J.C., 2012, "Development and testing of a rotating detonation engine run on hydrogen and air." Thesis. Air Force Institute of Technology, Wright-Patterson Air Force Base, Ohio.

[112] Thomas, L., Schauer, F., Hoke, J., et al., 2011, "Buildup and operation of a rotating detonation engine." 49th AIAA Aerospace Sciences Meeting including the New Horizons Forum and Aerospace Exposition, AIAA 2011-602. 10.2514/6.2011-602.

[113] Tellefsen, J., King, P., Schauer, F. and Hoke, J., 2012, "Analysis of an RDE with convergent nozzle in preparation for turbine integration." 50th AIAA Aerospace Sciences Meeting including the New Horizons Forum and Aerospace Exposition, AIAA 2012-0773. 10.2514/6.2012-773.

[114] Tellefsen, J., 2012, "Build up and operation of an axial turbine driven by a rotary detonation engine." Theses and Dissertations, Air Force Inst of Tech Wright-Patterson Afb oh Graduate School of Engineering and Management. 1071. https://scholar.afit.edu/etd/1071.

[115] Fotia, M., Kaemming, T.A., Hoke, J., et al., 2015, "Study of the experimental performance of a rotating detonation engine with nozzle exhaust flow." 53rd AIAA Aerospace Sciences Meeting. AIAA 2015-0631. 10.2514/6.2015-0631.

[116] Fotia, M., 2015, Update on Air Breathing Detonation Driven Propulsion Research. International Workshop on Detonation for Propulsion.

[117] Fotia, M., Hoke, J., Schauer, F., 2017, Experimental performance scaling of rotating detonation engines operated on gaseous fuels. J. Propul. Power, Vol. 33(5), pp. 1-10. 10.2514/1.B36213.

[118] Fotia, M., 2016, Thermodynamics Modelling and the Operation of Rotating Detonation Engines at Elevated Inlet Temperatures. International Workshop on Detonation for Propulsion.

[119] Theuerkauf, S.W., Schauer, F., Anthony, R., et al., 2014, "Average and Instantaneous Heat Release to the Walls of an RDE." 52nd Aerospace Sciences Meeting. 1503.

[120] Theuerkauf, S.W., Schauer, F., Anthony, R., et al., 2015, "Experimental characterization of high-frequency heat flux in a rotating detonation engine." 53rd AIAA Aerospace Sciences Meeting. 1603.

[121] Theuerkauf, S.W., Schauer, F., Anthony, R., et al., 2016, "Comparison of simulated and measured instantaneous heat flux in a rotating detonation engine." 54th AIAA Aerospace Sciences Meeting. 1200.

[122] Braun, J. Sousa, J. Paniagua. G., 2016, "Assessment of the boundary layer within a Rotating Detonation Combustor." 52nd AIAA/SAE/ASEE Joint Propulsion Conference. 4557.

[123] Meyer, S.J., Polanka, M.D., Schauer, F., et al., 2017, Experimental Characterization of Heat Transfer Coefficients in a Rotating Detonation Engine." 55th AIAA Aerospace Sciences Meeting. 1285.

[124] Rankin, B.A., Richardson, D.R., Caswell, A.W., et al., 2015, Imaging of $\mathrm{OH}^{*}$ chemiluminescence in an optically accessible nonpremixed rotating detonation engine." 53rd AIAA Aerospace Sciences Meeting. 1604.

[125] Rankin, B.A., Richardson, D.R., Caswell, A.W., et al., 2017, Chemiluminescence imaging of an optically accessible non-premixed rotating detonation engine. Combust. Flame, 176(1), pp. 12-22. 10.1016/j.combustflame.2016.09.020.

[126] Kailasanath, K., 2011, "The Rotating Detonation-Wave Engine Concept: A Brief Status Report." 49th AIAA aerospace sciences meeting including the new horizons forum and aerospace exposition. 580. 
[127] Kailasanath, K., 2017, "Recent developments in the research on rotating-detonation-wave engines." 55th AIAA Aerospace Sciences Meeting. 0784.

[128] Schwer, D. and Kailasanath, K., 2010, "Numerical investigation of rotating detonation engines." 46th AIAA/ASME/SAE/ASEE Joint Propulsion Conference \& Exhibit. 6880.

[129] Schwer, D. and Kailasanath, K., 2011, "Effect of inlet on fill region and performance of rotating detonation engines." 47th AIAA/ASME/SAE/ASEE Joint Propulsion Conference \& Exhibit. 6044.

[130] Schwer, D. and Kailasanath, K., 2011, "Numerical Study of the Effects of Engine Size n Rotating Detonation Engines." 49th AIAA aerospace sciences meeting including the new horizons forum and aerospace exposition. 581.

[131] Schwer, D. and Kailasanath, K., 2012, "Feedback into mixture plenums in rotating detonation engines." 50th AIAA Aerospace Sciences Meeting including the New Horizons Forum and Aerospace Exposition. 617.

[132] Schwer, D. and Kailasanath, K., 2016, Characterizing NOx Emissions for Air-Breathing Rotating Detonation Engines." 52nd AIAA/SAE/ASEE Joint Propulsion Conference. 4779.

[133] Edward, D.L., Jeffrey, S., et al., 2015, "Rotating Detonation Combustion for Gas Turbines Modeling and System Synthesis to Exceed 65\% Efficiency Goal.” University Turbine Systems Research Workshop. 23983.

[134] Ferguson, D., 2016, “Overview of Pressure Gain Combustion Studies at NETL." University Turbine Systems Research Workshop. 2301.

[135] Anand, V., George, A.S., Driscoll, R., et al., 2015, Characterization of instabilities in a rotating detonation combustor. Int. J. Hydrogen Energy, 40(46), pp. 16649-16659. 10.1016/j.ijhydene.2015.09.046.

[136] Anand, V., George, A.S., Driscoll, R., et al., 2016, Investigation of rotating detonation combustor operation with H2-air mixtures. Int. J. Hydrogen Energy, 41(2), pp. 1281-1292. 10.1016/j.ijhydene.2015.11.041.

[137] Anand, V., George, A.S., Driscoll, R., et al., 2016, Analysis of air inlet and fuel plenum behavior in a rotating detonation combustor. Exp. Therm. Fluid Sci, 70, pp. 408-416. 10.1016/j.expthermflusci.2015.10.007.

[138] Driscoll, R., Aghasi, P., George, S.A., et al., 2016, Three-dimensional, numerical investigation of reactant injection variation in a $\mathrm{H} 2$ /air rotating detonation engine. Int. J. Hydrogen Energy, 41(9), pp. 5162-5175. 10.1016/j.ijhydene.2016.01.116.

[139] Suchocki, J., Yu, S.T., Hoke, J., et al., 2012, “Rotating detonation engine operation.” 50th AIAA Aerospace Sciences Meeting including the New Horizons Forum and Aerospace Exposition. 119.

[140] Braun, E., Dunn, N. and Lu, F., 2010, "Testing of a continuous detonation wave engine with swirled injection." 48th AIAA Aerospace Sciences Meeting Including the New Horizons Forum and Aerospace Exposition. 146.

[141] Braun, E., Balcazar, T.S., Wilson, D.R., et al., 2012, Experimental Study of a High-Frequency Fluidic Valve Fuel Injector. J. Propul. Power, 28(5), pp. 1121-1125. 10.2514/1.B34442

[142] Heister, S., Slabaugh, C., et al., 2016, "Advancing Pressure Gain Combustion in Terrestrial Turbine Systems.” University Turbine Systems Research Workshop. 1004.

[143] Daniau, E., Falempin, F., Getin, N., et al., 2006, Design of a continuous detonation wave engine for space application." 42nd AIAA/ASME/SAE/ASEE Joint Propulsion Conference \& Exhibit. 4794.

[144] Falempin, F., Daniau, E., Getin, N., et al., 2006, "Toward a continuous detonation wave rocket engine." 14th AIAA/AHI Space Planes and Hypersonic Systems and Technologies Conference. 7956.

[145] Falempin, F. and Daniau, E., 2008, "A contribution to the development of actual continuous detonation wave engine." 15th AIAA International Space Planes and Hypersonic Systems and Technologies Conference. 2679. 
[146] Falempin, F. and Naour, B., 2009, "R\&T effort on pulsed and continuous detonation wave engines." 16th AIAA/DLR/DGLR International Space Planes and Hypersonic Systems and Technologies Conference. 7284.

[147] Falempin, F., Naour, B. and Miquel, F., 2011, "Recent experimental results obtained on continuous detonation wave engine." 17th AIAA International Space Planes and Hypersonic Systems and Technologies Conference. 2235.

[148] Eude, Y., Davidenko, D., Falempin, F., et al., 2011, "Use of the adaptive mesh refinement for 3D simulations of a CDWRE (continuous detonation wave rocket engine)." 17th AIAA International Space Planes and Hypersonic Systems and Technologies Conference. 2236.

[149] Davidenko, D., Eude, Y., Falempin, F., 2009, "Numerical study on the annular nozzle optimization for rocket application." 16th AIAA/DLR/DGLR International Space Planes and Hypersonic Systems and Technologies Conference. 7390.

[150] Wolanski, P. and Kindracki, J., 2009, Research on continuous rotating detonation and its applications to jet propulsion. ISABE, 2009-1313.

[151] Kindracki J., Wolański, P., Gut, Z., 2011, Experimental research on the rotating detonation in gaseous fuels-oxygen mixture. Shock Waves, 21(2), pp. 75-84. 10.1007/s00193-011-0298-y.

[152] Kindracki, J., 2012, Experimental studies of kerosene injection into a model of a detonation chamber. J. Power Technol., 92(2), p. 80.

[153] Kindracki, J., 2015, Experimental research on rotating detonation in liquid fuel-gaseous air mixtures. Aerosp. Sci. Technol., 43, pp. 445-453. 10.1016/j.ast.2015.04.006.

[154] Tobita, A., Fujiwara, T., Wolanski, P., 2010, "Detonation engine and flying object provided therewith." U.S. Patent, 7,784,267.

[155] Wolański, P., 2015, Application of the continuous rotating detonation to gas turbine." Applied Mechanics and Materials, 782, pp. 3-12. 10.4028/www.scientific.net/amm.782.3.

[156] Kindracki, J., 2016, Recent research on the rotating detonation at Warsaw University of Technology. Transactions of the Institute of Aviation, 245, pp. 37-45.

[157] Kawalec, M., Wolański, P., et al., 2016, "Influence of mixture on performance of rotating detonation rocket engine." International Constant-Volume and Detonation Combustion Workshop.

[158] Wolański, P., 2018, "Research Progress in Poland." International Workshop on Detonation for Propulsion.

[159] Folusiak, M., Kobiera, A. and Wolański, P., 2010, Rotating detonation engine simulations in-house code-REFloPS. Transactions of the Institute of Aviation, 207, pp. 3-12.

[160] Folusiak, M., Swiderski, K., Kobiera, A., et al., 2011, "Graphics Processors as a tool for rotating detonation simulations." 23rd International Colloquium on the Dynamics of Explosions and Reactive Systems, University of California, Irvine.

[161] Folusiak, M., Swiderski, K., Kindracki, J., et al., 2013, "Assessment of numerical simulations of RDE combustion chamber". 24th ICDERS, Taipei, Taiwan.

[162] Folusiak, M., Swiderski, K., Kindracki, J., et al., 2013, "Improving accuracy and performance of Rotating Detonation Engine simulations." European Conference for AeroSpace Sciences.

[163] Folusiak, M., Swiderski, K., Kobiera, A., et al., 2013, Three-dimensional numerical simulations of the combustion chamber of the rotating detonation engine. Journal of KONES, 20(1), pp. 83-88.

[164] Folusiak, M., Swiderski, K., Kobiera, A., et al., 2013, Numerical tools for three dimensional simulations of the rotating detonation engine in complex geometries. Journal of KONES, 20(1), pp. 329-336.

[165] Swiderski, K., Folusiak, M., Lukasik, B., et al., 2013, Three-dimensional numerical study of the propulsion system based on rotating detonation using Adaptive Mesh Refinement. ICDERS, Taipei, Taiwan. 
[166] Hishida, M., Fujiwara, T., Wolański, P., 2009, Fundamentals of rotating detonations. Shock waves, 19(1), pp. 1-10. 10.1007/s00193-008-0178-2.

[167] Hayashi, A.K., Kimura, Y., Yamada, T., et al., 2009, "Sensitivity analysis of rotating detonation engine with a detailed reaction model." 47th AIAA Aerospace Sciences Meeting Including the New Horizons Forum and Aerospace Exposition. 633.

[168] Tsuboi, N., Watanabe, Y., Kojima, T., et al., 2015, Numerical estimation of the thrust performance on a rotating detonation engine for a hydrogen-oxygen mixture. Proc. Combust. Inst., 35(2), pp. 2005-2013.

[169] Yamada, T., Hayashi, A.K., Tsuboi, N., et al., 2010, "Numerical analysis of threshold of limit detonation in rotating detonation engine." 48th AIAA Aerospace Sciences Meeting Including the New Horizons Forum and Aerospace Exposition. 153.

[170] Tsuboi, N., Hayashi, A.K., et al., 2016, "Simulation on rotating detonation engine: effects of converging-diverging nozzle, non-uniform injection, and hydrocarbon-fueled detonation." International Workshop on Detonation for Propulsion.

[171] Kasahara, J., Kato, Y., Ishihara, K., et al., 2016, "Research and development of rotating detonation engine for upper-stage kick motor system.” International Workshop on Detonation for Propulsion.

[172] Yi, T.H., Turangan, C., Lou, J., et al., 2009, "A three-dimensional numerical study of rotational detonation in an annular chamber." 47th AIAA Aerospace Sciences Meeting Including the New Horizons Forum and Aerospace Exposition. 634.

[173] Yi, T.H., Lou, J., Turangan, C., et al., 2010, "Effect of Nozzle Shapes on the Performance of Continuously-Rotating Detonation Engine." 48th AIAA Aerospace Sciences Meeting Including the New Horizons Forum and Aerospace Exposition. 152.

[174] Yi, T.H., Lou, J., Turangan, C., et al., 2011, Propulsive performance of a continuously rotating detonation engine. J. Propul. Power, 27(1), pp. 171-181. 10.2514/1.46686.

[175] Choi, J.Y., 2016, "Research progress of detonation studies for propulsion in PNU." International Workshop on Detonation for Propulsion.

[176] Liu, S.j., Lin, Z.Y., Sun, M.B., et al., 2010, Two-dimensional numerical simulation of rotating detonation wave engine. J. Propul. Technol, 31(5), pp. 634-640 (in Chinese).

[177] Liu, S.j., Qin, H., Lin, Z.Y., et al., 2011, Detailed structure and propagating mechanism research on continuous rotating detonation wave. J. Propul. Technol, 32(3), pp. 431-436 (in Chinese).

[178] Liu, S.j. Lin, Z.Y., Sun, M.B., et al., 2010, Numerical Simulation of Cell Detonation Using Different Chemical Reacting Source Term Methods. J. Natl. Univ. Def. Technol., 5, pp. 01-06 (in Chinese).

[179] Liu, S.j. Lin, Z.Y., Sun, M.B., et al., 2011, Thrust vectoring of a continuous rotating detonation engine by changing the local injection pressure. Chin. Phys. Lett., 28(9), pp. 094704.

[180] Liu, S.j., Lin, Z.Y., Liu, W.D., et al., 2012, Experimental realization of H2/air continuous rotating detonation in a cylindrical combustor. Combust. Sci. Technol., 184(9), pp. 1302-1317. 10.1080/00102202.2012.682669.

[181] Liu, S.j., Lin, Z.Y., Liu, W.D., et al., 2013, Experimental and three-dimensional numerical investigations on $\mathrm{H} 2$ /air continuous rotating detonation wave. Proceedings of the Institution of Mechanical Engineers, Part G: Journal of Aerospace Engineering, 227(2), pp. 326-341. $10.1177 / 0954410011433542$.

[182] Lin, W., Zhou, J., Lin, Z.Y., et al., 2015, Numerical simulation of detonation onset by hot jets. J. Natl. Univ. Def. Technol., 37(1), pp. 70-77 (in Chinese).

[183] Zhou, Z.L., Liu, W.D., Liu, S.j., et al., 2013, Investigation on Propagation Process of Detonation Wave Influenced by Lateral Expansion. J. Propul. Technol, 34(5), pp. 713-720 (in Chinese). 
[184] Wang, D., Zhou, J. and Zhou, Z.L., 2015, Numerical Simulation on the Working Process of the Hydrogen-Oxygen Continuous Rotating Engine with an Expansive Nozzle. Tactical Missile Technology, 2015(6), pp. 57-65 (in Chinese).

[185] Liu, S.j., Liu, W.D., Lin, Z.Y., et al., 2017, "Experimental Research on the Continuous Rotating Detonation Ramjet Engine.” The 9th National Hypersonic Technology Conference.

[186] Ma, H., Feng, F., Wu, X.S., et al., 2012, Effect of Pressure Condition on Rotating Detonation Engine. J. Ballist., 24(4), pp. 94-98.

[187] Chen, J., Wang, D., Ma, H., et al., 2013, Influence of Axial Length on Rotating Detonation Engine. J. Aerosp. Power, 28(4), pp. 844-849 (in Chinese).

[188] Gao, J., Wu, X.S., Ma, H., et al., 2016, Experiment of Effect of Nozzle Shapes on the Performance of Rotating Detonation Engine. J. Aerosp. Power, 31(10), pp. 2443-2453 (in Chinese).

[189] Gao, J., Wu, X.S., Ma, H., et al., 2016, Experimental Research on Rotating Detonation Engines with Different Combustion Chamber Length. J. Propul. Technol, 37(10), pp. 1991-2000 (in Chinese).

[190] Zhou, S.B., Wang, D., Ma, H., et al., 2016, “Experimental Study on Rotating Detonation with Small Oxidizer Injection Area." The first joint conference on Aerospace Power (in Chinese).

[191] Xu, C., Ma, H., Yan, Y., et al., 2017, Experimental Study on Operating Characteristics of Rotating Detonation Engine. J. Ballist., 29(3), pp. 74-81 (in Chinese).

[192] Ma, H., Feng, F., Wu, X.S., et al., 2012, Effect of pressure condition on rotating detonation engine. J. Ballist., 24(4), pp. 94-98.

[193] Zhou, S., Ma, H., Liu, D., et al., 2017, Experimental study of a hydrogen-air rotating detonation combustor. Int. J. Hydrogen Energy, 42(21), pp. 14741-14749. 10.1016/j.ijhydene.2017.04.214.

[194] Peng, L., Wang, D., Wu, X., et al., 2015, Ignition experiment with automotive spark on rotating detonation engine. Int. J. Hydrogen Energy, 40(26), pp. 8465-8474. 10.1016/j.ijhydene.2015.04.126.

[195] Zheng, Q., Weng, C.S. and Bai, Q.D., 2014, Experiment on Continuous Rotating Detonation Engine with Tilt Slot Injector. J. Propul. Technol., 35(4), pp. 570-576 (in Chinese).

[196] Zheng, Q., Weng, C.S. and Bai, Q.D., 2015, Experimental Study on Effects of Equivalence Ratio on Detonation Characteristics of Liquid-Fueled Rotating Detonation Engine. J. Propul. Technol, 36(6), pp. 947-952 (in Chinese).

[197] Li, B.X. and Weng, C.S., 2018, Influence of Liquid Fuel on the Detonation Characteristics of Continuous Rotating Detonation Engine. Explosion and Shock Waves, 38(2), pp. 331-338 (in Chinese).

[198] Wang, Y.Y. and Weng, C.S., 2013, Effects of Nozzle on Flow Field and Performance of MultiCycle Two-Phase Pulse Detonation Engines. J. Aerosp. Power, 28(10), pp. 2256-2266 (in Chinese).

[199] Shao, Y.T., Liu, M., Wang, J.P., 2009, Numerical Simulation of Continuous Rotating Detonation Engine in Column Coordinate. J. Propul. Technol, 30(6), pp. 717-721 (in Chinese).

[200] Tang, X.M., Wang, J.P. and Shao, Y.T., 2013, 3-D Simulation of Rotating Detonation Wave in Combustion Chambers Without Inner Wall. J. Aerosp. Power, 28(4), pp. 792-799 (in Chinese).

[201] Wu, D., Liu, Y., Wang, J.P., 2015, Three-Dimensional Numerical Simulation of the Parametric Properties of Continuously Rotating Detonation Engine. J. Aerosp. Power, 30(7), pp. 1576-1582 (in Chinese).

[202] Shao, Y.T. and Wang, J.P., 2009, Two-Dimensional Simulation of Continuous Detonation Engine. J. Aerosp. Power, 24(5), pp. 980-987 (in Chinese).

[203] Wu, D. and Wang, J.P., 2012, Influences of Viscosity and Thermal Conductivity on Detonation Waves. Chin. J. Appl. Mech, 29(6), pp. 630-635 (in Chinese). 
[204] Wang, Y., Wang, J.P., Li, Y., et al., 2014, Induction for multiple rotating detonation waves in the hydrogen-oxygen mixture with tangential flow. Int. J. Hydrogen Energy, 39(22), pp. 11792-11797. 10.1016/j.ijhydene.2014.05.162.

[205] Wu, D., Liu, Y., Liu, Y., et al., 2014, Numerical investigations of the restabilization of hydrogen-air rotating detonation engines. Int. J. Hydrogen Energy, 39(28), pp. 15803-15809. 10.1016/j.ijhydene.2014.07.159.

[206] Zhou, R. and Wang, J.P., 2012, Numerical investigation of flow particle paths and thermodynamic performance of continuously rotating detonation engines. Combust. Flame, 159(12), pp. 3632-3645. 10.1016/j.combustflame.2012.07.007.

[207] Shao, Y.T., Li, M. and Wang, J.P., 2010, Continuous detonation engine and effects of different types of nozzle on its propulsion performance. Chin. J. Aeronaut, 23(6), pp. 647-652. 10.1016/S1000-9361(09)60266-1.

[208] Shao, Y.T., Liu, M. and Wang, J.P., 2010, Numerical investigation of rotating detonation engine propulsive performance. Combust. Sci. Technol., 182(11-12), pp. 1586-1597. 10.1080/00102202.2010.497316.

[209] Shao, Y.T. and Wang, J.P., 2010, Change in continuous detonation wave propagation mode from rotating detonation to standing detonation. Chin. Phys. Lett., 27(3), pp. 034705. $10.1088 / 0256-307 \mathrm{X} / 27 / 3 / 034705$.

[210] Tang, X.M., Wang, J.P. and Shao, Y.T., 2015, Three-dimensional numerical investigations of the rotating detonation engine with a hollow combustor. Combust. Flame, 162(4), pp. 9971008. 10.1016/j.combustflame.2014.09.023.

[211] Wang, Y. and Wang, J., 2015, Effect of equivalence ratio on the velocity of rotating detonation. Int. J. Hydrogen Energy, 40(25), pp. 7949-7955. 10.1016/j.ijhydene.2015.04.072.

[212] Xie, Q. and Wang, B., 2014, "Performance analysis of rotating detonation rocket based combined cycle propulsion." 6th European Conference For Aeronautics and Space Sciences.

[213] Xie, Q. and Wang, B., 2015, "Performance analysis of propulsion powered by rotating detonation rocket based combined cycle." 22rd International Society for Air Breathing Engines.

[214] Wang, B., Xie, Q. and Zhang, H., 2013, "Key technical analysis of liquid rocket based combined cycle propulsion." 21rd International Society for Air Breathing Engines.

[215] Wang, B., Xie, Q., Zou, M., et al., 2013, “Theoretic analysis of ejector mode of rocket based combined cycle propulsion." 5th European Conference For Aeronautics and Space Sciences.

[216] Wang, B., Xie, Q. and Wen, H., 2016, “Stabilities of rotation detonation.” 1st International Conference in Aerospace for Young Scientists.

[217] Wen, H., Xie, Q. and Wang, B., 2017, "Stabilities of rotation detonation." 31st International Symposium on Shock Waves-Part 1: fundamentals, Springer.

[218] Xie, Q., Wen, H., Li, W., Ji, Z., Wang, B., et al., 2018, Analysis of Operating Diagram for H2/Air Rotating Detonation Combustors under Lean Fuel Condition. Energy, 151, pp. 408419. 10.1016/j.energy.2018.03.062

[219] Xie, Q., Wang, B., Wen, H., et al., 2018, Thermoacoustic Instabilities in an Annular Rotating Detonation Combustor Under Off-Design Condition. J. Propul. Power, 35(1), pp. 141-151. $10.2514 / 1 . B 37044$.

[220] Xie, Q., Wang, B., Wen, H., et al., 2019, Enhancement of continuously rotating detonation in hydrogen and oxygen-enriched air. Proc. Combust. Inst., 37(3), pp. 3425-3432. 10.1016/j.proci.2018.08.046.

[221] Frolov, S.M., Dubrovskii, A.V., Ivanov, V.S., 2013, Three-dimensional numerical simulation of the operation of a rotating-detonation chamber with separate supply of fuel and oxidizer. Russian Journal of Physical Chemistry B, 7(1), pp. 35-43. 10.1134/S1990793113010119. 
[222] Schwer, D. and Kailasanath, K., 2011, Numerical investigation of the physics of rotatingdetonation-engines. Proc. Combust. Inst., 33(2), pp. 2195-2202.

10.1016/j.proci.2010.07.050.

[223] Schwer, D. and Kailasanath, K., 2010, "Numerical investigation of rotating detonation engines." 46th AIAA/ASME/SAE/ASEE Joint Propulsion Conference \& Exhibit. 6880.

[224] Lin, W., Zhou, J., Liu, S., et al., 2015, Experimental study on propagation mode of H2/Air continuously rotating detonation wave. Int. J. Hydrogen Energy, 40(4), pp. 1980-1993. 10.1016/j.ijhydene.2014.11.119.

[225] Wu, D., Zhou, R., Liu, M., et al., 2014, Numerical investigation of the stability of rotating detonation engines. Combust. Sci. Technol., 186(10-11), pp. 1699-1715.

10.1080/00102202.2014.935641.

[226] Thomas, G.O., Sutton, P. and Edwards, D.H., 1991, The behavior of detonation waves at concentration gradients. Combust. Flame, 84(3-4), pp. 312-322.

10.1016/0010-2180(91)90008-Y.

[227] Ishii, K. and Kojima, M., 2007, Behavior of detonation propagation in mixtures with concentration gradients. Shock Waves, 17(1-2), pp. 95-102. 10.1007/s00193-007-0093-y.

[228] Boeck, L.R., Berger, F.M., Hasslberger, J., et al., 2016, Detonation propagation in hydrogenair mixtures with transverse concentration gradients. Shock Waves, 26(2), pp. 181-192. 10.1007/s00193-015-0598-8.

[229] Boulal, S., Vidal, P. and Zitoun, R., 2016, Experimental investigation of detonation quenching in non-uniform compositions. Combust. Flame, 2016, 172, pp. 222-233.

10.1016/j.combustflame.2016.07.022.

[230] Cullen, R.E., Nicholls, J.A. and Ragland, K.W., 1966, Feasibility studies of a rotating detonation wave rocket motor. J. Spacecr. Rockets, 3(6), pp. 893-898. 10.2514/3.28557.

[231] Braun, E., Dunn, N. and Lu, F., 2010, "Testing of a continuous detonation wave engine with swirled injection." 48th AIAA Aerospace Sciences Meeting Including the New Horizons Forum and Aerospace Exposition. 146.

[232] Bykovskii, F.A., Zhdan, S.A. and Vedernikov, E.F., 2014, Initiation of detonation of fuel-air mixtures in a flow-type annular combustor. Combustion, Explosion and Shock Waves, 50(2), pp. 214-222. 10.1134/S0010508214020130.

[233] Lu, F.K. and Braun, E., 2014, Rotating detonation wave propulsion: experimental challenges, modeling, and engine concepts. J. Propul. Power, 30(5), pp. 1125-1142. 10.2514/1.B34802

[234] Lentsch, A., Bec, R., Serre, L., et al., 2005, "Overview of current French activities on PDRE and continuous detonation wave rocket engines." AIAA/CIRA 13th International Space Planes and Hypersonic Systems and Technologies Conference. 3232.

[235] Yang, C., Wu, X., Ma, H., et al., 2016, Experimental research on initiation characteristics of a rotating detonation engine. Exp. Therm. Fluid Sci, 71, pp. 154-163.

10.1016/j.expthermflusci.2015.10.019

[236] Dyer, R., Naples, A., Kaemming, T., et al., 2012, "Parametric testing of a unique rotating detonation engine design." 50th AIAA Aerospace Sciences Meeting including the New Horizons Forum and Aerospace Exposition. 121.

[237] Driscoll, R., Anand, V., George, A., et al., 2015, "Investigation on RDE operation by geometric variation of the combustor annulus and nozzle exit area." 9th US National combustion meeting.

[238] Naples, A., Hoke, J., Schauer, F., 2014, "Rotating detonation engine interaction with an annular ejector." 52nd Aerospace Sciences Meeting. 0287.

[239] Schwer, D. and Kailasanath, K., 2011, "Effect of inlet on fill region and performance of rotating detonation engines." 47th AIAA/ASME/SAE/ASEE Joint Propulsion Conference \& Exhibit. 6044. 
[240] Schwer, D., Corrigan, A., Taylor, B., et al., 2013, "On reducing feedback pressure in rotating detonation engines." 51st AIAA Aerospace Sciences Meeting including the New Horizons Forum and Aerospace Exposition. 1178.

[241] Fotia, M., Hoke, J. and Schauer, F., 2014, "Propellant plenum dynamics in a two-dimensional rotating detonation experiment.” 52nd AIAA Aerospace Sciences Meeting. 1013.

[242] Anand, V., George, A., Driscoll, R., et al., 2015, "Statistical treatment of wave instability in rotating detonation combustors." 53rd AIAA Aerospace Sciences Meeting. 1103.

[243] Pan, Z., Fan, B., Zhang, X., et al., 2011, Wavelet pattern and self-sustained mechanism of gaseous detonation rotating in a coaxial cylinder. Combust. Flame, 158(11), pp. 2220-2228. 10.1016/j.combustflame.2011.03.016.

[244] Anand, V., George, A.S., Driscoll, R., et al., 2016, Investigation of rotating detonation combustor operation with H2-air mixtures. Int. J. Hydrogen Energy, 41(2), pp. 1281-1292. 10.1016/j.ijhydene.2015.11.041.

[245] Yao, S., Liu, M. and Wang, J., 2015, Numerical investigation of spontaneous formation of multiple detonation wave fronts in rotating detonation engine. Combust. Sci. Technol., 187(12), pp. 1867-1878. 10.1080/00102202.2015.1067202.

[246] Lin, W., Zhou, J., Liu, S., et al., 2015, Experimental study on propagation mode of H2/Air continuously rotating detonation wave. Int. J. Hydrogen Energy, 40(4), pp. 1980-1993. 10.1016/j.ijhydene.2014.11.119

[247] Liu, S.j., Liu, W.D., Lin, Z.Y., et al., 2014, Research on Continuous Rotating Detonation Wave Propagation Process (I): One Direction Mode. J. Propul. Technol., 35(1), pp. 138-144 (in Chinese).

[248] Liu, S.j., Liu, W.D., Lin, Z.Y., et al., 2014, Research on Continuous Rotating Detonation Wave Propagation Process (II): Two-Wave Collision Propagation Mode. J. Propul. Technol., 35(2), pp. 269-275 (in Chinese).

[249] Wolanski, P., 2012, “Detonative propulsion." Proceedings of the Combustion Institute, pp. 1-34.

\title{
PRZEGLĄD AKTUALNEGO STANU WIEDZY DOTYCZĄCEJ ROTACYJNEGO SILNIKA DETONACYJNEGO I ZWIAZZANYCH Z NIM TYPOWYCH PROBLEMÓW
}

\begin{abstract}
Abstrakt
Detonacja jest obiecującym sposobem spalania w celu poprawy wydajności silnika, zwiększenia wydajności spalania, redukcji emisji i polepszenia wydajności cyklu termicznego. W ostatniej dekadzie dokonano znacznego postępu w kierunku aplikacji trybów detonacji w silnikach, takich jak silnik detonacji stojącej (SDE), pulsacyjny silnik detonacyjny (PDE) i rotacyjny silnik detonacyjny (RDE), a także w celu zrozumienia fundamentalnych procesów chemicznych i fizycznych zachodzących w silnikach detonacyjnych poprzez badania numeryczne i eksperymentalne. Celem niniejszego artykułu jest dostarczenie obszernego przeglądu postępu wiedzy dotyczącej rotacyjnego silnika detonacyjnego z różnych krajów. Przedstawiono nowe obserwacje dotyczące wtrysku paliwa, zapłonu oraz geometrii komory spalania, sprzężenia zwrotnego ciśnienia, sposobów spalania w rotacyjnym silniku detonacyjnym RDE. Odkrycia te oraz postęp w badaniach dostarczyły nowych możliwości w opracowaniu wirującej detonacji dla praktycznych zastosowań. $\mathrm{Na}$ koniec wskazaliśmy istniejące obecnie luki w wiedzy w celu wykazania obszarów, na jakie przyszłe badania powinny być ukierunkowane.
\end{abstract}

Słowa kluczowe: detonacja, układ napędowy, wirująca detonacja. 